\title{
Functional Prediction of Hypothetical Proteins from Shigella flexneri and Validation of the Predicted Models by Using ROC Curve Analysis
}

\author{
Md. Amran Gazi ${ }^{1 *}$, Sultan Mahmud ${ }^{2}$, Shah Mohammad Fahim ${ }^{1}$, \\ Mohammad Golam Kibria ${ }^{2}$, Parag Palit ${ }^{1}$, Md. Rezaul Islam ${ }^{3}$, Humaira Rashid ${ }^{2}$, \\ Subhasish Das ${ }^{1}$, Mustafa Mahfuz ${ }^{1}$, Tahmeed Ahmeed ${ }^{1}$ \\ ${ }^{1}$ Nutrition and Clinical Services Division, International Centre for Diarrhoeal Disease Research, Bangladesh (icddr,b), \\ Dhaka 1212, Bangladesh, ${ }^{2}$ Infectious Diseases Division, International Centre for Diarrhoeal \\ Disease Research, Bangladesh (icddr,b), Dhaka 1212, Bangladesh, ${ }^{3}$ International Max Planck \\ Research School, Grisebachstraße 5, 37077 Göttingen, Germany
}

\begin{abstract}
Shigella spp. constitutes some of the key pathogens responsible for the global burden of diarrhoeal disease. With over 164 million reported cases per annum, shigellosis accounts for 1.1 million deaths each year. Majority of these cases occur among the children of the developing nations and the emergence of multi-drug resistance Shigella strains in clinical isolates demands the development of better/new drugs against this pathogen. The genome of Shigella flexneri was extensively analyzed and found 4,362 proteins among which the functions of 674 proteins, termed as hypothetical proteins (HPs) had not been previously elucidated. Amino acid sequences of all these $674 \mathrm{HPs}$ were studied and the functions of a total of $39 \mathrm{HPs}$ have been assigned with high level of confidence. Here we have utilized a combination of the latest versions of databases to assign the precise function of HPs for which no experimental information is available. These HPs were found to belong to various classes of proteins such as enzymes, binding proteins, signal transducers, lipoprotein, transporters, virulence and other proteins. Evaluation of the performance of the various computational tools conducted using receiver operating characteristic curve analysis and a resoundingly high average accuracy of $93.6 \%$ were obtained. Our comprehensive analysis will help to gain greater understanding for the development of many novel potential therapeutic interventions to defeat Shigella infection.
\end{abstract}

Keywords: hypothetical protein, in silico, NCBI, ROC curve, Shigella

\section{Introduction}

Shigella, refers to a genus of gram-negative facultative anaerobes that belongs to members of the family Enterobacteriaceae and is the causative agent of shigellosis, a severe enteric infection, one of the most common causes of morbidity and mortality among children in developing nations. The Global Burden of Disease (GBD) classified Shigella as the second leading cause of diarrheal deaths on a global scale in 2015 [1]. Shigellosis leads to the recurrent passing of small, bloody mucoidal stools with synchronous abdominal cramps and tenesmus caused by ulceration of the colonic epithelium [2]. In malnourished children, Shigella infection may lead to a vicious cycle of further impaired nutrition, frequent infection and growth retardation resulting from protein loss enteropathy [3].

The Shigella genus is divided into four species: Shigella flexneri, Shigella boydii, Shigella sonnei, and Shigella dysenteriae. These are further classified into serotypes based on biochemical differences and variations in their $\mathrm{O}$-antigen [4]. A total of 19 different serotypes of S. flexneri have been reported so far by various research groups [5]. Among the four Shigella species, shigellosis is predominantly caused by S. flexneri in the developing world especially in Asia, and is responsible for approximately $10 \%$ of all diarrheal episodes among children of $<5$ years [6]. Recent multicenter study in 
Asia revealed that the incidence of this disease might even exceed previous estimations, due to Shigella DNA being detectable in up to one third of the total culture negative specimens [7]. Currently, no effective vaccine with the ability to confer adequate protection against the many different serotypes of Shigella has been developed and made available. Existing antimicrobial treatments are becoming compromised in terms of efficacy due to increased antibiotic resistance, soaring cost of treatment, and persistence of poor hygiene and unsanitary conditions in the developing world.

A particular study conducted on numerous isolates of Shigella collected over a time span of 10 years, multi-drug resistance (MDR) were found to be exhibited by $78.5 \%$ of the isolates. $2 \%$ of the isolates were found to harbor genetic information capable of conferring resistance to azithromycin, a final resort antimicrobial agent for shigellosis [8]. On the other hand, a recent whole genome analysis of a particular strain of S. flexneri revealed 82 distinct chromosomal antibiotic resistance genes while successive re-sequencing platforms elucidated several distinct single nucleotide polymorphisms that contributed to eventual MDR [9]. Therefore, the development of new drugs has risen to become a subject of immense magnitude to not only shorten the medication period but also to treat MDR shigellosis. The genome sequence of $S$. flexneri serotype 2a strain 2457T, available in the NCBI database consists of 4,599,354 bp in a single circular chromosome containing 4,906 genes encoding 4,362 proteins and has $\mathrm{G}+\mathrm{C}$ content of $50.9 \%$ [10]. Among these, the functions of 674 proteins have not been experimentally determined till date and are termed as hypothetical proteins (HPs). A HP is one that has been predicted to be encoded by an identified open reading frame, but for which there is a lack of experimental evidence [11]. Nearly half of the proteins in most genomes belong to the class of HPs and this class of proteins presumably have their own importance to complete genomic and proteomic platform of an organism $[12,13]$. Precise annotation of the HPs of particular genome leads to the discovery of new structures as well as new functions, and elucidating a list of additional protein pathways and cascades, thus completing our incomplete understanding on the mosaic of proteins [13]. HPs may possibly play crucial roles in disease progression and survival of pathogen [11, 14]. Furthermore, novel HPs may also serve as markers and pharmacological targets for development of new drugs and therapies [15]. Functions of HPs from several pathogenic organisms have been already reported using a plethora of sequence and structure based methods [14, 16, 17].

Functional annotation of HPs utilizing advanced bioinformatics tools is a well-established platform in current proteomics [18]. Cost and time efficiency of these methods also favoring their preference over contemporary in vitro techniques [19]. In this study, we have used several well optimized and up to date bioinformatics tools to assign functions of a number of HPs from the genome of $S$. flexneri with high precision [20]. Functional domains were considered as the basis to infer the biological functions of HPs in this case. The receiver operating characteristic (ROC) analysis [21] was used for evaluating the performance of bioinformatics tools executed in our study. We also measured the confidence level of the functional predictions on the basis of bioinformatics tools employed during the course of the investigation [22]. We believe that this analysis will expand our knowledge regarding the functional roles of HPs of Shigella and provide an opportunity to unveil a number of potential novel drug targets [17].

\section{Methods}

The computational algorithm used for this study has been illustrated in Fig. 1. The entire work scheme has been divided into three phases namely, phase I, II and III. Phase I involves the characterization and sequence retrieval of the HPs, following the analysis of the $S$. flexneri genome. Phase II comprises of the annotation of various functional parameters using well optimized series of tools. The probable functions of the characterized HPs were predicted by the integration of various functional predictions. In phase III, an approach was made for systematic performance evaluation of various bioinformatics tools used in this study. In this case, $S$. flexneri protein sequences with known function were used as control. Finally, expert knowledge was applied for annotation of HPs at a considerable degree of confidence.

\section{Phase I}

\section{Accession of genome and sequence retrieval}

Complete genome sequence of $S$. flexneri 2 a str. 2457T was retrieved from NCBI database (http://www.ncbi.nlm.nih. gov/genome/) and was found to code for a total of 4,362 proteins (accessed July 5, 2017). Fasta sequences of the complete coding sequence of 682 proteins, characterized as HPs were retrieved from UniProt (http://www.uniprot.org/). Finally, a total of 674 proteins were retained for downstream analysis following exclusion of duplicates.

\section{Analysis of the conserved domains}

Domains are often identified as recurring (sequence or structure) units, and can be thought of as distinct functional and/or structural units of a protein. During molecular evolution, it is assumed that domains may have been utilized as building blocks and have encountered recombination to modulate protein function [23]. A domain or fold might also 


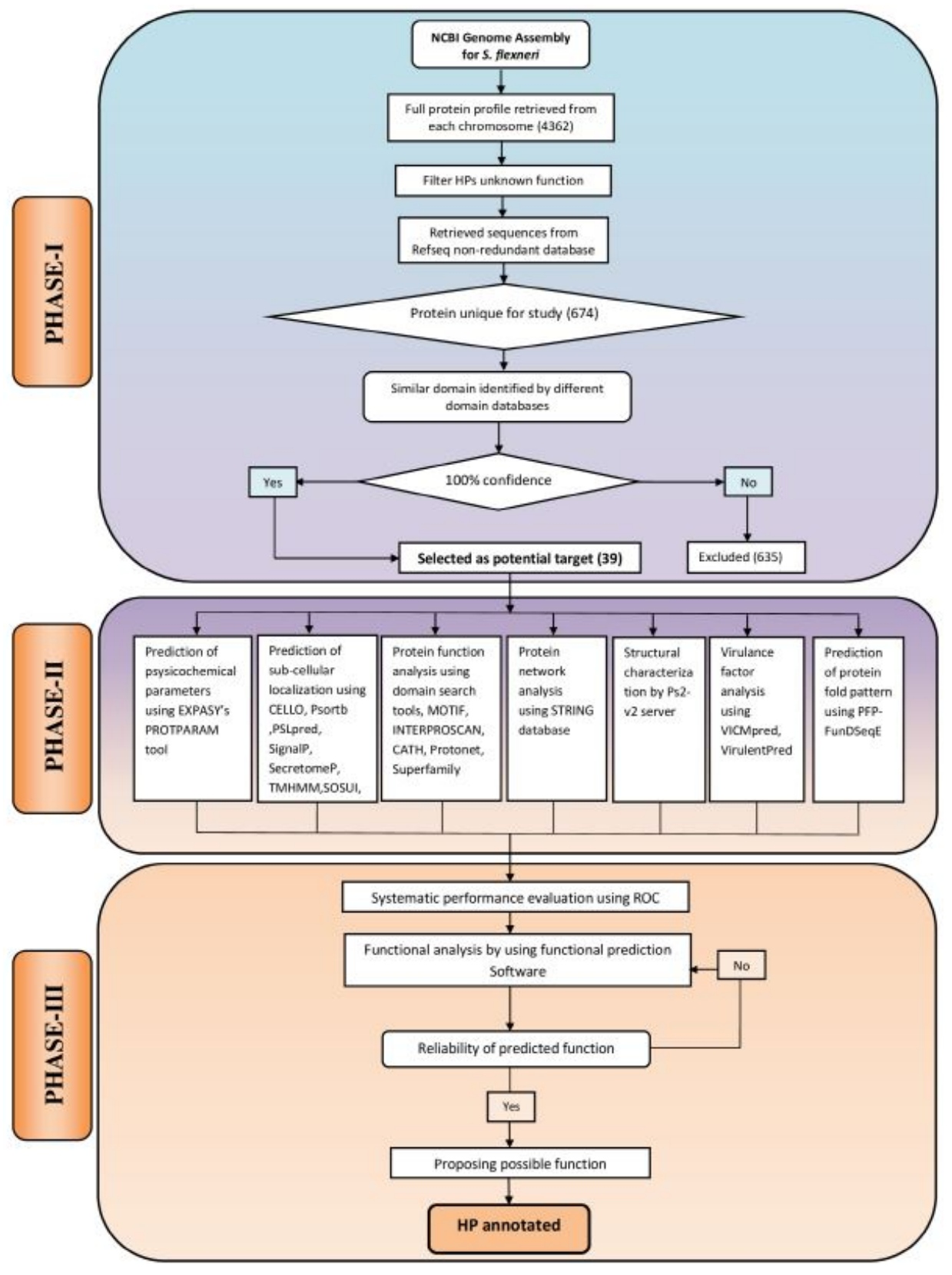

Fig. 1. Computational algorithm used for annotating function of 39 hypothetical proteins (HPs) from Shigella flexneri. The framework has been divided into three phases: PHASE I, sequence retrieval from online databases; PHASE II, the extensive analysis of sub-cellular localization, physicochemical parameters, virulence, function and domain present in HPs; PHASE III, assessment of the predicted functions using the protein with known function from $S$. flexneri and reliable prediction of possible functions of HPs. exhibit a higher degree of conservancy when compared with the entire sequence [24].

In our study, five bioinformatics tools namely: CDD-BLAST (Conserved Domain Database-Basic Local Alignment Search Tool) [25-27], PFAM [28], HmmScan [29], SMART (Simple Modular Architecture Research Tool) [30], and SCANPROSITE [31] were used. These tools are able to search for the defined conserved domains in the targeted protein sequences and further assist in the classification of putative proteins in a particular protein family. HPs analyzed by five aforementioned function prediction web tools revealed the variable results when searched for the conserved domains in hypothetical sequences. Therefore, different confidence levels were assigned on the basis of collective results of these web-tools. One hundred percentage confidence level was considered upon obtaining the same results from the five distinct tools. Finally, we obtained 39 such proteins from 674 primary collected proteins, which were taken for further analysis (Supplementary Table 1).

\section{Phase II}

\section{Physicochemical characterization}

Theoretical physiochemical parameters such as molecular weight, isoelectric point, aliphatic index, instability index and grand average of hydropathicity (GRAVY) of these HPs were analyzed using ProtParam server of the Expasy tools 
(http://web.expasy.org/protparam/). Results of this analysis have been listed in Supplementary Table 2.

\section{Determination of sub-cellular localization}

For the identification of a protein as a drug or vaccine candidate, determination of the sub-cellular localization of the protein becomes particularly important. Surface membrane protein can be served as a potential vaccine target while cytoplasmic proteins may act as promising drug targets [32]. We used CELLO [33], PSORTb [34], and PSLpred [35] for the denotation of sub-cellular localization of the query proteins. TMHMM, SOSUI, and HMMTOP were applied for the prediction of query proteins for being a membrane protein, based on Hidden Markov Model [36-38]. SingnalP 4.1 [39] was used to predict the signal peptide and SecretomeP 2.0 [40] were utilized for the identification of proteins involved in non-classical secretory pathway. Results of these predictions are summarized in Supplementary Table 3.

\section{Functional prediction of the query proteins}

Various tools were used for precise functional assignments of all 39 HPs from S. flexneri (described in Table 1) such as CDD-Blast, Pfam, HmmScan, SMART, Scanprosite, MOTIF [41], INTERPROSCAN [42], CATH [43], SUPERFAMILY

Table 1. List of annotated Hconf proteins from Shigella flexneri

\begin{tabular}{|c|c|c|}
\hline No & Protein name & Protein function \\
\hline 1 & WP_005053355.1 & Peptidase, C92 family \\
\hline 2 & WP_000092054.1 & DUF1615/lipoprotein \\
\hline 3 & WP_001382892.1 & DUF3251/lipoprotein Yajl/immunoglobulin like domain \\
\hline 4 & WP_005053036.1 & Lipoprotein_16/uncharacterized lipoprotein \\
\hline 5 & WP_000779831.1 & lipoprotein chaperone (YscW) \\
\hline 6 & WP_011110552.1 & YbfN-like lipoprotein \\
\hline 7 & WP_001269672.1 & LPS-assembly lipoprotein RlpB (LptE) \\
\hline 8 & WP_001247854.1 & Topoisomerases, DnaG-type primases, Hedgehog/intein domain \\
\hline 9 & WP_000070107.1 & ATP-binding cassette transporter \\
\hline 10 & WP_000224274.1 & MOSC beta barrel domain/2Fe-2S iron-sulfur cluster binding domain \\
\hline 11 & WP_on_00749269.1 & Ycel-like domain \\
\hline 12 & WP_001125713.1 & YcgL domain \\
\hline 13 & WP_001043881.1 & GAF domain \\
\hline 14 & WP_001295493.1 & Endoribonuclease L-PSP/YjgFfamily \\
\hline 15 & WP_000691930.1 & Domain of unknown function (DUF333) \\
\hline 16 & WP_000597196.1 & Glycine zipper 2TM domain \\
\hline 17 & WP_000248636.1 & AI-2E family transporter/permease \\
\hline 18 & WP_000755956.1 & SPFH domain/Band 7 family \\
\hline 19 & WP_001237866.1 & YecR-like lipoprotein \\
\hline 20 & WP_000454701.1 & TerC family/Transporter associated domain/CBS domain \\
\hline 21 & WP_on_00003197.1 & von Willebrand factor type A domain \\
\hline 22 & WP_005049020.1 & Uncharacterized lipoprotein YehR \\
\hline 23 & WP_o-048814497.1 & Leucine rich repeat protein/NEL or novel E3 ligase domain \\
\hline 24 & WP_000301054.1 & Lipopolysaccharide kinase (Kdo/WaaP) \\
\hline 25 & WP_000266171.1 & Tetratricopeptide repeat (TPR) \\
\hline 26 & WP_000589825.1 & Outer membrane protein (ompA) like domain/membrane lipoprotein \\
\hline 27 & WP_005051685.1 & LysM (lysin-like motif)/peptidase family M23 \\
\hline 28 & WP_001387238.1 & DNA repair protein RadC-like JAB domain \\
\hline 29 & WP_000248097.1 & Carrier protein $(\mathrm{CP})$ domain and phosphopantetheine attachment site \\
\hline 30 & WP_000848528.1 & Lipoprotein leucine-zipper \\
\hline 31 & WP_000189314.1 & GIY-YIG nuclease domain \\
\hline 32 & WP_001297375.1 & DNA repair protein RadC-like JAB domain \\
\hline 33 & WP_000858193.1 & yiaA/B two helix domain \\
\hline 34 & WP_001296791.1 & Autotransporter beta-domain \\
\hline 35 & WP_000778795.1 & Acetyltransferase (GNAT) domain \\
\hline 36 & WP_001205243.1 & Xylose isomerase-like TIM barrel (AP_endonuc_2) \\
\hline 37 & WP_001238362.1 & Lipocalin-like domain \\
\hline 38 & WP_000943980.1 & Glutathionylspermidine synthase \\
\hline 39 & WP_000132640.1 & Toxin SymE/SpoVT-AbrB domain \\
\hline
\end{tabular}


Table 2. Different types of folds identified in Shigella flexneri

\begin{tabular}{rll}
\hline No. & \multicolumn{1}{c}{ Fold type } & \multicolumn{1}{c}{ Accession number } \\
\hline 1 & Viral coat and capsid proteins & WP_005053355.1, WP_000691930.1 \\
2 & TIM-barrel & WP_000092054.1, WP_001247854.1, WP_001295493.1, WP_000266171.1, \\
& WP_001297375.1, WP_000943980.1, WP_000132640.1 \\
\hline 3 & Ferredoxin-like & WP_001382892.1, WP_000003197.1, WP_000301054.1 \\
4 & 4-Helical up-and-down bundle & WP_005053036.1, WP_000779831.1, WP_001269672.1 \\
5 & DNA-binding 3-helical bundle & WP_011110552.1, WP_000589825.1, WP_001387238.1, WP_000848528.1, \\
& WP_000189314.1 \\
\hline 6 & Small inhibitors, toxins, lectins & WP_000070107.1, WP_000454701.1, WP_048814497.1, WP_001205243.1 \\
7 & Belta-grasp & WP_000224274.1 \\
8 & Cupredoxins & WP_000749269.1, WP_000248636.1, WP_005051685.1 \\
9 & Thioredoxin-like & WP_001125713.1 \\
10 & Flavodoxin-like & WP_001043881.1 \\
11 & Trypsin-like serine proteases & WP_000597196.1 \\
12 & OB-fold & WP_000755956.1, WP_001237866.1, WP_000858193.1, WP_000778795.1 \\
13 & Immunoglobulin-like & WP_005049020.1 \\
14 & EF-hand & WP_000248097.1 \\
15 & ConA-like lectin/glucanases & WP_001296791.1 \\
16 & Lipocalins & WP_001238362.1 \\
\hline
\end{tabular}

[44], and Protonet [45]. Results of these analyses have been outlined in Supplementary Tables 4 and 5.

The computational prediction of the structure of a protein from its amino acid sequences greatly facilitates the subsequent prediction of its function [46]. An online server PS2-v2 (PS Square version 2) [47], a template based method were used to predict the structure of the HPs. The modeling of proteins using this online server further substantiated the function of HPs. Besides, PFP-FunDSeqE [48] has been used to elucidate the protein fold patterns based on a combination of functional domain information and evolutionary information (Table 2).

\section{Virulence factors analysis}

Virulence factors (VFs) are described as potent targets for developing drugs because it is essential for the severity of infection [49]. VICMpred [50] and Virulentpred [51] tools were employed to predict VFs from protein sequences with an accuracy of $70.75 \%$ and $81.8 \%$, respectively.

\section{Functional protein association networks}

The function and activity of a protein are often modulated by other proteins with which it interacts. Therefore, understanding of protein-protein interactions serve as valuable leads for predicting the function of a protein. In this investigation, we had employed STRING (Search Tool for the Retrieval of Interacting Genes/Proteins, https://string-db.org/) [52] to predict protein interactions partners of HPs. To predict functional association, only highest confidence score partner proteins were chosen in this study.

\section{Phase III}

\section{Performance assessment}

The predicted functions of HPs from S. flexneri and the accuracy of associated tools were validated using the ROC curve analysis. In this analysis, the diagnostics efficacy is evaluated at six levels where 1 and 0 classified as true positive and true negative respectively as binary numerals. In addition, the integers $(2,3,4$, and 5$)$ were used as confidence ratings for each case. The ROC curves were carried out using $25 \mathrm{~S}$. flexneri proteins with known function as control and were compared with the results obtained for the 39 HPs (Supplementary Tables 6 and 7). The results were submitted to web-based calculator for the ROC curves [53] in "format 1 " form and the program thereby calculated the ROC curves. The results were expressed in terms of accuracy (Ac), sensitivity (Se), specificity (Sp) and the area under the curve (AUC) [54]. The average accuracy of the employed pipeline was found $93.6 \%$ (Table 3, Fig. 2).

\section{Results and Discussion}

\section{Sequence analysis}

Sequences of all the $674 \mathrm{HPs}$ were analyzed for identification of the functional domains using five bioinformatics tools namely CDD-BLAST, Pfam, HmmScan, SMART, and SCANPROSITE. If the given five tools indicated the same domains for a protein, we considered it as $100 \%$ confidence level. In our study, all the five tools mentioned above revealed 39 such proteins and hence were grouped together. 
Table 3. List of accuracy, sensitivity, specificity, and ROC area of various bioinformatics tools used for predicting function of Hconf proteins from Shigella flexneri obtained after ROC analysis

\begin{tabular}{|c|c|c|c|c|c|}
\hline No. & Software name & Accuracy of prediction (\%) & Sensitivity (\%) & Specificity (\%) & ROC area \\
\hline 1 & BLAST & 100 & 100 & $\mathrm{n} / \mathrm{a}$ & $\mathrm{n} / \mathrm{a}$ \\
\hline 2 & Pfam & 100 & 100 & 100 & 1 \\
\hline 3 & HmmScan & 100 & 100 & 100 & 1 \\
\hline 4 & SMART & 100 & 100 & 100 & 1 \\
\hline 5 & Scanprosite & 72 & 100 & 12.50 & 0.662 \\
\hline 6 & MOTIF & 100 & 100 & 100 & 1 \\
\hline 7 & Interproscan & 100 & 100 & 100 & 1 \\
\hline 8 & CATH & 80 & 100 & 16.70 & 0.539 \\
\hline 9 & SUPERFAMILY & 84 & 100 & 20 & 0.54 \\
\hline 10 & ProtoNet & 100 & 100 & 100 & 1 \\
\hline 11 & Average & 93.6 & 100 & 64.35 & 0.774 \\
\hline
\end{tabular}

ROC, receiver operating characteristic.

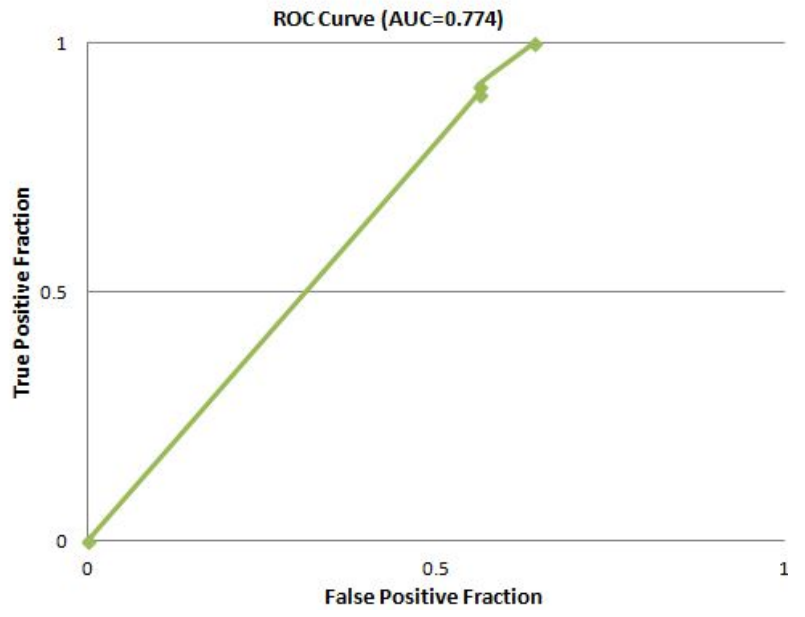

Fig. 2. Receiver operating characteristic (ROC) curve (area under the curve $[\mathrm{A \cup C}]=0.774)$ for average accuracy of prediction.

Only these HPs having $100 \%$ confidence level were considered for further analyses and termed as highly confident (Hconf) proteins. From the rest of the 635 proteins, no specific conserved domains were found for a total of 257 proteins. For other HPs $(n=378)$, specific domains were identified using several of these tools. To know accurate function of these proteins further studies are required.

The function of each of these 39 Hconf were successfully assigned by using different online tools, listed in Table 1. All sequence analyses were compiled and categorized into various functional classes constituting 9 enzymes, 10 binding proteins, 4 transporters, 4 lipoproteins, 6 which are involved in various cellular processes, while 6 proteins were predicted to exhibit miscellaneous functions (Fig. 3). Various functional classes of these classified Hconf proteins are described below.

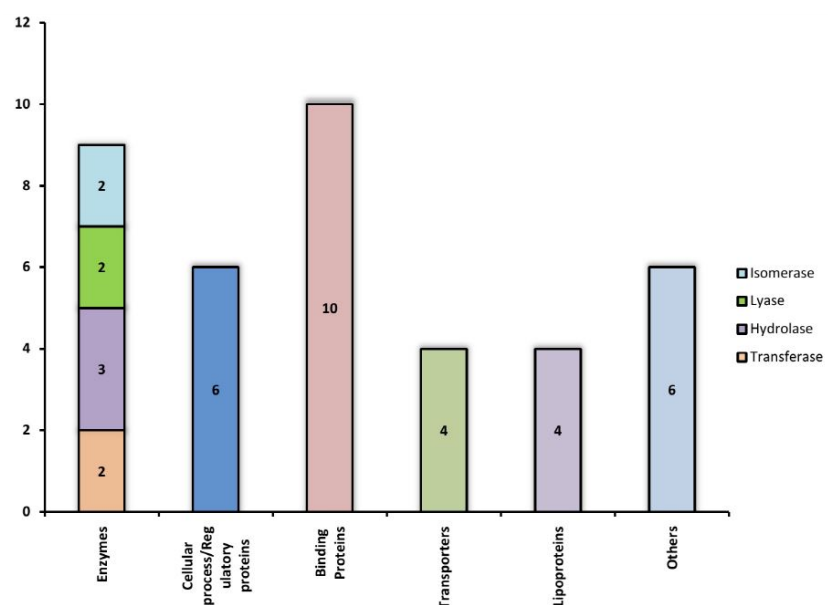

Fig. 3. Hypothetical proteins classified into different groups based on their functions.

\section{Enzymes}

Enzymes are key players in many leading biochemical processes in the living system and may facilitate the survival of pathogens in the host and making it viable for the course of infection. A total of 9 proteins out of 39 (23\%) of our annotated Hconfs were characterized as enzymes. Among these, two proteins were characterized as transferases, among which, WP_000301054.1 is a lipopolysaccharide kinase (Kdo/WaaP), involved in the formation of outer membrane (OM) of gram negative bacteria and is encoded by the Waap gene. The OM protects cells from toxic molecules and is important for survival during infection and is required for virulence of the pathogen [55]. According to reports made by Delucia [55], the depletion of WaaP gene was seen to halt the growth of the bacteria suggesting that WaaP is essential to produce the full-length lipopolysaccharide, 
recognized by the OM [49]. Therefore, WaaP may result in a potent target for the development of novel antimicrobial agents. The other transferase, protein WP_000778795.1 was found to consist of an acetyltransferase (GNAT) domain that uses acetyl coenzyme A (CoA) to transfer an acetyl group to a substrate, a reaction implicated in various functions for the development of antibiotic resistance of bacteria [56].

Three enzymes were predicted to be hydrolases, which plays key role in the invasion of the host tissue and evading the host defense mechanism and are thus associated with various VFs [57]. For instance, WP_005051685.1 marks the lysin-like motif/peptidase family M23, is found in proteins from viruses, bacteria, fungi, plants and mammals. It is present in bacterial extracellular proteins including hydrolases, adhesins and VFs such as protein A from Staphylococcus aureus. We report WP_001295493.1 protein as the endoribonuclease/YjgF family active on single-stranded mRNA that inhibits protein synthesis by cleaving mRNA [58]. YjgF family members are enamine/imine deaminases that hydrolyze reactive intermediates released by pyridoxal phosphate-dependent enzymes, including threonine dehydratase [59]. It has also been reported in the inhibition of transaminase B in Salmonella [60].

Among the other enzymes predicted, there has been two isomerase and one lyase enzyme. WP_001247854. 1 constitutes the toprim (topoisomerase-primase), a catalytic domain involved in breakage and rejoining of DNA strand [61]. WP_001205243.1 marks the Xylose isomerase-like TIM barrel involved in the myo-inositol catabolism pathway [62]. Lyases also play a key role in bacterial pathogenesis due to their involvements in various biosynthesis processes. WP_000943980.1 was found to demonstrate synthase activity that causes hydrolysis of ATP with the formation of an amide bond between spermidine and the glycine carboxylate of glutathione. In the pathogenic trypanosomatids, this reaction is the penultimate step in the biosynthesis of the antioxidant metabolite, and is a resounding target for target mediated drug design [63]. The WP_000454701.1 protein was found to be a cystathionine b-lyase, an enzyme which forms the cystathionine intermediate in cysteine biosynthesis and may be considered as the target for pyridiamine anti-microbial agents [64].

\section{Binding proteins}

Ten proteins annotated as binding proteins among which 1 RNA binding, 3 protein binding, 3 lipid binding, 1 metal binding, 1 peptidoglycan binding, and 1 adhesion protein have been predicted. WP_000132640.1 protein was predicted to be SymE (SOS-induced yjiW gene with similarity to MazE). It has been reported to involve in inhibiting cell growth, decrease protein synthesis and increase RNA degradation and thus exhibit a vital role in the survival and propagation of pathogen in the host $[65,66]$. Despite not manifesting any functional homology with other type I toxin proteins, SymE belongs to the type I toxin-antitoxin system. Its function resembles that of type II toxins such as MazF, which is able to perform the cleavage of mRNA in a ribosome independent manner. However, SymE shares homology to the AbrB-fold superfamily proteins such as MazE, which acts as transcriptional factors and antitoxins in various type II TA modules [67]. It seems probable that SymE has evolved into an RNA cleavage protein with toxin-like properties from a transcription factor or antitoxin [66]. In our study, we reported WP_000003197.1 as von Willebrand factor with a type A domain which has been reported responsible for various blood disorders [68-70]. The association of type A domain makes it liable to be involved in various significant activities such as cell adhesion and immune defense [71]. On the other hand, WP_000755956.1 has been predicted to belong to the band-7 protein family that comprises of a diverse set of membrane-bound proteins characterized by the presence of a conserved domain [72]. The exact function of this domain is not known, but concurrent reports from animal and bacterial stomatin-type proteins demonstrate the ability of binding to lipids and in the assembly of membrane-bound oligomers that form putative scaffolds [73]. We have also predicted WP_001269672.1 and WP_000749269.1 as the lipid binding domain called lipopolysaccharide (LPS)-assembly lipoprotein LptE and the Ycel-like domain respectively. The LPS transport machinery is composed of LptA, LptB, LptC, LptD, and LptE. LptE forms a complex with LptD, which is involved in the assembly of LPS in the outer leaflet of the OM [74]. This OM is an effective permeability barrier that protects the cells from toxic compounds, such as antibiotics and detergents, thus conferring the bacteria with the capability to adapt and consequently inhabit several different and often hostile environments. Among the binding prtoteins, WP 000266171.1 was found to be a tetratricopeptide repeat containing protein which is involved in protein-protein interactions and thus plays an important role in virulence [75].

\section{Cellular processes/regulatory proteins}

A total of 6 HPs have been predicted to be involved in various cellular and regulatory mechanisms, which are vital cognates in the pathogenesis of S. flexneri and thus can be treated as possible drug targets [76]. For example, WP_000189314.1 predicted to be a member of the GIY-YIG family involved in many cellular processes including DNA repair and recombination, transfer of mobile genetic elements, and restriction of incoming foreign DNA [77, 78]. 
WP_001387238.1 and WP_001297375.1 have been found to be RadC-like domain belonging to the JAB superfamily of metalloproteins [79]. In most instances, this domain shows fusions to an N-terminal Helix-hairpin-Helix $(\mathrm{HhH})$ domain and may also be function as a nuclease [79]. WP 000848528.1 has been predicted to be a leucine-zipper found in the enterobacterial OM lipoprotein LPP [80]. It is likely that this domain is involved in protein-protein interaction via subsequent oligomerization. WP_000597196.1 and WP_048814497.1 have been respectively found to be a Glycine zipper 2TM domain found in the Rickettsia genus and leucine-rich repeat involved in a variety of biological processes, including signal transduction, cell adhesion, DNA repair, recombination, transcription, RNA processing, disease resistance, apoptosis, and the immune response [81].

\section{Lipoprotein}

Bacterial lipoproteins are a set of membrane proteins with many different functions. Due to this broad-ranging functionality, these proteins have a considerable significance in many phenomena, from cellular physiology through cell division and virulence [82]. Lipoprotein of gram-negative bacteria is essential for growth and division [83]. In our analysis, we report a total of 4 lipoproteins from the group of HPs predicted in this study. It has been also revealed that lipoproteins may function as vaccines [82]. The knowledge of these facts may be utilized for the generation of novel countermeasures to bacterial diseases [82].

\section{Transport}

In our findings, we report the prediction of HP WP 000070107.1 to be a member of the ATP-binding cassette superfamily,largest of all protein families with a diversity of physiological functions [84]. It has recently been identified that these proteins may be involved in virulence and are essential for intracellular survival of pathogens [85]. We have found protein WP_001296791.1 to be an autotransporter of the YhjY type involved in DNA repair [86]. Protein WP_001238362.1 has been found to exhibit the function of transport of nutrients, control of cell regulation, pheromone transport, cryptic coloration and in the enzymatic synthesis of prostaglandins. An example a protein with such function is the retinol-binding protein 4 , which transfers retinol from liver to peripheral tissues [87].

\section{Other proteins}

Six HPs have been predicted to exhibit miscellaneous functions where most of them are protein with unknown function. Among them, WP_001382892.1 and WP 000691930.1 have been preicted to be domains of unknown function and are found in a number of bacterial proteins. WP_001125713.1 has been found to be YcgL domain with conserved class of small proteins widespread in gammaproteo bacteria. This group of proteins contain a 85-residue domain of unknown function and two alphahelices and four beta- strands in the sequential arrangement [88]. We have also predicted WP_001237866.1 and WP_005049020.1 as YecR and YehR like family of lipoproteins found in bacteria and viruses and are functionally uncharacterized.

\section{Virulent proteins}

Gram-negative bacteria undergo frequent genomic alterations and consequent evolutions thus increasing their virulence inside the host environment [89]. We have found 2 HPs that showed positive virulence scores servers among the Hconf proteins. These have been listed in Supplementary Table 8. It had already been hypothesized that targeting VF provides a better therapeutic intervention strategy against bacterial pathogenesis [89]. Predicted HPs having virulent characteristics thus provide powerful target-based therapies for the mitigation of an existing infection and are further considered as an adjunct therapy to existing antibiotics, or potentiators of the host immune response [90].

\section{ROC curve}

The average accuracy of the employed pipeline was identified $93.6 \%$ in our analysis which indicated that outcomes of the functional annotation of HPs were predicted with a high degree of confidence. We have also found sensitivity of $100 \%$ and specificity $64.3 \%$ for the tools used in this study. Finally, area under the curve was found to be 0.774 . AUC is an effective way to summarize the overall diagnostic accuracy of the test. It takes values from 0 to 1 , where 0.7 to 0.8 is considered acceptable.

\section{Conclusion}

Using an innovative in silico approach, all $674 \mathrm{HPs}$ from $S$. flexneri were primarily analyzed and then using the ROC analysis and confidence level measurements of the predicted results the functions of the $39 \mathrm{HPs}$ were precisely predicted with a reasonably high degree of confidence and thereby were successfully characterized. Following this, the validation of the functions of these proteins were carried out by using different approaches including structure based PS2-v2 server, sub-cellular localization and physicochemical parameters. These are important for distinguishing the HPs from the rest of the protein. The protein-protein interaction also gave insights in elucidation of the involvement of such proteins in various metabolic pathways. Moreover, some virulence proteins had also been detected which are essential 
for the survival of this pathogen. This in silico approach for functional annotation of the HPs can be further utilized in drug discovery for characterizing putative drug targets for other clinically important pathogens. The outcomes of ROC analysis indicated high reliability of bioinformatics tools used in this study. Hence, the functional annotation of HPs is reliable and can be further utilized for other experimental research.

ORCID: Md. Amran Gazi: https://orcid.org/0000-0002-3 286-7536; Sultan Mahmud: https://orcid.org/0000-0002-0 392-9646; Shah Mohammad Fahim: https://orcid.org/000 0-0002-3627-202X; Mohammad Golam Kibria: https://orc id.org/0000-0002-7821-2455; Parag Palit: https://orcid.org/ 0000-0001-7863-2639; Humaira Rashid: https://orcid.org/ 0000-0001-8607-573X; Subhasish Das: https://orcid.org/0 000-0002-7852-6569

\section{Author's contributions}

Conceptualization: MAG

Data curation: MAG, SM, SMF, MGK

Formal analysis: MAG, SM

Funding acquisition: MAG, MRI, HR, SD

Methodology: SM, MGK, PP, MRI, HR, SD

Writing - original draft: MAG, MM, TA

Writing - review \& editing: MAG, MM, TA

\section{Conflicts of Interest}

No potential conflicts of interest relevant to this article was reported.

\section{Acknowledgments}

The authors are grateful to core donors which provide unrestricted support to icddr,b for its operations and research. Current donors providing unrestricted support include: Government of the People's Republic of Bangladesh; Canadian International Development Agency (CIDA), Swedish International Development Cooperation Agency (Sida), and the Department for International Development, UK (DFID). We gratefully acknowledge these donors for their support and commitment to icddr,b's research efforts.

\section{Supplementary material}

Supplementary data including eight tables can be found with this article online at https://doi.org/10.5808/GI. 2018.16.4.e26.

\section{References}

1. GBD Diarrhoeal Diseases Collaborators. Estimates of global, regional, and national morbidity, mortality, and aetiologies of diarrhoeal diseases: a systematic analysis for the Global Burden of Disease Study 2015. Lancet Infect Dis 2017; 17:909-948.

2. Mathan MM, Mathan VI. Ultrastructural pathology of the rectal mucosa in Shigella dysentery. Am J Pathol 1986;123:25-38

3. Keusch GT. Shigella infections. Clin Gastroenterol 1979; 8:645-662.

4. Taneja N, Mewara A. Shigellosis: epidemiology in India. Indian J Med Res 2016;143:565-576.

5. Parajuli P, Adamski M, Verma NK. Bacteriophages are the major drivers of Shigella flexneri serotype 1c genome plasticity: a complete genome analysis. BMC Genomics 2017;18:722.

6. Ferreccio C, Prado V, Ojeda A, Cayyazo M, Abrego P, Guers L, et al. Epidemiologic patterns of acute diarrhea and endemic Shigella infections in children in a poor periurban setting in Santiago, Chile. Am J Epidemiol 1991;134:614-627.

7. von Seidlein L, Kim DR, Ali M, Lee H, Wang X, Thiem VD, et al. A multicentre study of Shigella diarrhoea in six Asian countries: disease burden, clinical manifestations, and microbiology. PLoS Med 2006;3:e353.

8. Nuesch-Inderbinen $M$, Heini N, Zurfluh K, Althaus D, Hachler H, Stephan R. Shigella antimicrobial drug resistance mechanisms, 2004-2014. Emerg Infect Dis 2016;22:1083-1085.

9. Zhu Z, Zhou X, Li B, Wang S, Cheng F, Zhang J. Genomic analysis and resistance mechanisms in Shigella flexneri 2a strain 301. Microb Drug Resist 2018;24:323-336.

10. Wei J, Goldberg MB, Burland V, Venkatesan MM, Deng W, Fournier G, et al. Complete genome sequence and comparative genomics of Shigella flexneri serotype 2a strain 2457T. Infect Immun 2003;71:2775-2786.

11. Desler C, Suravajhala P, Sanderhoff M, Rasmussen M, Rasmussen LJ. In silico screening for functional candidates amongst hypothetical proteins. BMC Bioinformatics 2009;10: 289.

12. Loewenstein Y, Raimondo D, Redfern OC, Watson J, Frishman $\mathrm{D}$, Linial $\mathrm{M}$, et al. Protein function annotation by homology-based inference. Genome Biol 2009;10:207.

13. Nimrod G, Schushan M, Steinberg DM, Ben-Tal N. Detection of functionally important regions in "hypothetical proteins" of known structure. Structure 2008;16:1755-1763.

14. Kumar K, Prakash A, Tasleem M, Islam A, Ahmad F, Hassan MI. Functional annotation of putative hypothetical proteins from Candida dubliniensis. Gene 2014;543:93-100.

15. Lubec G, Afjehi-Sadat L, Yang JW, John JP. Searching for hypothetical proteins: theory and practice based upon original data and literature. Prog Neurobiol 2005;77:90-127.

16. Shahbaaz M, Ahmad F, Imtaiyaz Hassan M. Structure-based functional annotation of putative conserved proteins having lyase activity from Haemophilus influenzae. 3 Biotech 2015;5: 317-336.

17. Sinha A, Ahmad F, Hassan MI. Structure based functional annotation of putative conserved proteins from Treponema pallidum: search for a potential drug target. Lett Drug Des Discov 
2015;12:46-59.

18. Adams MA, Suits MD, Zheng J, Jia Z. Piecing together the structure-function puzzle: experiences in structure-based functional annotation of hypothetical proteins. Proteomics 2007;7:2920-2932.

19. Doerks T, von Mering C, Bork P. Functional clues for hypothetical proteins based on genomic context analysis in prokaryotes. Nucleic Acids Res 2004;32:6321-6326.

20. Gazi MA, Kibria MG, Mahfuz M, Islam MR, Ghosh P, Afsar $\mathrm{MN}$, et al. Functional, structural and epitopic prediction of hypothetical proteins of Mycobacterium tuberculosis H37Rv: an in silico approach for prioritizing the targets. Gene 2016; 591:442-455.

21. Metz CE. Basic principles of ROC analysis. Semin Nucl Med 1978;8:283-298.

22. Anandakumar S, Shanmughavel P. Computational annotation for hypothetical proteins of Mycobacterium tuberculosis. J Comput Sci Syst Biol 2008;1:50-62.

23. Galperin MY, Koonin EV. 'Conserved hypothetical' proteins: prioritization of targets for experimental study. Nucleic Acids Res 2004;32:5452-5463.

24. Chothia C, Lesk AM. The relation between the divergence of sequence and structure in proteins. EMBO J 1986;5:823-826.

25. Altschul SF, Madden TL, Schaffer AA, Zhang J, Zhang Z, Miller $\mathrm{W}$, et al. Gapped BLAST and PSI-BLAST: a new generation of protein database search programs. Nucleic Acids Res 1997;25: 3389-3402.

26. Eddy SR. Profile hidden Markov models. Bioinformatics 1998;14:755-763.

27. Marchler-Bauer A, Anderson JB, Derbyshire MK, DeWeeseScott C, Gonzales NR, Gwadz M, et al. CDD: a conserved domain database for interactive domain family analysis. Nucleic Acids Res 2007;35:D237-D240.

28. Bateman A, Birney E, Cerruti L, Durbin R, Etwiller L, Eddy SR, et al. The Pfam protein families database. Nucleic Acids Res 2002;30:276-280.

29. Finn RD, Clements J, Arndt W, Miller BL, Wheeler TJ, Schreiber F, et al. HMMER web server: 2015 update. Nucleic Acids Res 2015;43:W30-W38.

30. Letunic I, Doerks T, Bork P. SMART 7: recent updates to the protein domain annotation resource. Nucleic Acids Res 2012; 40:D302-D305.

31. de Castro E, Sigrist CJ, Gattiker A, Bulliard V, LangendijkGenevaux PS, Gasteiger E, et al. ScanProsite: detection of PROSITE signature matches and ProRule-associated functional and structural residues in proteins. Nucleic Acids Res 2006;34:W362-W365.

32. Shanmugham B, Pan A. Identification and characterization of potential therapeutic candidates in emerging human pathogen Mycobacterium abscessus: a novel hierarchical in silico approach. PLoS One 2013;8:e59126.

33. Yu CS, Chen YC, Lu CH, Hwang JK. Prediction of protein subcellular localization. Proteins 2006;64:643-651.

34. Yu NY, Wagner JR, Laird MR, Melli G, Rey S, Lo R, et al. PSORTb 3.0: improved protein subcellular localization prediction with refined localization subcategories and predictive capabilities for all prokaryotes. Bioinformatics 2010;26:1608-
1615.

35. Bhasin M, Garg A, Raghava GP. PSLpred: prediction of subcellular localization of bacterial proteins. Bioinformatics 2005; 21:2522-2524.

36. Krogh A, Larsson B, von Heijne G, Sonnhammer EL. Predicting transmembrane protein topology with a hidden Markov model: application to complete genomes. J Mol Biol 2001;305:567-580.

37. Hirokawa T, Boon-Chieng S, Mitaku S. SOSUI: classification and secondary structure prediction system for membrane proteins. Bioinformatics 1998;14:378-379.

38. Tusnady GE, Simon I. The HMMTOP transmembrane topology prediction server. Bioinformatics 2001;17:849-850.

39. Petersen TN, Brunak S, von Heijne G, Nielsen H. SignalP 4.0: discriminating signal peptides from transmembrane regions. Nat Methods 2011;8:785-786.

40. Bendtsen JD, Kiemer L, Fausboll A, Brunak S. Non-classical protein secretion in bacteria. BMC Microbiol 2005;5:58.

41. Kanehisa M, Goto S, Kawashima S, Nakaya A. The KEGG databases at GenomeNet. Nucleic Acids Res 2002;30:42-46.

42. Quevillon E, Silventoinen V, Pillai S, Harte N, Mulder N, Apweiler $\mathrm{R}$, et al. InterProScan: protein domains identifier. Nucleic Acids Res 2005;33:W116-W120.

43. Sillitoe I, Cuff AL, Dessailly BH, Dawson NL, Furnham N, Lee $\mathrm{D}$, et al. New functional families (FunFams) in CATH to improve the mapping of conserved functional sites to $3 \mathrm{D}$ structures. Nucleic Acids Res 2013;41:D490-D498.

44. Gough J, Karplus K, Hughey R, Chothia C. Assignment of homology to genome sequences using a library of hidden Markov models that represent all proteins of known structure. J Mol Biol 2001;313:903-919.

45. Rappoport N, Karsenty S, Stern A, Linial N, Linial M. ProtoNet 6.0: organizing 10 million protein sequences in a compact hierarchical family tree. Nucleic Acids Res 2012;40:D313-D320.

46. Xu D, Xu Y, Uberbacher EC. Computational tools for protein modeling. Curr Protein Pept Sci 2000;1:1-21.

47. Chen CC, Hwang JK, Yang JM. (PS)2-v2: template-based protein structure prediction server. BMC Bioinformatics 2009; 10:366.

48. Shen HB, Chou KC. Predicting protein fold pattern with functional domain and sequential evolution information. $J$ Theor Biol 2009;256:441-446.

49. Baron C, Coombes B. Targeting bacterial secretion systems: benefits of disarmament in the microcosm. Infect Disord Drug Targets 2007;7:19-27.

50. Saha S, Raghava GP. VICMpred: an SVM-based method for the prediction of functional proteins of Gram-negative bacteria using amino acid patterns and composition. Genomics Proteomics Bioinformatics 2006;4:42-47.

51. Garg A, Gupta D. VirulentPred: a SVM based prediction method for virulent proteins in bacterial pathogens. BMC Bioinformatics 2008;9:62.

52. Szklarczyk D, Franceschini A, Kuhn M, Simonovic M, Roth A, Minguez P, et al. The STRING database in 2011: functional in teraction networks of proteins, globally integrated and scored. Nucleic Acids Res 2011;39:D561-D568.

53. Eng J. ROC analysis: web-based calculator for ROC curves. 
Baltimore: Johns Hopkins University, 2006. Accessed 2018 Sep 1. Available from: http://www.jrocfit.org.

54. Shahbaaz M, Hassan MI, Ahmad F. Functional annotation of conserved hypothetical proteins from Haemophilus influenzae Rd KW20. PLoS One 2013;8:e84263.

55. Delucia AM, Six DA, Caughlan RE, Gee P, Hunt I, Lam JS, et al. Lipopolysaccharide (LPS) inner-core phosphates are required for complete LPS synthesis and transport to the outer membrane in Pseudomonas aeruginosa PAO1. MBio 2011;2: e00142-11.

56. Burk DL, Ghuman N, Wybenga-Groot LE, Berghuis AM. X-ray structure of the AAC(6')-Ii antibiotic resistance enzyme at 1.8 A resolution: examination of oligomeric arrangements in GNAT superfamily members. Protein Sci 2003;12:426-437.

57. Bjornson HS. Enzymes associated with the survival and virulence of gram-negative anaerobes. Rev Infect Dis 1984;6 Suppl 1:S21-S24.

58. Morishita R, Kawagoshi A, Sawasaki T, Madin K, Ogasawara T, Oka $\mathrm{T}$, et al. Ribonuclease activity of rat liver perchloric acid-soluble protein, a potent inhibitor of protein synthesis. J Biol Chem 1999;274:20688-20692.

59. Lambrecht JA, Flynn JM, Downs DM. Conserved YjgF protein family deaminates reactive enamine/imine intermediates of pyridoxal 5'-phosphate (PLP)-dependent enzyme reactions. J Biol Chem 2012;287:3454-3461.

60. Schmitz G, Downs DM. Reduced transaminase B (IlvE) activity caused by the lack of yjgF is dependent on the status of threonine deaminase (IlvA) in Salmonella enterica serovar Typhimurium. J Bacteriol 2004;186:803-810.

61. Aravind L, Leipe DD, Koonin EV. Toprim: a conserved catalytic domain in type IA and II topoisomerases, DnaG-type primases, OLD family nucleases and RecR proteins. Nucleic Acids Res 1998;26:4205-4213.

62. Fry J, Wood M, Poole PS. Investigation of myo-inositol catabolism in Rhizobium leguminosarum bv. viciae and its effect on nodulation competitiveness. Mol Plant Microbe Interact 2001;14:1016-1025.

63. Bollinger JM Jr, Kwon DS, Huisman GW, Kolter R, Walsh CT. Glutathionylspermidine metabolism in Escherichia coli: purification, cloning, overproduction, and characterization of a bifunctional glutathionylspermidine synthetase/amidase. J Biol Chem 1995;270:14031-14041.

64. Ejim LJ, D'Costa VM, Elowe NH, Loredo-Osti JC, Malo D, Wright GD. Cystathionine beta-lyase is important for virulence of Salmonella enterica serovar Typhimurium. Infect Immun 2004;72:3310-3314.

65. Gerdes K, Wagner EG. RNA antitoxins. Curr Opin Microbiol 2007; 10:117-124.

66. Kawano M, Aravind L, Storz G. An antisense RNA controls synthesis of an SOS-induced toxin evolved from an antitoxin. Mol Microbiol 2007;64:738-754.

67. Kawano M. Divergently overlapping cis-encoded antisense RNA regulating toxin-antitoxin systems from $E$. coli: hok/sok, ldr/rdl, symE/symR. RNA Biol 2012;9:1520-1527.

68. Ruggeri ZM, Ware J. von Willebrand factor. FASEB J 1993; 7:308-316

69. Ahmad F, Jan R, Kannan M, Obser T, Hassan MI, Oyen F, et al.
Characterisation of mutations and molecular studies of type 2 von Willebrand disease. Thromb Haemost 2013;109:39-46.

70. Naqvi AA, Shahbaaz M, Ahmad F, Hassan MI. Identification of functional candidates amongst hypothetical proteins of Treponema pallidum ssp. pallidum. PLoS One 2015;10:e0124177.

71. Colombatti A, Bonaldo P, Doliana R. Type A modules: interacting domains found in several non-fibrillar collagens and in other extracellular matrix proteins. Matrix 1993;13:297-306.

72. Tavernarakis N, Driscoll M, Kyrpides NC. The SPFH domain: implicated in regulating targeted protein turnover in stomatins and other membrane-associated proteins. Trends Biochem Sci 1999;24:425-427.

73. Gehl B, Sweetlove LJ. Mitochondrial Band-7 family proteins: scaffolds for respiratory chain assembly? Front Plant Sci 2014;5:141.

74. Wu T, McCandlish AC, Gronenberg LS, Chng SS, Silhavy TJ, Kahne D. Identification of a protein complex that assembles lipopolysaccharide in the outer membrane of Escherichia coli. Proc Natl Acad Sci U S A 2006;103:11754-11759.

75. Cerveny L, Straskova A, Dankova V, Hartlova A, Ceckova M, Staud F, et al. Tetratricopeptide repeat motifs in the world of bacterial pathogens: role in virulence mechanisms. Infect Immun 2013;81:629-635.

76. Singer HM, Kuhne C, Deditius JA, Hughes KT, Erhardt M. The Salmonella Spi 1 virulence regulatory protein HilD directly activates transcription of the flagellar master operon flhDC. $J$ Bacteriol 2014;196:1448-1457.

77. Kowalski JC, Belfort M, Stapleton MA, Holpert M, Dansereau JT, Pietrokovski S, et al. Configuration of the catalytic GIY-YIG domain of intron endonuclease I-TevI: coincidence of computational and molecular findings. Nucleic Acids Res 1999;27: 2115-2125.

78. Van Roey P, Meehan L, Kowalski JC, Belfort M, Derbyshire V. Catalytic domain structure and hypothesis for function of GIY-YIG intron endonuclease I-TevI. Nat Struct Biol 2002;9: 806-811.

79. Iyer LM, Zhang D, Rogozin IB, Aravind L. Evolution of the deaminase fold and multiple origins of eukaryotic editing and mutagenic nucleic acid deaminases from bacterial toxin systems. Nucleic Acids Res 2011;39:9473-9497.

80. Shu W, Liu J, Ji H, Lu M. Core structure of the outer membrane lipoprotein from Escherichia coli at 1.9 A resolution. J Mol Biol 2000;299:1101-1112.

81. Rothberg JM, Jacobs JR, Goodman CS, Artavanis-Tsakonas S. slit: an extracellular protein necessary for development of midline glia and commissural axon pathways contains both EGF and LRR domains. Genes Dev 1990;4:2169-2187.

82. Kovacs-Simon A, Titball RW, Michell SL. Lipoproteins of bacterial pathogens. Infect Immun 2011;79:548-561.

83. Torti SV, Park JT. Lipoprotein of gram-negative bacteria is essential for growth and division. Nature 1976;263:323-326.

84. Saurin W, Hofnung M, Dassa E. Getting in or out: early segregation between importers and exporters in the evolution of ATP-binding cassette (ABC) transporters. J Mol Evol 1999;48: 22-41.

85. Freeman ZN, Dorus S, Waterfield NR. The KdpD/KdpE two-component system: integrating $\mathrm{K}(+)$ homeostasis and 
virulence. PLoS Pathog 2013;9:e1003201.

86. Ibanez-Ruiz M, Robbe-Saule V, Hermant D, Labrude S, Norel F. Identification of RpoS (sigma(S))-regulated genes in Salmonella enterica serovar Typhimurium. J Bacteriol 2000; 182:5749-5756.

87. Peterson PA, Rask L, Ostberg L, Andersson L, Kamwendo F, Pertoft $\mathrm{H}$. Studies on the transport and cellular distribution of vitamin A in normal and vitamin A-deficient rats with special reference to the vitamin A-binding plasma protein.J Biol Chem 1973;248:4009-4022.

88. Minailiuc OM, Vavelyuk O, Gandhi S, Hung MN, Cygler M,
Ekiel I. NMR structure of YcgL, a conserved protein from Escherichia coli representing the DUF709 family, with a novel alpha/beta/alpha sandwich fold. Proteins 2007;66:1004-1007.

89. Livorsi DJ, Stenehjem E, Stephens DS. Virulence factors of gram-negative bacteria in sepsis with a focus on Neisseria meningitidis. In: Sepsis: Pro-Inflammatory and Anti-Inflammatory Responses (Herwald H, Egesten A, eds.). Basel: Karger Publishers, 2011. pp. 31-47.

90. Marra A. Targeting virulence for antibacterial chemotherapy: identifying and characterising virulence factors for lead discovery. Drugs R D 2006;7:1-16. 


\title{
SUPPLEMENTARY INFORMATION
}

\section{Functional Prediction of Hypothetical Proteins from Shigella flexneri and Validation of the Predicted Models by Using ROC Curve Analysis}

\author{
Md. Amran Gazi ${ }^{1^{*}}$, Sultan Mahmud², Shah Mohammad Fahim, \\ Mohammad Golam Kibria ${ }^{2}$, Parag Palit ${ }^{1}$, Md. Rezaul Islam ${ }^{3}$, Humaira Rashid", \\ Subhasish Das ${ }^{1}$, Mustafa Mahfuz ${ }^{1}$, Tahmeed Ahmeed ${ }^{1}$
}

${ }^{1}$ Nutrition and Clinical Services Division, International Centre for Diarrhoeal Disease Research, Bangladesh (icddr,b), Dhaka 1212, Bangladesh, ${ }^{2}$ Infectious Diseases Division, International Centre for Diarrhoeal Disease

Research, Bangladesh (icddr,b), Dhaka 1212, Bangladesh, ${ }^{3}$ International Max Planck Research School, Grisebachstraße 5, 37077 Göttingen, Germany 
Supplementary Table 1. Scores of conserved domain search for 674 hypothetical proteins of Shigella flexneri serotype 2a strain 2457T using CDD-Blast, Pfam, HmmScan, SMART, and Scanprosite tools

\begin{tabular}{|c|c|c|c|c|c|c|c|c|}
\hline SI No. & Nucleotide ID & $\begin{array}{l}\text { Accession } \\
\text { ID_Protein }\end{array}$ & $\begin{array}{l}\text { CDD } \\
\text { Blast }\end{array}$ & Pfam & HmmScan & SMART & Scanprosite & Percentage \\
\hline 1 & NC_004741.1 & WP_000414150.1 & 0 & 0 & 0 & 0 & 0 & 0 \\
\hline 2 & NC_004741.1 & WP_000738723.1 & 1 & 1 & 1 & 1 & 0 & 80 \\
\hline 3 & NC_004741.1 & WP_001102351.1 & 1 & 1 & 1 & 1 & 0 & 80 \\
\hline 4 & NC_004741.1 & WP_000843568.1 & 1 & 1 & 1 & 1 & 0 & 80 \\
\hline 5 & NC_004741.1 & WP_032155592.1 & 0 & 0 & 0 & 0 & 0 & 0 \\
\hline 6 & NC_004741.1 & WP_011110533.1 & 1 & 1 & 1 & 1 & 0 & 80 \\
\hline 7 & NC_004741.1 & WP_032155631.1 & 0 & 0 & 0 & 0 & 0 & 0 \\
\hline 8 & NC_004741.1 & WP_000196533.1 & 0 & 0 & 0 & 0 & 0 & 0 \\
\hline 9 & NC_004741.1 & WP_001255305.1 & 0 & 0 & 0 & 0 & 0 & 0 \\
\hline 10 & NC_004741.1 & WP_001303790.1 & 0 & 0 & 0 & 0 & 0 & 0 \\
\hline 11 & NC_004741.1 & WP_000464383.1 & 1 & 0 & 0 & 0 & 0 & 20 \\
\hline 12 & NC_004741.1 & WP_032155552.1 & 0 & 0 & 0 & 0 & 0 & 0 \\
\hline 13 & NC_004741.1 & WP_005053505.1 & 1 & 1 & 1 & 1 & 0 & 80 \\
\hline 14 & NC_004741.1 & WP_005094211.1 & 1 & 1 & 1 & 1 & 0 & 80 \\
\hline 15 & NC_004741.1 & WP_001347263.1 & 0 & 0 & 0 & 0 & 0 & 0 \\
\hline 16 & NC_004741.1 & WP_000964241.1 & 1 & 1 & 1 & 1 & 0 & 80 \\
\hline 17 & NC_004741.1 & WP_000272188.1 & 1 & 1 & 1 & 1 & 0 & 80 \\
\hline 18 & NC_004741.1 & WP_000417058.1 & 1 & 1 & 1 & 1 & 0 & 80 \\
\hline 19 & NC_004741.1 & WP_005053355.1 & 1 & 1 & 1 & 1 & 1 & 100 \\
\hline 20 & NC_004741.1 & WP_000402248.1 & 1 & 1 & 1 & 1 & 0 & 80 \\
\hline 21 & NC_004741.1 & WP_024259146.1 & 0 & 0 & 0 & 0 & 0 & 0 \\
\hline 22 & NC_004741.1 & WP_001276640.1 & 1 & 1 & 1 & 1 & 0 & 80 \\
\hline 23 & NC_004741.1 & WP_000183806.1 & 1 & 1 & 1 & 1 & 0 & 80 \\
\hline 24 & NC_004741.1 & WP_000343116.1 & 0 & 0 & 0 & 0 & 0 & 0 \\
\hline
\end{tabular}




\begin{tabular}{|l|l|l|l|l|l|l|l|l|}
\hline 25 & NC_004741.1 & WP_000192453.1 & 1 & 1 & 1 & 1 & 0 & 80 \\
\hline 26 & NC_004741.1 & WP_005053303.1 & 0 & 0 & 0 & 0 & 0 & 0 \\
\hline 27 & NC_004741.1 & WP_000627639.1 & 1 & 1 & 1 & 1 & 0 & 80 \\
\hline 28 & NC_004741.1 & WP_032333103.1 & 0 & 0 & 0 & 0 & 0 & 0 \\
\hline 29 & NC_004741.1 & WP_001191885.1 & 0 & 0 & 0 & 0 & 0 & 0 \\
\hline 30 & NC_004741.1 & WP_000092054.1 & 1 & 1 & 1 & 1 & 1 & 100 \\
\hline 31 & NC_004741.1 & WP_001110751.1 & 0 & 0 & 0 & 0 & 0 & 0 \\
\hline 32 & NC_004741.1 & WP_005053269.1 & 0 & 0 & 0 & 0 & 0 & 0 \\
\hline 33 & NC_004741.1 & WP_000556489.1 & 0 & 0 & 0 & 0 & 0 & 0 \\
\hline 34 & NC_004741.1 & WP_000003122.1 & 0 & 0 & 0 & 1 & 0 & 20 \\
\hline 35 & NC_004741.1 & WP_001102097.1 & 1 & 1 & 1 & 1 & 0 & 80 \\
\hline 36 & NC_004741.1 & WP_001201712.1 & 0 & 0 & 0 & 0 & 0 & 0 \\
\hline 37 & NC_004741.1 & WP_000667623.1 & 0 & 0 & 0 & 0 & 0 & 0 \\
\hline 38 & NC_004741.1 & WP_000343515.1 & 1 & 0 & 0 & 0 & 0 & 20 \\
\hline 39 & NC_004741.1 & WP_005100645.1 & 1 & 1 & 1 & 1 & 1 & 80 \\
\hline 40 & NC_004741.1 & WP_000554647.1 & 0 & 0 & 0 & 0 & 0 & 0 \\
\hline 41 & NC_004741.1 & WP_005060548.1 & 0 & 0 & 0 & 0 & 0 & 0 \\
\hline 42 & NC_004741.1 & WP_001142439.1 & 1 & 1 & 1 & 1 & 0 & 80 \\
\hline 43 & NC_004741.1 & WP_032155747.1 & 0 & 0 & 0 & 0 & 0 & 0 \\
\hline 44 & NC_004741.1 & WP_000941942.1 & 1 & 1 & 1 & 1 & 0 & 80 \\
\hline 45 & NC_004741.1 & WP_000942006.1 & 1 & 1 & 1 & 1 & 0 & 80 \\
\hline 46 & NC_004741.1 & WP_000194195.1 & 1 & 0 & 0 & 0 & 0 & 20 \\
\hline 47 & NC_004741.1 & WP_001326928.1 & 0 & 1 & 0 & 1 & 0 & 40 \\
\hline 48 & NC_004741.1 & WP_001382892.1 & 1 & 1 & 1 & 1 & 1 & 100 \\
\hline 49 & NC_004741.1 & WP_000645013.1 & 0 & 0 & 0 & 0 & 0 & 0 \\
\hline 50 & NC_004741.1 & WP_005060811.1 & 1 & 1 & 1 & 1 & 0 & 80 \\
\hline 51 & NC_004741.1 & WP_005053055.1 & 0 & 0 & 0 & 0 & 0 & 0 \\
\hline 52 & NC_004741.1 & WP_005053036.1 & 1 & 1 & 1 & 1 & 1 & 100 \\
\hline & & & & & & & & \\
\hline
\end{tabular}




\begin{tabular}{|c|c|c|c|c|c|c|c|c|}
\hline 53 & NC_004741.1 & WP_001177122.1 & 0 & 0 & 0 & 0 & 0 & 0 \\
\hline 54 & NC_004741.1 & WP_000680312.1 & 1 & 1 & 1 & 1 & 0 & 80 \\
\hline 55 & NC_004741.1 & WP_005053020.1 & 1 & 1 & 1 & 1 & 0 & 80 \\
\hline 56 & NC_004741.1 & WP_000779831.1 & 1 & 1 & 1 & 1 & 1 & 100 \\
\hline 57 & NC_004741.1 & WP_000136192.1 & 1 & 1 & 1 & 1 & 0 & 80 \\
\hline 58 & NC_004741.1 & WP_032140245.1 & 0 & 1 & 0 & 1 & 0 & 40 \\
\hline 59 & NC_004741.1 & WP_001188905.1 & 1 & 1 & 1 & 1 & 0 & 80 \\
\hline 60 & NC_004741.1 & WP_000970323.1 & 1 & 1 & 1 & 1 & 0 & 80 \\
\hline 61 & NC_004741.1 & WP_000701358.1 & 1 & 1 & 1 & 1 & 0 & 80 \\
\hline 62 & NC_004741.1 & WP_001224555.1 & 1 & 1 & 1 & 1 & 0 & 80 \\
\hline 63 & NC_004741.1 & WP_000752567.1 & 1 & 1 & 1 & 1 & 0 & 80 \\
\hline 64 & NC_004741.1 & WP_000360957.1 & 1 & 1 & 1 & 1 & 0 & 80 \\
\hline 65 & NC_004741.1 & WP_064193753.1 & 0 & 0 & 0 & 0 & 0 & 0 \\
\hline 66 & NC_004741.1 & WP_000460431.1 & 1 & 1 & 1 & 1 & 0 & 80 \\
\hline 67 & NC_004741.1 & WP_000283754.1 & 1 & 1 & 1 & 1 & 0 & 80 \\
\hline 68 & NC_004741.1 & WP_000287805.1 & 1 & 0 & 0 & 0 & 0 & 20 \\
\hline 69 & NC_004741.1 & WP_001301130.1 & 0 & 0 & 0 & 0 & 0 & 0 \\
\hline 70 & NC_004741.1 & WP_005083189.1 & 0 & 0 & 0 & 0 & 0 & 0 \\
\hline 71 & NC_004741.1 & WP_001303843.1 & 0 & 0 & 0 & 0 & 0 & 0 \\
\hline 72 & NC_004741.1 & WP_005049395.1 & 0 & 0 & 0 & 0 & 0 & 0 \\
\hline 73 & NC_004741.1 & WP_005083246.1 & 0 & 0 & 0 & 0 & 0 & 0 \\
\hline 74 & NC_004741.1 & WP_001188346.1 & 1 & 1 & 1 & 1 & 0 & 80 \\
\hline 75 & NC_004741.1 & WP_001053303.1 & 1 & 1 & 1 & 1 & 0 & 80 \\
\hline 76 & NC_004741.1 & WP_000807562.1 & 1 & 1 & 1 & 1 & 0 & 80 \\
\hline 77 & NC_004741.1 & WP_025715253.1 & 0 & 0 & 0 & 0 & 0 & 0 \\
\hline 78 & NC_004741.1 & WP_000405563.1 & 1 & 1 & 1 & 1 & 0 & 80 \\
\hline 79 & NC_004741.1 & WP_001325427.1 & 0 & 0 & 0 & 0 & 0 & 0 \\
\hline 80 & NC_004741.1 & WP_011110552.1 & 1 & 1 & 1 & 1 & 1 & 100 \\
\hline
\end{tabular}




\begin{tabular}{|l|l|l|l|l|l|l|l|l|}
\hline 81 & NC_004741.1 & WP_000153125.1 & 1 & 1 & 1 & 1 & 0 & 80 \\
\hline 82 & NC_004741.1 & WP_000232643.1 & 1 & 1 & 1 & 1 & 0 & 80 \\
\hline 83 & NC_004741.1 & WP_005049464.1 & 0 & 0 & 0 & 1 & 0 & 20 \\
\hline 84 & NC_004741.1 & WP_001030938.1 & 1 & 1 & 1 & 1 & 0 & 80 \\
\hline 85 & NC_004741.1 & WP_000367140.1 & 1 & 1 & 1 & 1 & 0 & 80 \\
\hline 86 & NC_004741.1 & WP_000578172.1 & 1 & 1 & 1 & 1 & 0 & 80 \\
\hline 87 & NC_004741.1 & WP_001044870.1 & 1 & 1 & 1 & 1 & 0 & 80 \\
\hline 88 & NC_004741.1 & WP_001269672.1 & 1 & 1 & 1 & 1 & 1 & 100 \\
\hline 89 & NC_004741.1 & WP_000850550.1 & 1 & 1 & 1 & 1 & 0 & 80 \\
\hline 90 & NC_004741.1 & WP_000073523.1 & 0 & 0 & 0 & 0 & 0 & 0 \\
\hline 91 & NC_004741.1 & WP_005049496.1 & 0 & 0 & 0 & 0 & 0 & 0 \\
\hline 92 & NC_004741.1 & WP_000627468.1 & 1 & 1 & 1 & 1 & 0 & 80 \\
\hline 93 & NC_004741.1 & WP_005060669.1 & 0 & 0 & 0 & 0 & 0 & 0 \\
\hline 94 & NC_004741.1 & WP_000873153.1 & 1 & 1 & 1 & 1 & 0 & 80 \\
\hline 95 & NC_004741.1 & WP_000113500.1 & 1 & 1 & 1 & 1 & 0 & 80 \\
\hline 96 & NC_004741.1 & WP_005020049.1 & 0 & 0 & 0 & 0 & 0 & 0 \\
\hline 97 & NC_004741.1 & WP_005098291.1 & 0 & 0 & 0 & 0 & 0 & 0 \\
\hline 98 & NC_004741.1 & WP_001108106.1 & 0 & 0 & 0 & 0 & 0 & 0 \\
\hline 99 & NC_004741.1 & WP_000454800.1 & 1 & 1 & 1 & 1 & 0 & 80 \\
\hline 100 & NC_004741.1 & WP_047199943.1 & 1 & 1 & 1 & 1 & 0 & 80 \\
\hline 101 & NC_004741.1 & WP_001247854.1 & 1 & 1 & 1 & 1 & 1 & 100 \\
\hline 102 & NC_004741.1 & WP_001343960.1 & 0 & 0 & 0 & 0 & 0 & 0 \\
\hline 103 & NC_004741.1 & WP_005053437.1 & 0 & 0 & 0 & 0 & 0 & 0 \\
\hline 104 & NC_004741.1 & WP_000551132.1 & 1 & 1 & 1 & 1 & 0 & 80 \\
\hline 105 & NC_004741.1 & WP_000266134.1 & 1 & 0 & 0 & 0 & 0 & 20 \\
\hline 106 & NC_004741.1 & WP_005048534.1 & 1 & 1 & 1 & 1 & 0 & 80 \\
\hline 107 & NC_004741.1 & WP_000446914.1 & 1 & 1 & 1 & 1 & 0 & 80 \\
\hline 108 & NC_004741.1 & WP_000871982.1 & 1 & 1 & 1 & 1 & 0 & 80 \\
\hline & & & & & & & & \\
\hline
\end{tabular}




\begin{tabular}{|l|l|l|l|l|l|l|l|l|}
\hline 109 & NC_004741.1 & WP_000070107.1 & 1 & 1 & 1 & 1 & 1 & 100 \\
\hline 110 & NC_004741.1 & WP_001336078.1 & 0 & 1 & 0 & 1 & 0 & 40 \\
\hline 111 & NC_004741.1 & WP_005048500.1 & 1 & 1 & 1 & 1 & 0 & 80 \\
\hline 112 & NC_004741.1 & WP_000849301.1 & 1 & 1 & 1 & 1 & 0 & 80 \\
\hline 113 & NC_004741.1 & WP_000710620.1 & 1 & 1 & 1 & 1 & 0 & 80 \\
\hline 114 & NC_004741.1 & WP_000188784.1 & 0 & 0 & 0 & 0 & 0 & 0 \\
\hline 115 & NC_004741.1 & WP_000168813.1 & 1 & 1 & 1 & 1 & 0 & 80 \\
\hline 116 & NC_004741.1 & WP_001295900.1 & 0 & 0 & 0 & 0 & 0 & 0 \\
\hline 117 & NC_004741.1 & WP_000681108.1 & 1 & 1 & 1 & 1 & 0 & 80 \\
\hline 118 & NC_004741.1 & WP_001201557.1 & 1 & 1 & 1 & 1 & 0 & 80 \\
\hline 119 & NC_004741.1 & WP_000389260.1 & 1 & 1 & 1 & 1 & 0 & 80 \\
\hline 120 & NC_004741.1 & WP_001303862.1 & 0 & 0 & 0 & 0 & 0 & 0 \\
\hline 121 & NC_004741.1 & WP_001160722.1 & 1 & 1 & 1 & 1 & 0 & 80 \\
\hline 122 & NC_004741.1 & WP_032155760.1 & 0 & 0 & 0 & 0 & 0 & 0 \\
\hline 123 & NC_004741.1 & WP_000687442.1 & 0 & 0 & 0 & 0 & 0 & 0 \\
\hline 124 & NC_004741.1 & WP_029716636.1 & 1 & 1 & 1 & 1 & 0 & 80 \\
\hline 125 & NC_004741.1 & WP_005048249.1 & 0 & 0 & 1 & 0 & 0 & 20 \\
\hline 126 & NC_004741.1 & WP_001118167.1 & 1 & 1 & 1 & 1 & 0 & 80 \\
\hline 127 & NC_004741.1 & WP_000702036.1 & 1 & 1 & 1 & 1 & 0 & 80 \\
\hline 128 & NC_004741.1 & WP_001091985.1 & 1 & 1 & 1 & 1 & 0 & 80 \\
\hline 129 & NC_004741.1 & WP_001005968.1 & 0 & 0 & 0 & 0 & 0 & 0 \\
\hline 130 & NC_004741.1 & WP_005051132.1 & 1 & 0 & 0 & 0 & 0 & 20 \\
\hline 131 & NC_004741.1 & WP_005061679.1 & 1 & 1 & 1 & 1 & 0 & 80 \\
\hline 132 & NC_004741.1 & WP_001039888.1 & 1 & 0 & 1 & 0 & 0 & 40 \\
\hline 133 & NC_004741.1 & WP_000723623.1 & 1 & 1 & 1 & 1 & 0 & 80 \\
\hline 134 & NC_004741.1 & WP_000959226.1 & 0 & 0 & 0 & 0 & 0 & 0 \\
\hline 135 & NC_004741.1 & WP_000350058.1 & 1 & 1 & 1 & 1 & 0 & 80 \\
\hline 136 & NC_004741.1 & WP_000196607.1 & 0 & 0 & 0 & 0 & 0 & 0 \\
\hline & & & & & & & & \\
\hline
\end{tabular}




\begin{tabular}{|l|l|l|l|l|l|l|l|l|}
\hline 137 & NC_004741.1 & WP_000235193.1 & 1 & 0 & 0 & 0 & 0 & 20 \\
\hline 138 & NC_004741.1 & WP_000224274.1 & 1 & 1 & 1 & 1 & 1 & 100 \\
\hline 139 & NC_004741.1 & WP_001261235.1 & 1 & 1 & 1 & 1 & 0 & 80 \\
\hline 140 & NC_004741.1 & WP_000847791.1 & 1 & 1 & 1 & 1 & 0 & 80 \\
\hline 141 & NC_004741.1 & WP_001301416.1 & 0 & 0 & 0 & 0 & 0 & 0 \\
\hline 142 & NC_004741.1 & WP_001038092.1 & 1 & 1 & 1 & 1 & 0 & 80 \\
\hline 143 & NC_004741.1 & WP_005083611.1 & 0 & 0 & 0 & & 0 & 0 \\
\hline 144 & NC_004741.1 & WP_000505101.1 & 1 & 0 & 0 & 0 & 0 & 20 \\
\hline 145 & NC_004741.1 & WP_000535353.1 & 1 & 0 & 0 & 0 & 0 & 20 \\
\hline 146 & NC_004741.1 & WP_001143120.1 & 1 & 1 & 1 & 1 & 0 & 80 \\
\hline 147 & NC_004741.1 & WP_000124106.1 & 0 & 0 & 0 & 0 & 0 & 0 \\
\hline 148 & NC_004741.1 & WP_000611853.1 & 0 & 0 & 0 & 0 & 0 & 0 \\
\hline 149 & NC_004741.1 & WP_001297187.1 & 1 & 1 & 1 & 1 & 0 & 80 \\
\hline 150 & NC_004741.1 & WP_032155907.1 & 0 & 0 & 0 & 0 & 0 & 0 \\
\hline 151 & NC_004741.1 & WP_001111218.1 & 0 & 0 & 0 & 0 & 0 & 0 \\
\hline 152 & NC_004741.1 & WP_005047366.1 & 0 & 0 & & 0 & 0 & 0 \\
\hline 153 & NC_004741.1 & WP_000818776.1 & 0 & 0 & 0 & 0 & 0 & 0 \\
\hline 154 & NC_004741.1 & WP_000749269.1 & 1 & 1 & 1 & 1 & 1 & 100 \\
\hline 155 & NC_004741.1 & WP_000877111.1 & 1 & 1 & 1 & 1 & 0 & 80 \\
\hline 156 & NC_004741.1 & WP_001295962.1 & 1 & 1 & 1 & 1 & 0 & 80 \\
\hline 157 & NC_004741.1 & WP_000587933.1 & 1 & 1 & 1 & 1 & 0 & 80 \\
\hline 158 & NC_004741.1 & WP_001043459.1 & 1 & 1 & 1 & 1 & 0 & 80 \\
\hline 159 & NC_004741.1 & WP_032155646.1 & 0 & 0 & 0 & 0 & 0 & 0 \\
\hline 160 & NC_004741.1 & WP_000103622.1 & 0 & 0 & 0 & 0 & 0 & 0 \\
\hline 161 & NC_004741.1 & WP_005005155.1 & 0 & 0 & 0 & 0 & 0 & 0 \\
\hline 162 & NC_004741.1 & WP_001204964.1 & 0 & 0 & 0 & 0 & 1 & 20 \\
\hline 163 & NC_004741.1 & WP_000770157.1 & 1 & 1 & 1 & 1 & 0 & 80 \\
\hline 164 & NC_004741.1 & WP_000557473.1 & 0 & 0 & 0 & 0 & 0 & 0 \\
\hline & & & & & & & & 0 \\
\hline
\end{tabular}




\begin{tabular}{|l|l|l|l|l|l|l|l|l|}
\hline 165 & NC_004741.1 & WP_001294167.1 & 0 & 0 & 0 & 0 & 0 & 0 \\
\hline 166 & NC_004741.1 & WP_001132078.1 & 0 & 0 & 0 & 0 & 0 & 0 \\
\hline 167 & NC_004741.1 & WP_000267598.1 & 1 & 1 & 1 & 1 & 0 & 80 \\
\hline 168 & NC_004741.1 & WP_000134107.1 & 1 & 1 & 1 & 1 & 0 & 80 \\
\hline 169 & NC_004741.1 & WP_001005703.1 & 0 & 0 & 0 & 0 & 0 & 0 \\
\hline 170 & NC_004741.1 & WP_029716858.1 & 1 & 1 & 1 & 1 & 0 & 80 \\
\hline 171 & NC_004741.1 & WP_000133415.1 & 0 & 0 & 0 & 0 & 0 & 0 \\
\hline 172 & NC_004741.1 & WP_005047957.1 & 0 & 0 & 0 & 0 & 0 & 0 \\
\hline 173 & NC_004741.1 & WP_032155828.1 & 0 & 0 & 0 & 0 & 0 & 0 \\
\hline 174 & NC_004741.1 & WP_005047951.1 & 0 & 0 & 0 & 0 & 0 & 0 \\
\hline 175 & NC_004741.1 & WP_001295611.1 & 1 & 1 & 1 & 1 & 0 & 80 \\
\hline 176 & NC_004741.1 & WP_000122462.1 & 0 & 0 & 0 & 0 & 0 & 0 \\
\hline 177 & NC_004741.1 & WP_005061990.1 & 0 & 0 & 0 & 0 & 0 & 0 \\
\hline 178 & NC_004741.1 & WP_001125713.1 & 1 & 1 & 1 & 1 & 1 & 100 \\
\hline 179 & NC_004741.1 & WP_000807626.1 & 1 & 1 & 1 & 1 & 0 & 80 \\
\hline 180 & NC_004741.1 & WP_011069340.1 & 0 & 0 & 0 & 0 & 0 & 0 \\
\hline 181 & NC_004741.1 & WP_000280742.1 & 0 & 0 & 0 & 0 & 0 & 0 \\
\hline 182 & NC_004741.1 & WP_001257042.1 & 1 & 1 & 1 & 1 & 0 & 80 \\
\hline 183 & NC_004741.1 & WP_000950192.1 & 1 & 1 & 1 & 1 & 0 & 80 \\
\hline 184 & NC_004741.1 & WP_001169669.1 & 1 & 1 & 1 & 1 & 0 & 80 \\
\hline 185 & NC_004741.1 & WP_000069487.1 & 0 & 0 & 0 & 0 & 0 & 0 \\
\hline 186 & NC_004741.1 & WP_005105319.1 & 1 & 1 & 1 & 1 & 0 & 80 \\
\hline 187 & NC_004741.1 & WP_001303937.1 & 0 & 0 & 0 & 0 & 0 & 0 \\
\hline 188 & NC_004741.1 & WP_000967595.1 & 1 & 1 & 1 & 1 & 0 & 80 \\
\hline 189 & NC_004741.1 & WP_000028536.1 & 1 & 1 & 1 & 1 & 0 & 80 \\
\hline 190 & NC_004741.1 & WP_000807659.1 & 1 & 1 & 1 & 1 & 0 & 80 \\
\hline 191 & NC_004741.1 & WP_001303289.1 & 0 & 0 & 0 & 0 & 0 & 0 \\
\hline 192 & NC_004741.1 & WP_001031530.1 & 1 & 1 & 1 & 1 & 0 & 80 \\
\hline & & & & & & & & \\
\hline
\end{tabular}




\begin{tabular}{|l|l|l|l|l|l|l|l|l|}
\hline 193 & NC_004741.1 & WP_014640285.1 & 0 & 0 & 0 & 0 & 0 & 0 \\
\hline 194 & NC_004741.1 & WP_000233043.1 & 0 & 0 & 0 & 0 & 0 & 0 \\
\hline 195 & NC_004741.1 & WP_000616081.1 & 0 & 0 & 0 & 0 & 0 & 0 \\
\hline 196 & NC_004741.1 & WP_001288369.1 & 1 & 0 & 0 & 0 & 0 & 0 \\
\hline 197 & NC_004741.1 & WP_001331106.1 & 1 & 1 & 1 & 1 & 0 & 80 \\
\hline 198 & NC_004741.1 & WP_023636694.1 & 0 & 0 & 0 & 0 & 1 & 20 \\
\hline 199 & NC_004741.1 & WP_000825769.1 & 1 & 1 & 1 & 1 & 0 & 80 \\
\hline 200 & NC_004741.1 & WP_032155686.1 & 1 & 0 & 0 & 0 & 0 & 20 \\
\hline 201 & NC_004741.1 & WP_000124119.1 & 0 & 0 & 0 & 0 & 0 & 0 \\
\hline 202 & NC_004741.1 & WP_001296046.1 & 0 & 0 & 0 & 0 & 0 & 0 \\
\hline 203 & NC_004741.1 & WP_005047705.1 & 1 & 0 & 0 & 0 & 0 & 20 \\
\hline 204 & NC_004741.1 & WP_005047713.1 & 1 & 1 & 1 & 1 & 0 & 80 \\
\hline 205 & NC_004741.1 & WP_023517638.1 & 1 & 1 & 1 & 1 & 0 & 80 \\
\hline 206 & NC_004741.1 & WP_011069401.1 & 1 & 1 & 1 & 1 & 0 & 80 \\
\hline 207 & NC_004741.1 & WP_000431885.1 & 1 & 1 & 1 & 1 & 0 & 80 \\
\hline 208 & NC_004741.1 & WP_011069399.1 & 0 & 0 & 0 & 0 & 0 & 0 \\
\hline 209 & NC_004741.1 & WP_001296778.1 & 0 & 0 & 0 & 0 & 0 & 80 \\
\hline 210 & NC_004741.1 & WP_001077956.1 & 0 & 0 & 0 & 0 & 0 & 0 \\
\hline 211 & NC_004741.1 & WP_000554382.1 & 1 & 0 & 0 & 0 & 0 & 20 \\
\hline 212 & NC_004741.1 & WP_005049838.1 & 1 & 1 & 1 & 1 & 0 & 80 \\
\hline 213 & NC_004741.1 & WP_001295499.1 & 1 & 1 & 1 & 1 & 0 & 80 \\
\hline 214 & NC_004741.1 & WP_001043881.1 & 1 & 1 & 1 & 1 & 1 & 100 \\
\hline 215 & NC_004741.1 & WP_001006860.1 & 1 & 1 & 1 & 1 & 0 & 80 \\
\hline 216 & NC_004741.1 & WP_032155836.1 & 0 & 0 & 0 & 0 & 0 & 0 \\
\hline 217 & NC_004741.1 & WP_000156246.1 & 1 & 1 & 1 & 1 & 0 & 80 \\
\hline 218 & NC_004741.1 & WP_001306763.1 & 0 & 0 & 0 & 0 & 0 & 0 \\
\hline 219 & NC_004741.1 & WP_001295493.1 & 1 & 1 & 1 & 1 & 1 & 100 \\
\hline 220 & NC_004741.1 & WP_032155854.1 & 0 & 0 & 0 & 0 & 1 & 20 \\
\hline & & & & & & & & \\
\hline
\end{tabular}




\begin{tabular}{|c|c|c|c|c|c|c|c|c|}
\hline 221 & NC_004741.1 & WP_000691930.1 & 1 & 1 & 1 & 1 & 1 & 100 \\
\hline 222 & NC_004741.1 & WP_005126892.1 & 0 & 0 & 0 & 0 & 0 & 0 \\
\hline 223 & NC_004741.1 & WP_000138039.1 & 1 & 1 & 1 & 1 & 0 & 80 \\
\hline 224 & NC_004741.1 & WP_001046790.1 & 1 & 1 & 1 & 1 & 0 & 80 \\
\hline 225 & NC_004741.1 & WP_001453023.1 & 0 & 0 & 0 & 0 & 0 & 0 \\
\hline 226 & NC_004741.1 & WP_012602004.1 & 0 & 0 & 0 & 0 & 0 & 0 \\
\hline 227 & NC_004741.1 & WP_000756955.1 & 1 & 1 & 1 & 1 & 0 & 80 \\
\hline 228 & NC_004741.1 & WP_000085238.1 & 1 & 1 & 1 & 1 & 0 & 80 \\
\hline 229 & NC_004741.1 & WP_001215295.1 & 1 & 0 & 0 & 0 & 0 & 20 \\
\hline 230 & NC_004741.1 & WP_000077934.1 & 0 & 0 & 0 & 0 & 1 & 20 \\
\hline 231 & NC_004741.1 & WP_032145487.1 & 0 & 1 & 0 & 1 & 0 & 40 \\
\hline 232 & NC_004741.1 & WP_001297653.1 & 1 & 1 & 1 & 1 & 0 & 80 \\
\hline 233 & NC_004741.1 & WP_000146138.1 & 1 & 1 & 1 & 1 & 0 & 80 \\
\hline 234 & NC_004741.1 & WP_001142445.1 & 0 & 0 & 0 & 0 & 0 & 0 \\
\hline 235 & NC_004741.1 & WP_005050031.1 & 1 & 1 & 1 & 1 & 0 & 80 \\
\hline 236 & NC_004741.1 & WP_042003723.1 & 0 & 0 & 0 & 0 & 0 & 0 \\
\hline 237 & NC_004741.1 & WP_000398613.1 & 0 & 0 & 0 & 0 & 0 & 0 \\
\hline 238 & NC_004741.1 & WP_005062520.1 & 0 & 0 & 0 & 0 & 0 & 0 \\
\hline 239 & NC_004741.1 & WP_000726666.1 & 1 & 1 & 1 & 1 & 0 & 80 \\
\hline 240 & NC_004741.1 & WP_000874243.1 & 1 & 1 & 1 & 1 & 0 & 80 \\
\hline 241 & NC_004741.1 & WP_045177689.1 & 0 & 0 & 0 & 0 & 0 & 0 \\
\hline 242 & NC_004741.1 & WP_001265249.1 & 1 & 1 & 1 & 1 & 0 & 80 \\
\hline 243 & NC_004741.1 & WP_000980987.1 & 0 & 0 & 0 & 0 & 0 & 0 \\
\hline 244 & NC_004741.1 & WP_000214712.1 & 1 & 1 & 1 & 1 & 0 & 80 \\
\hline 245 & NC_004741.1 & WP_001024558.1 & 1 & 1 & 1 & 1 & 0 & 80 \\
\hline 246 & NC_004741.1 & WP_000901367.1 & 0 & 0 & 0 & 0 & 0 & 0 \\
\hline 247 & NC_004741.1 & WP_000258546.1 & 0 & 0 & 0 & 0 & 0 & 0 \\
\hline 248 & NC_004741.1 & WP_000957853.1 & 0 & 0 & 0 & 0 & 0 & 0 \\
\hline
\end{tabular}




\begin{tabular}{|l|l|l|l|l|l|l|l|l|}
\hline 249 & NC_004741.1 & WP_005050130.1 & 1 & 1 & 1 & 1 & 0 & 80 \\
\hline 250 & NC_004741.1 & WP_001295395.1 & 1 & 1 & 1 & 1 & 0 & 80 \\
\hline 251 & NC_004741.1 & WP_000705197.1 & 1 & 1 & 1 & 1 & 0 & 80 \\
\hline 252 & NC_004741.1 & WP_000234660.1 & 0 & 0 & 0 & 0 & 0 & 0 \\
\hline 253 & NC_004741.1 & WP_000520318.1 & 0 & 0 & 1 & 1 & 0 & 40 \\
\hline 254 & NC_004741.1 & WP_000207512.1 & 0 & 0 & 0 & 0 & 0 & 0 \\
\hline 255 & NC_004741.1 & WP_000971490.1 & 1 & 0 & 1 & 0 & 0 & 40 \\
\hline 256 & NC_004741.1 & WP_001240758.1 & 0 & 0 & 0 & 0 & 0 & 0 \\
\hline 257 & NC_004741.1 & WP_000199921.1 & 0 & 0 & 0 & 0 & 0 & 0 \\
\hline 258 & NC_004741.1 & WP_001091024.1 & 0 & 0 & 0 & 0 & 0 & 0 \\
\hline 259 & NC_004741.1 & WP_000113584.1 & 0 & 0 & 0 & 0 & 0 & 0 \\
\hline 260 & NC_004741.1 & WP_000091718.1 & 0 & 0 & 0 & 0 & 0 & 0 \\
\hline 261 & NC_004741.1 & WP_001249851.1 & 0 & 0 & 0 & 0 & 0 & 0 \\
\hline 262 & NC_004741.1 & WP_000233090.1 & 1 & 0 & 0 & 0 & 0 & 20 \\
\hline 263 & NC_004741.1 & WP_000769323.1 & 1 & 1 & 1 & 1 & 0 & 80 \\
\hline 264 & NC_004741.1 & WP_000524868.1 & 1 & 1 & 1 & 1 & 0 & 80 \\
\hline 265 & NC_004741.1 & WP_000597196.1 & 1 & 1 & 1 & 1 & 1 & 100 \\
\hline 266 & NC_004741.1 & WP_032155892.1 & 1 & 0 & 0 & 0 & 0 & 20 \\
\hline 267 & NC_004741.1 & WP_000534313.1 & 1 & 1 & 1 & 1 & 0 & 80 \\
\hline 268 & NC_004741.1 & WP_000212657.1 & 1 & 1 & 1 & 1 & 0 & 80 \\
\hline 269 & NC_004741.1 & WP_000587595.1 & 1 & 0 & 0 & 0 & 0 & 20 \\
\hline 270 & NC_004741.1 & WP_001344535.1 & 1 & 0 & 0 & 0 & 0 & 20 \\
\hline 271 & NC_004741.1 & WP_000528342.1 & 1 & 1 & 1 & 1 & 0 & 80 \\
\hline 272 & NC_004741.1 & WP_001296104.1 & 1 & 1 & 1 & 1 & 0 & 80 \\
\hline 273 & NC_004741.1 & WP_000248636.1 & 1 & 1 & 1 & 1 & 1 & 100 \\
\hline 274 & NC_004741.1 & WP_001301287.1 & 1 & 1 & 1 & 1 & 0 & 80 \\
\hline 275 & NC_004741.1 & WP_032155900.1 & 0 & 0 & 0 & 0 & 0 & 0 \\
\hline 276 & NC_004741.1 & WP_000627104.1 & 1 & 0 & 0 & 0 & 1 & 40 \\
\hline & & & & & & & & \\
\hline
\end{tabular}




\begin{tabular}{|c|c|c|c|c|c|c|c|c|}
\hline 277 & NC_004741.1 & WP_000124121.1 & 0 & 0 & 1 & 0 & 0 & 20 \\
\hline 278 & NC_004741.1 & WP_000018633.1 & 1 & 1 & 1 & 1 & 0 & 80 \\
\hline 279 & NC_004741.1 & WP_012817775.1 & 0 & 0 & 0 & 0 & 0 & 0 \\
\hline 280 & NC_004741.1 & WP_032155659.1 & 0 & 0 & 0 & 0 & 0 & 0 \\
\hline 281 & NC_004741.1 & WP_001380520.1 & 1 & 1 & 1 & 1 & 0 & 80 \\
\hline 282 & NC_004741.1 & WP_000879272.1 & 1 & 0 & 0 & 0 & 0 & 20 \\
\hline 283 & NC_004741.1 & WP_000168747.1 & 1 & 1 & 1 & 1 & 0 & 80 \\
\hline 284 & NC_004741.1 & WP_000275187.1 & 0 & 0 & 0 & 0 & 0 & 0 \\
\hline 285 & NC_004741.1 & WP_005047608.1 & 1 & 1 & 1 & 1 & 0 & 80 \\
\hline 286 & NC_004741.1 & WP_000155622.1 & 0 & 0 & 0 & 0 & 0 & 0 \\
\hline 287 & NC_004741.1 & WP_001024930.1 & 1 & 1 & 1 & 1 & 0 & 80 \\
\hline 288 & NC_004741.1 & WP_005084198.1 & 0 & 0 & 0 & 0 & 0 & 0 \\
\hline 289 & NC_004741.1 & WP_001039885.1 & 1 & 0 & 1 & 0 & 0 & 40 \\
\hline 290 & NC_004741.1 & WP_000930145.1 & 1 & 1 & 1 & 1 & 0 & 80 \\
\hline 291 & NC_004741.1 & WP_000009987.1 & 0 & 0 & 0 & 0 & 0 & 0 \\
\hline 292 & NC_004741.1 & WP_000245528.1 & 1 & 1 & 1 & 1 & 0 & 80 \\
\hline 293 & NC_004741.1 & WP_005049830.1 & 1 & 0 & 0 & 0 & 0 & 20 \\
\hline 294 & NC_004741.1 & WP_001173294.1 & 1 & 1 & 1 & 0 & 0 & 60 \\
\hline 295 & NC_004741.1 & WP_000930141.1 & 1 & 1 & 1 & 1 & 0 & 80 \\
\hline 296 & NC_004741.1 & WP_001007942.1 & 0 & 0 & 0 & 0 & 0 & 0 \\
\hline 297 & NC_004741.1 & WP_000082749.1 & 1 & 1 & 1 & 1 & 0 & 80 \\
\hline 298 & NC_004741.1 & WP_005048633.1 & 0 & 0 & 0 & 0 & 0 & 0 \\
\hline 299 & NC_004741.1 & WP_001028876.1 & 0 & 0 & 0 & 0 & 0 & 0 \\
\hline 300 & NC_004741.1 & WP_000755956.1 & 1 & 1 & 1 & 1 & 1 & 100 \\
\hline 301 & NC_004741.1 & WP_001099210.1 & 1 & 1 & 1 & 1 & 0 & 80 \\
\hline 302 & NC_004741.1 & WP_000586688.1 & 1 & 0 & 0 & 0 & 0 & 20 \\
\hline 303 & NC_004741.1 & WP_000457719.1 & 1 & 1 & 1 & 1 & 0 & 80 \\
\hline 304 & NC_004741.1 & WP_001030133.1 & 0 & 0 & 0 & 0 & 0 & 0 \\
\hline
\end{tabular}




\begin{tabular}{|l|l|l|l|l|l|l|l|l|}
\hline 305 & NC_004741.1 & WP_005063152.1 & 1 & 1 & 1 & 1 & 0 & 80 \\
\hline 306 & NC_004741.1 & WP_000455174.1 & 1 & 1 & 1 & 1 & 0 & 80 \\
\hline 307 & NC_004741.1 & WP_001103659.1 & 1 & 0 & 0 & 0 & 0 & 20 \\
\hline 308 & NC_004741.1 & WP_042791229.1 & 0 & 0 & 0 & 0 & 0 & 0 \\
\hline 309 & NC_004741.1 & WP_000082120.1 & 1 & 1 & 1 & 1 & 0 & 80 \\
\hline 310 & NC_004741.1 & WP_001297814.1 & 0 & 0 & 0 & 0 & 0 & 0 \\
\hline 311 & NC_004741.1 & WP_001237866.1 & 1 & 1 & 1 & 1 & 1 & 100 \\
\hline 312 & NC_004741.1 & WP_000377229.1 & 1 & 1 & 1 & 1 & 0 & 80 \\
\hline 313 & NC_004741.1 & WP_032155628.1 & 0 & 0 & 0 & 0 & 0 & 0 \\
\hline 314 & NC_004741.1 & WP_000106474.1 & 1 & 1 & 1 & 1 & 0 & 80 \\
\hline 315 & NC_004741.1 & WP_000118898.1 & 1 & 1 & 1 & 1 & 0 & 80 \\
\hline 316 & NC_004741.1 & WP_000230645.1 & 0 & 0 & 0 & 0 & 0 & 0 \\
\hline 317 & NC_004741.1 & WP_024259260.1 & 0 & 0 & 0 & 0 & 0 & 0 \\
\hline 318 & NC_004741.1 & WP_005048789.1 & 1 & 1 & 1 & 1 & 0 & 80 \\
\hline 319 & NC_004741.1 & WP_000431460.1 & 1 & 0 & 0 & 0 & 0 & 20 \\
\hline 320 & NC_004741.1 & WP_032155863.1 & 1 & 0 & 0 & 0 & 0 & 20 \\
\hline 321 & NC_004741.1 & WP_032155819.1 & 0 & 0 & 0 & 0 & 0 & 0 \\
\hline 322 & NC_004741.1 & WP_001039899.1 & 0 & 0 & 0 & 0 & 0 & 0 \\
\hline 323 & NC_004741.1 & WP_064716611.1 & 1 & 1 & 1 & 1 & 0 & 80 \\
\hline 324 & NC_004741.1 & WP_000594909.1 & 0 & 0 & 0 & 0 & 1 & 20 \\
\hline 325 & NC_004741.1 & WP_001062338.1 & 1 & 1 & 1 & 1 & 0 & 80 \\
\hline 326 & NC_004741.1 & WP_001265248.1 & 1 & 1 & 1 & 1 & 0 & 80 \\
\hline 327 & NC_004741.1 & WP_000152435.1 & 0 & 0 & 0 & 0 & 0 & 0 \\
\hline 328 & NC_004741.1 & WP_032155691.1 & 1 & 0 & 0 & 0 & 0 & 20 \\
\hline 329 & NC_004741.1 & WP_001343759.1 & 0 & 0 & 0 & 0 & 0 & 0 \\
\hline 330 & NC_004741.1 & WP_000466572.1 & 1 & 0 & 0 & 0 & 0 & 20 \\
\hline 331 & NC_004741.1 & WP_061440266.1 & 1 & 0 & 0 & 0 & 0 & 20 \\
\hline 332 & NC_004741.1 & WP_001016348.1 & 1 & 1 & 1 & 1 & 0 & 80 \\
\hline & & & & & & & & \\
\hline
\end{tabular}




\begin{tabular}{|l|l|l|l|l|l|l|l|l|}
\hline 333 & NC_004741.1 & WP_000450409.1 & 1 & 1 & 1 & 1 & 0 & 80 \\
\hline 334 & NC_004741.1 & WP_005088730.1 & 0 & 0 & 1 & 0 & 0 & 20 \\
\hline 335 & NC_004741.1 & WP_000282151.1 & 1 & 1 & 1 & 1 & 0 & 80 \\
\hline 336 & NC_004741.1 & WP_001243860.1 & 1 & 1 & 1 & 1 & 0 & 80 \\
\hline 337 & NC_004741.1 & WP_011110604.1 & 0 & 0 & 0 & 0 & 0 & 0 \\
\hline 338 & NC_004741.1 & WP_011069433.1 & 0 & 0 & 0 & 0 & 0 & 0 \\
\hline 339 & NC_004741.1 & WP_000055830.1 & 0 & 0 & 0 & 0 & 0 & 0 \\
\hline 340 & NC_004741.1 & WP_011069434.1 & 1 & 0 & 1 & 0 & 0 & 40 \\
\hline 341 & NC_004741.1 & WP_000454701.1 & 1 & 1 & 1 & 1 & 1 & 100 \\
\hline 342 & NC_004741.1 & WP_000489605.1 & 1 & 0 & 0 & 0 & 0 & 20 \\
\hline 343 & NC_004741.1 & WP_000003197.1 & 1 & 1 & 1 & 1 & 1 & 100 \\
\hline 344 & NC_004741.1 & WP_000929408.1 & 1 & 1 & 1 & 1 & 0 & 80 \\
\hline 345 & NC_004741.1 & WP_014532286.1 & 0 & 0 & 0 & 0 & 0 & 0 \\
\hline 346 & NC_004741.1 & WP_001324860.1 & 0 & 0 & 0 & 0 & 1 & 20 \\
\hline 347 & NC_004741.1 & WP_000830460.1 & 1 & 0 & 1 & 0 & 0 & 40 \\
\hline 348 & NC_004741.1 & WP_011110605.1 & 1 & 1 & 1 & 1 & 0 & 80 \\
\hline 349 & NC_004741.1 & WP_000261596.1 & 0 & 0 & 0 & 0 & 0 & 0 \\
\hline 350 & NC_004741.1 & WP_005049040.1 & 0 & 0 & 0 & 0 & 0 & 0 \\
\hline 351 & NC_004741.1 & WP_005098884.1 & 1 & 1 & 1 & 1 & 0 & 80 \\
\hline 352 & NC_004741.1 & WP_005049034.1 & 1 & 1 & 1 & 1 & 0 & 80 \\
\hline 353 & NC_004741.1 & WP_024259269.1 & 1 & 1 & 1 & 1 & 0 & 80 \\
\hline 354 & NC_004741.1 & WP_000636931.1 & 0 & 0 & 0 & 0 & 0 & 0 \\
\hline 355 & NC_004741.1 & WP_000380421.1 & 0 & 0 & 0 & 0 & 0 & 0 \\
\hline 356 & NC_004741.1 & WP_001294399.1 & 0 & 0 & 0 & 0 & 0 & 0 \\
\hline 357 & NC_004741.1 & WP_005049026.1 & 1 & 1 & 1 & 1 & 0 & 80 \\
\hline 358 & NC_004741.1 & WP_001087240.1 & 1 & 0 & 1 & 0 & 1 & 60 \\
\hline 359 & NC_004741.1 & WP_005049020.1 & 1 & 1 & 1 & 1 & 1 & 100 \\
\hline 360 & NC_004741.1 & WP_048814497.1 & 1 & 1 & 1 & 1 & 1 & 100 \\
\hline & & & & & & & & \\
\hline
\end{tabular}




\begin{tabular}{|l|l|l|l|l|l|l|l|l|}
\hline 361 & NC_004741.1 & WP_011069443.1 & 0 & 0 & 0 & 0 & 0 & 0 \\
\hline 362 & NC_004741.1 & WP_000691708.1 & 0 & 0 & 0 & 0 & 0 & 0 \\
\hline 363 & NC_004741.1 & WP_001295452.1 & 1 & 1 & 1 & 1 & 0 & 80 \\
\hline 364 & NC_004741.1 & WP_032155550.1 & 0 & 0 & 0 & 0 & 0 & 0 \\
\hline 365 & NC_004741.1 & WP_001308773.1 & 0 & 0 & 0 & 0 & 0 & 0 \\
\hline 366 & NC_004741.1 & WP_000182053.1 & 1 & 1 & 1 & 1 & 0 & 80 \\
\hline 367 & NC_004741.1 & WP_000202798.1 & 1 & 1 & 1 & 1 & 0 & 80 \\
\hline 368 & NC_004741.1 & WP_001135673.1 & 1 & 1 & 1 & 1 & 0 & 80 \\
\hline 369 & NC_004741.1 & WP_001303596.1 & 0 & 0 & 0 & 0 & 0 & 0 \\
\hline 370 & NC_004741.1 & WP_001296837.1 & 0 & 0 & 0 & 0 & 0 & 0 \\
\hline 371 & NC_004741.1 & WP_001225855.1 & 1 & 1 & 1 & 1 & 0 & 80 \\
\hline 372 & NC_004741.1 & WP_001104543.1 & 1 & 1 & 1 & 1 & 0 & 80 \\
\hline 373 & NC_004741.1 & WP_005046832.1 & 1 & 0 & 0 & 0 & 0 & 20 \\
\hline 374 & NC_004741.1 & WP_001215763.1 & 1 & 1 & 1 & 1 & 0 & 80 \\
\hline 375 & NC_004741.1 & WP_032083391.1 & 0 & 0 & 0 & 0 & 0 & 0 \\
\hline 376 & NC_004741.1 & WP_000301054.1 & 1 & 1 & 1 & 1 & 1 & 100 \\
\hline 377 & NC_004741.1 & WP_001009396.1 & 1 & 0 & 0 & 0 & 0 & 20 \\
\hline 378 & NC_004741.1 & WP_000140529.1 & 1 & 1 & 1 & 1 & 0 & 80 \\
\hline 379 & NC_004741.1 & WP_000070619.1 & 1 & 1 & 1 & 1 & 0 & 80 \\
\hline 380 & NC_004741.1 & WP_001446945.1 & 1 & 1 & 1 & 1 & 0 & 80 \\
\hline 381 & NC_004741.1 & WP_000525371.1 & 1 & 1 & 1 & 1 & 0 & 80 \\
\hline 382 & NC_004741.1 & WP_000426116.1 & 1 & 1 & 1 & 1 & 0 & 80 \\
\hline 383 & NC_004741.1 & WP_000106622.1 & 1 & 1 & 1 & 1 & 0 & 80 \\
\hline 384 & NC_004741.1 & WP_001115612.1 & 0 & 0 & 0 & 0 & 0 & 0 \\
\hline 385 & NC_004741.1 & WP_001274496.1 & 1 & 1 & 1 & 1 & 0 & 80 \\
\hline 386 & NC_004741.1 & WP_000559763.1 & 1 & 1 & 1 & 1 & 0 & 80 \\
\hline 387 & NC_004741.1 & WP_005070009.1 & 1 & 1 & 1 & 1 & 0 & 80 \\
\hline 388 & NC_004741.1 & WP_000937783.1 & 0 & 0 & 0 & 0 & 0 & 0 \\
\hline & & & & & & & & \\
\hline
\end{tabular}




\begin{tabular}{|l|l|l|l|l|l|l|l|l|}
\hline 389 & NC_004741.1 & WP_000937210.1 & 1 & 1 & 1 & 1 & 0 & 80 \\
\hline 390 & NC_004741.1 & WP_000825597.1 & 1 & 1 & 1 & 1 & 0 & 80 \\
\hline 391 & NC_004741.1 & WP_000867638.1 & 0 & 0 & 0 & 0 & 1 & 20 \\
\hline 392 & NC_004741.1 & WP_009008053.1 & 0 & 0 & 0 & 0 & 0 & 0 \\
\hline 393 & NC_004741.1 & WP_000639883.1 & 1 & 1 & 1 & 1 & 0 & 80 \\
\hline 394 & NC_004741.1 & WP_000490072.1 & 1 & 1 & 1 & 1 & 0 & 80 \\
\hline 395 & NC_004741.1 & WP_042188255.1 & 0 & 0 & 0 & 0 & 0 & 0 \\
\hline 396 & NC_004741.1 & WP_000826512.1 & 1 & 1 & 1 & 1 & 0 & 80 \\
\hline 397 & NC_004741.1 & WP_000201413.1 & 1 & 1 & 1 & 1 & 0 & 80 \\
\hline 398 & NC_004741.1 & WP_000719924.1 & 1 & 0 & 1 & 0 & 0 & 40 \\
\hline 399 & NC_004741.1 & WP_001107736.1 & 0 & 0 & 0 & 0 & 0 & 0 \\
\hline 400 & NC_004741.1 & WP_000555795.1 & 0 & 0 & 0 & 0 & 0 & 0 \\
\hline 401 & NC_004741.1 & WP_000338539.1 & 0 & 0 & 0 & 0 & 0 & 0 \\
\hline 402 & NC_004741.1 & WP_001373377.1 & 0 & 0 & 0 & 0 & 0 & 0 \\
\hline 403 & NC_004741.1 & WP_000806589.1 & 0 & 0 & 0 & 0 & 0 & 0 \\
\hline 404 & NC_004741.1 & WP_001507728.1 & 1 & 1 & 1 & 1 & 0 & 80 \\
\hline 405 & NC_004741.1 & WP_001308835.1 & 0 & 0 & 0 & 0 & 0 & 0 \\
\hline 406 & NC_004741.1 & WP_001349976.1 & 1 & 0 & 0 & 0 & 0 & 20 \\
\hline 407 & NC_004741.1 & WP_000339447.1 & 1 & 1 & 1 & 1 & 0 & 80 \\
\hline 408 & NC_004741.1 & WP_001244758.1 & 1 & 0 & 0 & 0 & 0 & 20 \\
\hline 409 & NC_004741.1 & WP_000017552.1 & 0 & 0 & 0 & 0 & 0 & 0 \\
\hline 410 & NC_004741.1 & WP_000076001.1 & 1 & 1 & 1 & 1 & 0 & 80 \\
\hline 411 & NC_004741.1 & WP_000755178.1 & 0 & 0 & 1 & 0 & 0 & 20 \\
\hline 412 & NC_004741.1 & WP_000743213.1 & 0 & 0 & 0 & 0 & 0 & 0 \\
\hline 413 & NC_004741.1 & WP_000131871.1 & 0 & 0 & 0 & 0 & 0 & 0 \\
\hline 414 & NC_004741.1 & WP_000211355.1 & 1 & 1 & 1 & 1 & 0 & 80 \\
\hline 415 & NC_004741.1 & WP_000213809.1 & 0 & 0 & 0 & 0 & 0 & 0 \\
\hline 416 & NC_004741.1 & WP_001162384.1 & 1 & 1 & 1 & 1 & 0 & 80 \\
\hline & & & & & & & & \\
\hline
\end{tabular}




\begin{tabular}{|l|l|l|l|l|l|l|l|l|}
\hline 417 & NC_004741.1 & WP_005047279.1 & 1 & 1 & 1 & 1 & 0 & 80 \\
\hline 418 & NC_004741.1 & WP_001094726.1 & 1 & 1 & 1 & 1 & 0 & 80 \\
\hline 419 & NC_004741.1 & WP_000266171.1 & 1 & 1 & 1 & 1 & 1 & 100 \\
\hline 420 & NC_004741.1 & WP_000951754.1 & 1 & 0 & 0 & 0 & 0 & 20 \\
\hline 421 & NC_004741.1 & WP_000647601.1 & 1 & 0 & 0 & 0 & 0 & 20 \\
\hline 422 & NC_004741.1 & WP_012135949.1 & 0 & 0 & 0 & 0 & 0 & 0 \\
\hline 423 & NC_004741.1 & WP_001303621.1 & 0 & 0 & 0 & 0 & 0 & 0 \\
\hline 424 & NC_004741.1 & WP_032155618.1 & 0 & 0 & 0 & 0 & 0 & 0 \\
\hline 425 & NC_004741.1 & WP_001330697.1 & 0 & 0 & 0 & 0 & 0 & 0 \\
\hline 426 & NC_004741.1 & WP_001212392.1 & 1 & 1 & 1 & 1 & 0 & 80 \\
\hline 427 & NC_004741.1 & WP_000589825.1 & 1 & 1 & 1 & 1 & 1 & 100 \\
\hline 428 & NC_004741.1 & WP_000284119.1 & 0 & 0 & 0 & 0 & 0 & 0 \\
\hline 429 & NC_004741.1 & WP_000491410.1 & 1 & 1 & 1 & 1 & 0 & 80 \\
\hline 430 & NC_004741.1 & WP_000281320.1 & 1 & 1 & 1 & 1 & 0 & 80 \\
\hline 431 & NC_004741.1 & WP_000483311.1 & 1 & 0 & 0 & 0 & 0 & 20 \\
\hline 432 & NC_004741.1 & WP_001287454.1 & 1 & 1 & 1 & 1 & 0 & 80 \\
\hline 433 & NC_004741.1 & WP_001307965.1 & 0 & 0 & 0 & 0 & 0 & 0 \\
\hline 434 & NC_004741.1 & WP_000493764.1 & 1 & 0 & 0 & 0 & 0 & 20 \\
\hline 435 & NC_004741.1 & WP_032155822.1 & 0 & 0 & 0 & 0 & 0 & 0 \\
\hline 436 & NC_004741.1 & WP_000611930.1 & 0 & 0 & 0 & 0 & 0 & 0 \\
\hline 437 & NC_004741.1 & WP_001224024.1 & 1 & 0 & 0 & 0 & 0 & 20 \\
\hline 438 & NC_004741.1 & WP_001288227.1 & 0 & 0 & 0 & 0 & 0 & 0 \\
\hline 439 & NC_004741.1 & WP_000444999.1 & 1 & 1 & 1 & 1 & 0 & 80 \\
\hline 440 & NC_004741.1 & WP_000206987.1 & 1 & 1 & 1 & 1 & 0 & 80 \\
\hline 441 & NC_004741.1 & WP_001393510.1 & 0 & 0 & 0 & 0 & 0 & 0 \\
\hline 442 & NC_004741.1 & WP_000203905.1 & 1 & 1 & 1 & 1 & 0 & 80 \\
\hline 443 & NC_004741.1 & WP_000184250.1 & 1 & 1 & 1 & 1 & 0 & 80 \\
\hline 444 & NC_004741.1 & WP_001078387.1 & 1 & 1 & 1 & 1 & 0 & 80 \\
\hline & & & & & & & & \\
\hline
\end{tabular}




\begin{tabular}{|c|c|c|c|c|c|c|c|c|}
\hline 445 & NC_004741.1 & WP_032155588.1 & 0 & 0 & 0 & 0 & 0 & 0 \\
\hline 446 & NC_004741.1 & WP_000860229.1 & 0 & 0 & 0 & 0 & 0 & 0 \\
\hline 447 & NC_004741.1 & WP_000242461.1 & 1 & 0 & 0 & 0 & 0 & 20 \\
\hline 448 & NC_004741.1 & WP_000379402.1 & 0 & 0 & 0 & 0 & 0 & 0 \\
\hline 449 & NC_004741.1 & WP_005099217.1 & 0 & 0 & 0 & 0 & 0 & 0 \\
\hline 450 & NC_004741.1 & WP_005099219.1 & 0 & 0 & 0 & 0 & 0 & 0 \\
\hline 451 & NC_004741.1 & WP_000971492.1 & 1 & 0 & 0 & 0 & 0 & 20 \\
\hline 452 & NC_004741.1 & WP_005051685.1 & 1 & 1 & 1 & 1 & 1 & 100 \\
\hline 453 & NC_004741.1 & WP_000528349.1 & 0 & 0 & 0 & 0 & 0 & 0 \\
\hline 454 & NC_004741.1 & WP_001010156.1 & 0 & 0 & 0 & 0 & 0 & 0 \\
\hline 455 & NC_004741.1 & WP_005051767.1 & 1 & 1 & 1 & 1 & 0 & 80 \\
\hline 456 & NC_004741.1 & WP_011110620.1 & 0 & 1 & 1 & 0 & 0 & 40 \\
\hline 457 & NC_004741.1 & WP_001094817.1 & 1 & 1 & 1 & 1 & 0 & 80 \\
\hline 458 & NC_004741.1 & WP_000745204.1 & 1 & 1 & 1 & 1 & 0 & 80 \\
\hline 459 & NC_004741.1 & WP_000984792.1 & 1 & 1 & 1 & 1 & 0 & 80 \\
\hline 460 & NC_004741.1 & WP_005064025.1 & 0 & 1 & 0 & 1 & 0 & 40 \\
\hline 461 & NC_004741.1 & WP_000338035.1 & 0 & 0 & 0 & 0 & 0 & 0 \\
\hline 462 & NC_004741.1 & WP_000291751.1 & 0 & 0 & 0 & 0 & 0 & 0 \\
\hline 463 & NC_004741.1 & WP_001323220.1 & 0 & 0 & 0 & 0 & 0 & 0 \\
\hline 464 & NC_004741.1 & WP_032142224.1 & 0 & 0 & 0 & 0 & 0 & 0 \\
\hline 465 & NC_004741.1 & WP_001128940.1 & 1 & 1 & 1 & 1 & 0 & 80 \\
\hline 466 & NC_004741.1 & WP_001013320.1 & 1 & 1 & 1 & 1 & 0 & 80 \\
\hline 467 & NC_004741.1 & WP_000271035.1 & 1 & 1 & 1 & 1 & 0 & 80 \\
\hline 468 & NC_004741.1 & WP_001195464.1 & 1 & 1 & 1 & 1 & 0 & 80 \\
\hline 469 & NC_004741.1 & WP_011069510.1 & 0 & 0 & 0 & 0 & 0 & 0 \\
\hline 470 & NC_004741.1 & WP_005093820.1 & 0 & 0 & 0 & 0 & 1 & 20 \\
\hline 471 & NC_004741.1 & WP_000261147.1 & 0 & 0 & 0 & 0 & 0 & 0 \\
\hline 472 & NC_004741.1 & WP_005051842.1 & 0 & 0 & 0 & 0 & 0 & 0 \\
\hline
\end{tabular}




\begin{tabular}{|c|c|c|c|c|c|c|c|c|}
\hline 473 & NC_004741.1 & WP_001069724.1 & 1 & 1 & 1 & 1 & 0 & 80 \\
\hline 474 & NC_004741.1 & WP_005093816.1 & 0 & 0 & 0 & 0 & 0 & 0 \\
\hline 475 & NC_004741.1 & WP_005051844.1 & 0 & 0 & 0 & 0 & 0 & 0 \\
\hline 476 & NC_004741.1 & WP_001387238.1 & 1 & 1 & 1 & 1 & 1 & 100 \\
\hline 477 & NC_004741.1 & WP_000692350.1 & 1 & 1 & 1 & 1 & 0 & 80 \\
\hline 478 & NC_004741.1 & WP_000761715.1 & 0 & 0 & 0 & 0 & 0 & 0 \\
\hline 479 & NC_004741.1 & WP_000772029.1 & 1 & 1 & 1 & 1 & 0 & 80 \\
\hline 480 & NC_004741.1 & WP_000340141.1 & 0 & 0 & 0 & 0 & 0 & 0 \\
\hline 481 & NC_004741.1 & WP_000853257.1 & 1 & 1 & 1 & 1 & 0 & 80 \\
\hline 482 & NC_004741.1 & WP_000248097.1 & 1 & 1 & 1 & 1 & 1 & 100 \\
\hline 483 & NC_004741.1 & WP_000984979.1 & 0 & 0 & 0 & 0 & 0 & 0 \\
\hline 484 & NC_004741.1 & WP_000339534.1 & 1 & 0 & 0 & 0 & 0 & 20 \\
\hline 485 & NC_004741.1 & WP_005051896.1 & 0 & 0 & 0 & 0 & 0 & 0 \\
\hline 486 & NC_004741.1 & WP_001059136.1 & 1 & 1 & 1 & 1 & 0 & 80 \\
\hline 487 & NC_004741.1 & WP_024167679.1 & 0 & 0 & 0 & 0 & 0 & 0 \\
\hline 488 & NC_004741.1 & WP_001298764.1 & 0 & 0 & 0 & 0 & 0 & 0 \\
\hline 489 & NC_004741.1 & WP_000691640.1 & 1 & 1 & 1 & 1 & 0 & 80 \\
\hline 490 & NC_004741.1 & WP_000848528.1 & 1 & 1 & 1 & 1 & 1 & 100 \\
\hline 491 & NC_004741.1 & WP_000527661.1 & 0 & 0 & 0 & 0 & 0 & 0 \\
\hline 492 & NC_004741.1 & WP_001701108.1 & 0 & 0 & 0 & 0 & 0 & 0 \\
\hline 493 & NC_004741.1 & WP_000442868.1 & 1 & 1 & 1 & 1 & 0 & 80 \\
\hline 494 & NC_004741.1 & WP_001406537.1 & 0 & 0 & 0 & 0 & 0 & 0 \\
\hline 495 & NC_004741.1 & WP_024259304.1 & 0 & 0 & 0 & 0 & 0 & 0 \\
\hline 496 & NC_004741.1 & WP_001298386.1 & 0 & 0 & 0 & 0 & 0 & 0 \\
\hline 497 & NC_004741.1 & WP_032140301.1 & 0 & 0 & 0 & 0 & 0 & 0 \\
\hline 498 & NC_004741.1 & WP_000942538.1 & 1 & 1 & 1 & 1 & 0 & 80 \\
\hline 499 & NC_004741.1 & WP_000016819.1 & 1 & 1 & 1 & 1 & 0 & 80 \\
\hline 500 & NC_004741.1 & WP_000422149.1 & 1 & 1 & 1 & 1 & 0 & 80 \\
\hline
\end{tabular}




\begin{tabular}{|c|c|c|c|c|c|c|c|c|}
\hline 501 & NC_004741.1 & WP_005050960.1 & 1 & 1 & 1 & 1 & 0 & 80 \\
\hline 502 & NC_004741.1 & WP_000031415.1 & 1 & 1 & 1 & 1 & 0 & 80 \\
\hline 503 & NC_004741.1 & WP_000785722.1 & 1 & 1 & 1 & 1 & 0 & 80 \\
\hline 504 & NC_004741.1 & WP_000096080.1 & 1 & 1 & 1 & 1 & 0 & 80 \\
\hline 505 & NC_004741.1 & WP_000732225.1 & 1 & 1 & 1 & 1 & 0 & 80 \\
\hline 506 & NC_004741.1 & WP_005089560.1 & 0 & 0 & 0 & 0 & 0 & 0 \\
\hline 507 & NC_004741.1 & WP_005050890.1 & 0 & 0 & 0 & 0 & 0 & 0 \\
\hline 508 & NC_004741.1 & WP_001343556.1 & 1 & 1 & 1 & 1 & 0 & 80 \\
\hline 509 & NC_004741.1 & WP_000449030.1 & 1 & 0 & 0 & 0 & 0 & 20 \\
\hline 510 & NC_004741.1 & WP_000189314.1 & 1 & 1 & 1 & 1 & 1 & 100 \\
\hline 511 & NC_004741.1 & WP_001346700.1 & 0 & 0 & 0 & 0 & 0 & 0 \\
\hline 512 & NC_004741.1 & WP_000620405.1 & 1 & 1 & 1 & 1 & 0 & 80 \\
\hline 513 & NC_004741.1 & WP_005077180.1 & 0 & 0 & 0 & 0 & 0 & 0 \\
\hline 514 & NC_004741.1 & WP_005050708.1 & 1 & 1 & 1 & 1 & 0 & 80 \\
\hline 515 & NC_004741.1 & WP_001028769.1 & 1 & 1 & 1 & 1 & 0 & 80 \\
\hline 516 & NC_004741.1 & WP_001303690.1 & 0 & 0 & 0 & 0 & 0 & 0 \\
\hline 517 & NC_004741.1 & WP_011110633.1 & 0 & 0 & 0 & 0 & 0 & 0 \\
\hline 518 & NC_004741.1 & WP_001061203.1 & 0 & 0 & 0 & 0 & 0 & 0 \\
\hline 519 & NC_004741.1 & WP_001326891.1 & 1 & 0 & 0 & 0 & 0 & 20 \\
\hline 520 & NC_004741.1 & WP_024259309.1 & 1 & 1 & 1 & 1 & 0 & 80 \\
\hline 521 & NC_004741.1 & WP_005050690.1 & 0 & 0 & 0 & 0 & 0 & 0 \\
\hline 522 & NC_004741.1 & WP_000460680.1 & 1 & 1 & 1 & 1 & 0 & 80 \\
\hline 523 & NC_004741.1 & WP_000757326.1 & 0 & 1 & 1 & 1 & 0 & 60 \\
\hline 524 & NC_004741.1 & WP_000595564.1 & 1 & 1 & 1 & 1 & 0 & 80 \\
\hline 525 & NC_004741.1 & WP_000487766.1 & 0 & 0 & 0 & 0 & 0 & 0 \\
\hline 526 & NC_004741.1 & WP_024166609.1 & 0 & 0 & 0 & 0 & 0 & 0 \\
\hline 527 & NC_004741.1 & WP_005050602.1 & 0 & 0 & 0 & 0 & 0 & 0 \\
\hline 528 & NC_004741.1 & WP_011069598.1 & 1 & 1 & 1 & 1 & 0 & 80 \\
\hline
\end{tabular}




\begin{tabular}{|c|c|c|c|c|c|c|c|c|}
\hline 529 & NC_004741.1 & WP_000155673.1 & 1 & 1 & 1 & 1 & 0 & 80 \\
\hline 530 & NC_004741.1 & WP_001014565.1 & 1 & 1 & 1 & 1 & 0 & 80 \\
\hline 531 & NC_004741.1 & WP_001324833.1 & 0 & 0 & 0 & 0 & 0 & 0 \\
\hline 532 & NC_004741.1 & WP_000719886.1 & 1 & 1 & 1 & 1 & 0 & 80 \\
\hline 533 & NC_004741.1 & WP_001112357.1 & 1 & 0 & 0 & 0 & 0 & 20 \\
\hline 534 & NC_004741.1 & WP_000169147.1 & 1 & 1 & 1 & 1 & 0 & 80 \\
\hline 535 & NC_004741.1 & WP_032155643.1 & 0 & 0 & 0 & 0 & 0 & 0 \\
\hline 536 & NC_004741.1 & WP_000627171.1 & 1 & 1 & 1 & 1 & 0 & 80 \\
\hline 537 & NC_004741.1 & WP_023517643.1 & 0 & 1 & 0 & 1 & 0 & 40 \\
\hline 538 & NC_004741.1 & WP_046201574.1 & 1 & 0 & 0 & 0 & 0 & 20 \\
\hline 539 & NC_004741.1 & WP_000940102.1 & 1 & 1 & 1 & 1 & 0 & 80 \\
\hline 540 & NC_004741.1 & WP_011110634.1 & 0 & 0 & 0 & 0 & 0 & 0 \\
\hline 541 & NC_004741.1 & WP_001442985.1 & 0 & 1 & 0 & 1 & 0 & 40 \\
\hline 542 & NC_004741.1 & WP_000660586.1 & 0 & 0 & 0 & 0 & 0 & 0 \\
\hline 543 & NC_004741.1 & WP_000797352.1 & 1 & 1 & 1 & 1 & 0 & 80 \\
\hline 544 & NC_004741.1 & WP_000655986.1 & 1 & 1 & 1 & 1 & 0 & 80 \\
\hline 545 & NC_004741.1 & WP_000802226.1 & 1 & 1 & 1 & 1 & 0 & 80 \\
\hline 546 & NC_004741.1 & WP_000591073.1 & 0 & 0 & 0 & 0 & 0 & 0 \\
\hline 547 & NC_004741.1 & WP_000510376.1 & 0 & 0 & 0 & 0 & 0 & 0 \\
\hline 548 & NC_004741.1 & WP_014334093.1 & 0 & 1 & 0 & 1 & 0 & 40 \\
\hline 549 & NC_004741.1 & WP_001086388.1 & 0 & 0 & 0 & 0 & 0 & 0 \\
\hline 550 & NC_004741.1 & WP_001295676.1 & 1 & 1 & 1 & 1 & 0 & 80 \\
\hline 551 & NC_004741.1 & WP_032155602.1 & 0 & 0 & 0 & 0 & 0 & 0 \\
\hline 552 & NC_004741.1 & WP_024259324.1 & 0 & 0 & 1 & 0 & 0 & 20 \\
\hline 553 & NC_004741.1 & WP_000256409.1 & 1 & 1 & 1 & 1 & 0 & 80 \\
\hline 554 & NC_004741.1 & WP_032142137.1 & 0 & 0 & 0 & 0 & 0 & 0 \\
\hline 555 & NC_004741.1 & WP_000893994.1 & 0 & 0 & 0 & 0 & 0 & 0 \\
\hline 556 & NC_004741.1 & WP_000115988.1 & 0 & 0 & 0 & 0 & 0 & 0 \\
\hline
\end{tabular}




\begin{tabular}{|c|c|c|c|c|c|c|c|c|}
\hline 557 & NC_004741.1 & WP_001295264.1 & 1 & 1 & 1 & 1 & 0 & 80 \\
\hline 558 & NC_004741.1 & WP_005052859.1 & 1 & 1 & 1 & 1 & 0 & 80 \\
\hline 559 & NC_004741.1 & WP_001277142.1 & 1 & 1 & 1 & 1 & 0 & 80 \\
\hline 560 & NC_004741.1 & WP_024259323.1 & 1 & 0 & 0 & 0 & 0 & 20 \\
\hline 561 & NC_004741.1 & WP_000032578.1 & 1 & 1 & 1 & 1 & 0 & 80 \\
\hline 562 & NC_004741.1 & WP_001127088.1 & 0 & 0 & 0 & 0 & 0 & 0 \\
\hline 563 & NC_004741.1 & WP_000841001.1 & 1 & 1 & 1 & 1 & 0 & 80 \\
\hline 564 & NC_004741.1 & WP_000336276.1 & 0 & 0 & 0 & 0 & 0 & 0 \\
\hline 565 & NC_004741.1 & WP_000456043.1 & 0 & 0 & 0 & 0 & 0 & 0 \\
\hline 566 & NC_004741.1 & WP_005051995.1 & 1 & 1 & 1 & 1 & 0 & 80 \\
\hline 567 & NC_004741.1 & WP_000454294.1 & 0 & 0 & 0 & 0 & 0 & 0 \\
\hline 568 & NC_004741.1 & WP_032155619.1 & 0 & 0 & 0 & 0 & 0 & 0 \\
\hline 569 & NC_004741.1 & WP_001113432.1 & 1 & 1 & 1 & 1 & 0 & 80 \\
\hline 570 & NC_004741.1 & WP_000703959.1 & 1 & 1 & 1 & 1 & 0 & 80 \\
\hline 571 & NC_004741.1 & WP_000511292.1 & 0 & 0 & 0 & 0 & 0 & 0 \\
\hline 572 & NC_004741.1 & WP_005052029.1 & 1 & 1 & 1 & 1 & 0 & 80 \\
\hline 573 & NC_004741.1 & WP_000772934.1 & 1 & 0 & 0 & 0 & 1 & 40 \\
\hline 574 & NC_004741.1 & WP_005052034.1 & 1 & 1 & 1 & 1 & 0 & 80 \\
\hline 575 & NC_004741.1 & WP_032155621.1 & 0 & 1 & 0 & 1 & 0 & 40 \\
\hline 576 & NC_004741.1 & WP_000190670.1 & 1 & 0 & 0 & 0 & 0 & 20 \\
\hline 577 & NC_004741.1 & WP_045178171.1 & 1 & 1 & 1 & 1 & 0 & 80 \\
\hline 578 & NC_004741.1 & WP_005052068.1 & 1 & 1 & 1 & 1 & 0 & 80 \\
\hline 579 & NC_004741.1 & WP_000542440.1 & 1 & 1 & 1 & 1 & 0 & 80 \\
\hline 580 & NC_004741.1 & WP_032155816.1 & 0 & 0 & 0 & 0 & 0 & 0 \\
\hline 581 & NC_004741.1 & WP_011069564.1 & 0 & 0 & 0 & 0 & 0 & 0 \\
\hline 582 & NC_004741.1 & WP_001304210.1 & 0 & 0 & 0 & 0 & 0 & 0 \\
\hline 583 & NC_004741.1 & WP_001004881.1 & 0 & 0 & 0 & 0 & 0 & 0 \\
\hline 584 & NC_004741.1 & WP_045178164.1 & 0 & 0 & 0 & 0 & 0 & 0 \\
\hline
\end{tabular}




\begin{tabular}{|c|c|c|c|c|c|c|c|c|}
\hline 585 & NC_004741.1 & WP_001390447.1 & 0 & 0 & 0 & 0 & 0 & 0 \\
\hline 586 & NC_004741.1 & WP_005052132.1 & 0 & 0 & 0 & 0 & 0 & 0 \\
\hline 587 & NC_004741.1 & WP_011069562.1 & 1 & 0 & 0 & 0 & 0 & 20 \\
\hline 588 & NC_004741.1 & WP_000344113.1 & 0 & 0 & 0 & 0 & 0 & 0 \\
\hline 589 & NC_004741.1 & WP_000999840.1 & 1 & 0 & 0 & 0 & 0 & 20 \\
\hline 590 & NC_004741.1 & WP_000924289.1 & 1 & 1 & 1 & 1 & 0 & 80 \\
\hline 591 & NC_004741.1 & WP_000621323.1 & 1 & 1 & 1 & 1 & 0 & 80 \\
\hline 592 & NC_004741.1 & WP_001297375.1 & 1 & 1 & 1 & 1 & 1 & 100 \\
\hline 593 & NC_004741.1 & WP_000483856.1 & 1 & 1 & 1 & 1 & 0 & 80 \\
\hline 594 & NC_004741.1 & WP_000665677.1 & 1 & 1 & 1 & 1 & 0 & 80 \\
\hline 595 & NC_004741.1 & WP_000517100.1 & 0 & 0 & 0 & 0 & 0 & 0 \\
\hline 596 & NC_004741.1 & WP_000479627.1 & 1 & 1 & 1 & 1 & 0 & 80 \\
\hline 597 & NC_004741.1 & WP_000332751.1 & 0 & 0 & 0 & 0 & 0 & 0 \\
\hline 598 & NC_004741.1 & WP_001331222.1 & 0 & 1 & 0 & 1 & 0 & 40 \\
\hline 599 & NC_004741.1 & WP_011069558.1 & 1 & 1 & 1 & 1 & 0 & 80 \\
\hline 600 & NC_004741.1 & WP_000858193.1 & 1 & 1 & 1 & 1 & 1 & 100 \\
\hline 601 & NC_004741.1 & WP_001296808.1 & 1 & 1 & 1 & 1 & 0 & 80 \\
\hline 602 & NC_004741.1 & WP_000576411.1 & 1 & 1 & 1 & 1 & 0 & 80 \\
\hline 603 & NC_004741.1 & WP_001296791.1 & 1 & 1 & 1 & 1 & 1 & 100 \\
\hline 604 & NC_004741.1 & WP_000198578.1 & 0 & 0 & 0 & 0 & 0 & 0 \\
\hline 605 & NC_004741.1 & WP_032155594.1 & 0 & 0 & 0 & 0 & 0 & 0 \\
\hline 606 & NC_004741.1 & WP_001063318.1 & 1 & 1 & 1 & 1 & 0 & 80 \\
\hline 607 & NC_004741.1 & WP_001328969.1 & 0 & 0 & 0 & 0 & 0 & 0 \\
\hline 608 & NC_004741.1 & WP_001205330.1 & 0 & 0 & 0 & 0 & 1 & 20 \\
\hline 609 & NC_004741.1 & WP_000020617.1 & 0 & 0 & 0 & 0 & 0 & 0 \\
\hline 610 & NC_004741.1 & WP_005064932.1 & 0 & 0 & 0 & 0 & 0 & 0 \\
\hline 611 & NC_004741.1 & WP_000555608.1 & 0 & 0 & 0 & 0 & 0 & 0 \\
\hline 612 & NC_004741.1 & WP_000751953.1 & 0 & 0 & 0 & 0 & 0 & 0 \\
\hline
\end{tabular}




\begin{tabular}{|c|c|c|c|c|c|c|c|c|}
\hline 613 & NC_004741.1 & WP_011069548.1 & 0 & 0 & 0 & 0 & 0 & 0 \\
\hline 614 & NC_004741.1 & WP_032155607.1 & 0 & 0 & 0 & 0 & 0 & 0 \\
\hline 615 & NC_004741.1 & WP_000643692.1 & 1 & 1 & 1 & 1 & 0 & 80 \\
\hline 616 & NC_004741.1 & WP_005052620.1 & 1 & 1 & 1 & 1 & 0 & 80 \\
\hline 617 & NC_004741.1 & WP_000042900.1 & 1 & 1 & 1 & 1 & 0 & 80 \\
\hline 618 & NC_004741.1 & WP_000778795.1 & 1 & 1 & 1 & 1 & 1 & 100 \\
\hline 619 & NC_004741.1 & WP_005093467.1 & 0 & 1 & 0 & 1 & 0 & 40 \\
\hline 620 & NC_004741.1 & WP_001181212.1 & 0 & 0 & 0 & 0 & 0 & 0 \\
\hline 621 & NC_004741.1 & WP_000907005.1 & 1 & 0 & 0 & 1 & 0 & 40 \\
\hline 622 & NC_004741.1 & WP_005097678.1 & 1 & 0 & 0 & 0 & 0 & 20 \\
\hline 623 & NC_004741.1 & WP_011069541.1 & 1 & 0 & 0 & 1 & 0 & 40 \\
\hline 624 & NC_004741.1 & WP_001303701.1 & 1 & 0 & 0 & 0 & 0 & 20 \\
\hline 625 & NC_004741.1 & WP_005052731.1 & 0 & 0 & 0 & 0 & 0 & 0 \\
\hline 626 & NC_004741.1 & WP_001055752.1 & 0 & 0 & 0 & 0 & 0 & 0 \\
\hline 627 & NC_004741.1 & WP_001254807.1 & 1 & 1 & 1 & 1 & 0 & 80 \\
\hline 628 & NC_004741.1 & WP_005052744.1 & 1 & 0 & 0 & 0 & 1 & 40 \\
\hline 629 & NC_004741.1 & WP_000497332.1 & 1 & 1 & 1 & 1 & 0 & 80 \\
\hline 630 & NC_004741.1 & WP_000847163.1 & 1 & 1 & 1 & 1 & 0 & 80 \\
\hline 631 & NC_004741.1 & WP_001303699.1 & 0 & 0 & 0 & 0 & 0 & 0 \\
\hline 632 & NC_004741.1 & WP_001148908.1 & 1 & 1 & 1 & 1 & 0 & 80 \\
\hline 633 & NC_004741.1 & WP_000907085.1 & 1 & 1 & 1 & 1 & 0 & 80 \\
\hline 634 & NC_004741.1 & WP_001007729.1 & 1 & 1 & 1 & 1 & 0 & 80 \\
\hline 635 & NC_004741.1 & WP_000786137.1 & 0 & 0 & 0 & 0 & 0 & 0 \\
\hline 636 & NC_004741.1 & WP_005065417.1 & 1 & 1 & 1 & 1 & 0 & 80 \\
\hline 637 & NC_004741.1 & WP_001295738.1 & 0 & 0 & 0 & 0 & 0 & 0 \\
\hline 638 & NC_004741.1 & WP_000062539.1 & 1 & 1 & 1 & 1 & 0 & 80 \\
\hline 639 & NC_004741.1 & WP_000242065.1 & 1 & 1 & 0 & 1 & 0 & 60 \\
\hline 640 & NC_004741.1 & WP_032155811.1 & 0 & 0 & 0 & 0 & 0 & 0 \\
\hline
\end{tabular}




\begin{tabular}{|c|c|c|c|c|c|c|c|c|}
\hline 641 & NC_004741.1 & WP_000121001.1 & 1 & 1 & 1 & 1 & 0 & 80 \\
\hline 642 & NC_004741.1 & WP_024259336.1 & 0 & 0 & 0 & 0 & 0 & 0 \\
\hline 643 & NC_004741.1 & WP_032155640.1 & 0 & 0 & 0 & 0 & 0 & 0 \\
\hline 644 & NC_004741.1 & WP_001243676.1 & 1 & 1 & 1 & 1 & 0 & 80 \\
\hline 645 & NC_004741.1 & WP_001351186.1 & 1 & 0 & 0 & 0 & 0 & 20 \\
\hline 646 & NC_004741.1 & WP_011110644.1 & 1 & 1 & 1 & 1 & 0 & 80 \\
\hline 647 & NC_004741.1 & WP_000079652.1 & 1 & 1 & 1 & 1 & 0 & 80 \\
\hline 648 & NC_004741.1 & WP_001243871.1 & 1 & 1 & 1 & 1 & 0 & 80 \\
\hline 649 & NC_004741.1 & WP_011069606.1 & 0 & 0 & 0 & 0 & 0 & 0 \\
\hline 650 & NC_004741.1 & WP_000166281.1 & 1 & 1 & 1 & 1 & 0 & 80 \\
\hline 651 & NC_004741.1 & WP_001296688.1 & 0 & 0 & 0 & 0 & 0 & 0 \\
\hline 652 & NC_004741.1 & WP_005053984.1 & 1 & 1 & 1 & 1 & 0 & 80 \\
\hline 653 & NC_004741.1 & WP_000937635.1 & 0 & 0 & 0 & 0 & 0 & 0 \\
\hline 654 & NC_004741.1 & WP_001119485.1 & 1 & 1 & 1 & 1 & 0 & 80 \\
\hline 655 & NC_004741.1 & WP_001205243.1 & 1 & 1 & 1 & 1 & 1 & 100 \\
\hline 656 & NC_004741.1 & WP_000044756.1 & 0 & 0 & 0 & 0 & 0 & 0 \\
\hline 657 & NC_004741.1 & WP_001008046.1 & 1 & 1 & 1 & 1 & 0 & 80 \\
\hline 658 & NC_004741.1 & WP_001238362.1 & 1 & 1 & 1 & 1 & 1 & 100 \\
\hline 659 & NC_004741.1 & WP_005134385.1 & 1 & 0 & 0 & 0 & 0 & 20 \\
\hline 660 & NC_004741.1 & WP_001243705.1 & 1 & 1 & 1 & 1 & 0 & 80 \\
\hline 661 & NC_004741.1 & WP_000943980.1 & 1 & 1 & 1 & 1 & 1 & 100 \\
\hline 662 & NC_004741.1 & WP_005053837.1 & 1 & 0 & 0 & 0 & 0 & 20 \\
\hline 663 & NC_004741.1 & WP_000492914.1 & 1 & 1 & 1 & 1 & 0 & 80 \\
\hline 664 & NC_004741.1 & WP_032155818.1 & 0 & 0 & 0 & 0 & 0 & 0 \\
\hline 665 & NC_004741.1 & WP_000895690.1 & 1 & 0 & 0 & 0 & 0 & 20 \\
\hline 666 & NC_004741.1 & WP_000132640.1 & 1 & 1 & 1 & 1 & 1 & 100 \\
\hline 667 & NC_004741.1 & WP_000467859.1 & 1 & 1 & 1 & 1 & 0 & 80 \\
\hline 668 & NC_004741.1 & WP_005053796.1 & 0 & 0 & 0 & 0 & 0 & 0 \\
\hline
\end{tabular}




\begin{tabular}{|l|l|l|l|l|l|l|l|l|}
\hline 669 & NC_004741.1 & WP_000538192.1 & 1 & 1 & 1 & 1 & 0 & 80 \\
\hline 670 & NC_004741.1 & WP_001338213.1 & 1 & 1 & 1 & 1 & 0 & 80 \\
\hline 671 & NC_004741.1 & WP_000604352.1 & 1 & 1 & 1 & 1 & 0 & 80 \\
\hline 672 & NC_004741.1 & WP_000494556.1 & 0 & 0 & 0 & 0 & 0 & 0 \\
\hline 673 & NC_004741.1 & WP_000007444.1 & 0 & 0 & 0 & 0 & 0 & 0 \\
\hline 674 & NC_004741.1 & WP_001303782.1 & 0 & 0 & 0 & 0 & 0 & 0 \\
\hline
\end{tabular}

Note: $0=0 \%, 1=25 \%$. 
Supplementary Table 2. List of predicted physicochemical parameters of 39 hypothetical proteins

\begin{tabular}{|c|c|c|c|c|c|c|c|c|c|}
\hline $\begin{array}{l}\text { Sl. } \\
\text { No } \\
.\end{array}$ & $\begin{array}{l}\text { Accession } \\
\text { ID_Protein }\end{array}$ & $\begin{array}{l}\text { No. of } \\
\text { amino } \\
\text { acids }\end{array}$ & MW & PI & $\begin{array}{l}\text { Extinctio } \\
\text { n } \\
\text { coefficient }\end{array}$ & $\begin{array}{l}\text { Instability } \\
\text { index }\end{array}$ & $\begin{array}{l}\text { Classificatio } \\
\text { n }\end{array}$ & $\begin{array}{l}\text { Alphabatic } \\
\text { index }\end{array}$ & $\begin{array}{l}\text { Grand average of } \\
\text { hydropathicity } \\
\text { (GRAVY) }\end{array}$ \\
\hline 1 & WP_005053355.1 & 274 & 29970.4 & 7.62 & 24325 & 28.39 & Stable & 84.01 & -0.016 \\
\hline 2 & WP_000092054.1 & 364 & 40443.3 & 9.61 & 51005 & 47.89 & Unstable & 79.67 & -0.384 \\
\hline 3 & WP_001382892.1 & 179 & 19590.3 & 5.28 & 2980 & 35.06 & Stable & 101.23 & -0.143 \\
\hline 4 & WP_005053036.1 & 192 & 20906 & 9.04 & 7450 & 35.73 & Stable & 95.05 & -0.062 \\
\hline 5 & WP_000779831.1 & 190 & 19441.2 & 7.87 & 6990 & 45.39 & Unstable & 96.58 & 0.172 \\
\hline 6 & WP_011110552.1 & 108 & 12039.7 & 7.61 & 8730 & 66.94 & Unstable & 77.78 & -0.544 \\
\hline 7 & WP_001269672.1 & 193 & 21386.6 & 8.73 & 11460 & 31.1 & Stable & 90.98 & -0.238 \\
\hline 8 & WP_001247854.1 & 619 & 69683.8 & 5.5 & 107425 & 33.35 & Stable & 78.24 & -0.458 \\
\hline 9 & WP_000070107.1 & 377 & 42056.8 & 7.71 & 52035 & 31.62 & Stable & 124.14 & 0.611 \\
\hline 10 & WP_000224274.1 & 369 & 40593.3 & 7.03 & 40950 & 37.16 & Stable & 82.22 & -0.191 \\
\hline 11 & WP_000749269.1 & 191 & 20942.5 & 5.57 & 16960 & 11.14 & Stable & 75.6 & -0.436 \\
\hline 12 & WP_001125713.1 & 108 & 12371.5 & 9.16 & 7450 & 53.58 & Unstable & 82.13 & -0.624 \\
\hline 13 & WP_001043881.1 & 165 & 18093.6 & 4.66 & 11585 & 35.37 & Stable & 101.09 & 0.133 \\
\hline 14 & WP_001295493.1 & 114 & 12493.2 & 4.96 & 20970 & 30.77 & Stable & 97.63 & 0.024 \\
\hline 15 & WP_000691930.1 & 84 & 8942.38 & 7.66 & 12740 & 41.42 & Unstable & 81.31 & -0.167 \\
\hline 16 & WP_000597196.1 & 155 & 15601.7 & 9.36 & 2980 & 24.38 & Stable & 94.77 & 0.114 \\
\hline 17 & WP_000248636.1 & 370 & 39841.2 & 8.49 & 79075 & 32.75 & Stable & 143.05 & 1.029 \\
\hline 18 & WP_000755956.1 & 275 & 30284.6 & 5.68 & 30035 & 24.35 & Stable & 84.04 & -0.331 \\
\hline 19 & WP_001237866.1 & 107 & 11755.5 & 6.56 & 6210 & 30.08 & Stable & 97.57 & 0.277 \\
\hline 20 & WP_000454701.1 & 527 & 59450.2 & 5.15 & 37930 & 32.47 & Stable & 116.7 & 0.177 \\
\hline 21 & WP_000003197.1 & 219 & 24222.7 & 5.17 & 26595 & 42.24 & Unstable & 85.98 & -0.055 \\
\hline 22 & WP_005049020.1 & 153 & 16568.1 & 7.7 & 7450 & 23.39 & Stable & 82.94 & -0.176 \\
\hline 23 & WP_048814497.1 & 243 & 27279.8 & 4.72 & 22585 & 43.49 & Unstable & 104.32 & -0.255 \\
\hline
\end{tabular}




\begin{tabular}{|l|l|l|l|l|l|l|l|l|l|}
\hline 24 & WP_000301054.1 & 216 & 25324.2 & 9.31 & 51005 & 44.31 & Unstable & 77.64 & -0.482 \\
\hline 25 & WP_000266171.1 & 1033 & 117109 & 5.58 & 244955 & 42.42 & Unstable & 83.71 & -0.343 \\
\hline 26 & WP_000589825.1 & 160 & 17240.6 & 8.71 & 18450 & 39.1 & Stable & 82.44 & -0.271 \\
\hline 27 & WP_005051685.1 & 251 & 26572.5 & 10.11 & 34505 & 23.04 & Stable & 76.18 & -0.279 \\
\hline 28 & WP_001387238.1 & 158 & 17740.4 & 6.76 & 8480 & 28.12 & Stable & 108.04 & -0.073 \\
\hline 29 & WP_000248097.1 & 82 & 9417.1 & 4.02 & 6990 & 44.78 & Unstable & 135.37 & 0.266 \\
\hline 30 & WP_000848528.1 & 85 & 9513.04 & 8.8 & 4720 & 42.38 & Unstable & 94.24 & -0.107 \\
\hline 31 & WP_000189314.1 & 100 & 11241.9 & 9.84 & 11460 & 36.12 & Stable & 84 & -0.544 \\
\hline 32 & WP_001297375.1 & 222 & 25258.4 & 7.84 & 13075 & 32.89 & Stable & 101.49 & -0.086 \\
\hline 33 & WP_000858193.1 & 113 & 12552.2 & 9.33 & 14565 & 22.75 & Stable & 129.38 & 1.041 \\
\hline 34 & WP_001296791.1 & 232 & 25960.7 & 4.58 & 65890 & 36.83 & Stable & 74.87 & -0.38 \\
\hline 35 & WP_000778795.1 & 127 & 14544.5 & 6.59 & 26470 & 47.26 & Unstable & 85.98 & -0.412 \\
\hline 36 & WP_001205243.1 & 294 & 32718.5 & 4.96 & 50795 & 48.91 & Unstable & 98.91 & -0.096 \\
\hline 37 & WP_001238362.1 & 177 & 19911.7 & 8.88 & 35535 & 27.45 & Stable & 78.25 & -0.194 \\
\hline 38 & WP_000943980.1 & 387 & 45038.7 & 4.64 & 94685 & 46.38 & Unstable & 83.7 & -0.434 \\
\hline 39 & WP_000132640.1 & 113 & 12294.1 & 8.64 & 10095 & 36.84 & Stable & 87.26 & -0.168 \\
\hline
\end{tabular}

MW, molecular weight; GRAVY, grand average of hydropathicity. 
Supplementary Table 3. List of predicted sub-cellular localization of 39 hypothetical proteins

\begin{tabular}{|c|c|c|c|c|c|c|c|c|c|}
\hline \multirow[t]{2}{*}{$\begin{array}{l}\text { S. } \\
\text { No. }\end{array}$} & \multirow[t]{2}{*}{ Accession No. } & \multicolumn{3}{|c|}{ Sub-cellular localization } & \multirow{2}{*}{$\begin{array}{l}\text { Signal } \\
\text { peptid } \\
\text { e } \\
\text { (Signa } \\
\text { I P) }\end{array}$} & \multirow{2}{*}{$\begin{array}{l}\text { Secretor } \\
\text { y protein } \\
\text { (Secreto } \\
\text { me } P \text { ) }\end{array}$} & \multicolumn{3}{|c|}{$\begin{array}{l}\text { Trans membrane helices } \\
\text { prediction }\end{array}$} \\
\hline & & CELLO & PSORT B & PSLpred & & & $\begin{array}{l}\text { HMMT } \\
\text { OP }\end{array}$ & $\begin{array}{l}\text { TMHM } \\
\text { M }\end{array}$ & SOSUI \\
\hline 1 & $\begin{array}{l}\text { WP_0050533 } \\
55.1\end{array}$ & Periplasmic & Unknown & Periplasmic & Yes & Yes & No & No & Soluble \\
\hline 2 & $\begin{array}{l}\text { WP_0000920 } \\
54.1\end{array}$ & Periplasmic & Unknown & Periplasmic & Yes & Yes & $\begin{array}{l}1 \mathrm{TM} \\
\text { Helices }\end{array}$ & No & Soluble \\
\hline 3 & $\begin{array}{l}\text { WP_0013828 } \\
92.1\end{array}$ & $\begin{array}{l}\text { Periplasmic/ } \\
\text { Extracellular }\end{array}$ & Unknown & $\begin{array}{l}\text { Outer } \\
\text { membrane }\end{array}$ & Yes & Yes & No & No & Soluble \\
\hline 4 & $\begin{array}{l}\text { WP_0050530 } \\
36.1\end{array}$ & Periplasmic & Unknown & Periplasmic & Yes & Yes & $\begin{array}{l}1 \mathrm{TM} \\
\text { Helices }\end{array}$ & No & $\begin{array}{l}\text { Membrane, } \\
1 \text { TM helix }\end{array}$ \\
\hline 5 & $\begin{array}{l}\text { WP_0007798 } \\
31.1\end{array}$ & Periplasmic & Periplasmic & Periplasmic & Yes & Yes & No & No & Soluble \\
\hline 6 & $\begin{array}{l}\text { WP_0111105 } \\
52.1\end{array}$ & Periplasmic & Unknown & Periplasmic & Yes & Yes & No & No & $\begin{array}{l}\text { Membrane, } \\
1 \text { TM helix }\end{array}$ \\
\hline 7 & $\begin{array}{l}\text { WP_0012696 } \\
72.1\end{array}$ & Periplasmic & $\begin{array}{l}\text { Outer } \\
\text { membrane }\end{array}$ & Periplasmic & No & Yes & $\begin{array}{l}2 \mathrm{TM} \\
\text { Helices }\end{array}$ & No & $\begin{array}{l}\text { Membrane, } \\
1 \text { TM helix }\end{array}$ \\
\hline 8 & $\begin{array}{l}\text { WP_0012478 } \\
54.1\end{array}$ & Cytoplasmic & Cytoplasmic & Cytoplasmic & No & No & No & No & Soluble \\
\hline 9 & $\begin{array}{l}\text { WP_0000701 } \\
07.1\end{array}$ & Inner membrane & $\begin{array}{l}\text { Cytoplasmic } \\
\text { membrane }\end{array}$ & $\begin{array}{l}\text { Inner- } \\
\text { membrane }\end{array}$ & No & No & $\begin{array}{l}6 \mathrm{TM} \\
\text { Helices }\end{array}$ & $\begin{array}{l}6 \mathrm{TM} \\
\text { Helices }\end{array}$ & $\begin{array}{l}\text { membrane, } \\
6 \text { TM helix }\end{array}$ \\
\hline 10 & $\begin{array}{l}\text { WP_0002242 } \\
74.1\end{array}$ & Periplasmic & Unknown & Cytoplasmic & No & No & No & No & Soluble \\
\hline 11 & $\begin{array}{l}\text { WP_0007492 } \\
69.1\end{array}$ & Periplasmic & Unknown & Periplasmic & Yes & No & $\begin{array}{l}1 \mathrm{TM} \\
\text { Helices }\end{array}$ & No & Soluble \\
\hline
\end{tabular}




\begin{tabular}{|l|l|l|l|l|l|l|l|l|l|}
\hline 12 & $\begin{array}{l}\text { WP_0011257 } \\
13.1\end{array}$ & Cytoplasmic & Cytoplasmic & Periplasmic & No & Yes & No & No & Soluble \\
\hline 13 & $\begin{array}{l}\text { WP_0010438 } \\
81.1\end{array}$ & Cytoplasmic & Unknown & Cytoplasmic & No & No & No & No & Soluble \\
\hline 14 & $\begin{array}{l}\text { WP_0012954 } \\
93.1\end{array}$ & Cytoplasmic & Cytoplasmic & Cytoplasmic & No & No & No & No & Soluble \\
\hline 15 & $\begin{array}{l}\text { WP_0006919 } \\
30.1\end{array}$ & Periplasmic & Unknown & Periplasmic & Yes & Yes & No & No & $\begin{array}{l}\text { Membrane, } \\
1 \text { TM helix }\end{array}$ \\
\hline 16 & $\begin{array}{l}\text { WP_0005971 } \\
96.1\end{array}$ & Extracellular & $\begin{array}{l}\text { Outer } \\
\text { membrane }\end{array}$ & Extracellular & No & Yes & No & No & $\begin{array}{l}\text { Membrane, } \\
1 \text { TM helix }\end{array}$ \\
\hline 17 & $\begin{array}{l}\text { WP_0002486 } \\
36.1\end{array}$ & Inner membrane & $\begin{array}{l}\text { Cytoplasmic } \\
\text { membrane }\end{array}$ & $\begin{array}{l}\text { Inner } \\
\text { membrane }\end{array}$ & No & No & $\begin{array}{l}9 \text { TM } \\
\text { Helices }\end{array}$ & $\begin{array}{l}10 \text { TM } \\
\text { Helices }\end{array}$ & $\begin{array}{l}\text { Helices } \\
\text { Hes }\end{array}$ \\
\hline 18 & $\begin{array}{l}\text { WP_0007559 } \\
56.1\end{array}$ & Periplasmic & Unknown & Periplasmic & No & Yes & No & No & Soluble \\
\hline 19 & $\begin{array}{l}\text { WP_0012378 } \\
66.1\end{array}$ & Cytoplasmic & Unknown & Cytoplasmic & No & No & No & No & $\begin{array}{l}\text { Membrane, } \\
1 \text { TM helix }\end{array}$ \\
\hline 20 & $\begin{array}{l}\text { WP_0004547 } \\
01.1\end{array}$ & Inner membrane & $\begin{array}{l}\text { Cytoplasmic } \\
\text { membrane }\end{array}$ & $\begin{array}{l}\text { InnerMembr } \\
\text { ane }\end{array}$ & No & No & $\begin{array}{l}7 \text { TM } \\
\text { Helices }\end{array}$ & $\begin{array}{l}7 \text { TM } \\
\text { Helices }\end{array}$ & $\begin{array}{l}\text { Membrane, } \\
7 \text { TM helix }\end{array}$ \\
\hline 21 & $\begin{array}{l}\text { WP_0000031 } \\
97.1\end{array}$ & Cytoplasmic & Unknown & Cytoplasmic & No & No & No & No & Soluble \\
\hline 22 & $\begin{array}{l}\text { WP_0050490 } \\
20.1\end{array}$ & Periplasmic & Unknown & Periplasmic & Yes & Yes & No & No & $\begin{array}{l}\text { Membrane, } \\
1 \text { TM helix }\end{array}$ \\
\hline 23 & $\begin{array}{l}\text { WP_0488144 } \\
97.1\end{array}$ & $\begin{array}{l}\text { Cytoplasmic/ Outer } \\
\text { membrane }\end{array}$ & Extracellular & Extracellular & No & No & No & No & Soluble \\
\hline 24 & $\begin{array}{l}\text { WP_0003010 } \\
54.1\end{array}$ & Cytoplasmic & Cytoplasmic & Cytoplasmic & No & No & No & No & Soluble \\
\hline 25 & $\begin{array}{l}\text { WP_0002661 } \\
71.1\end{array}$ & Cytoplasmic & Unknown & Cytoplasmic & No & No & No & No & Soluble \\
\hline
\end{tabular}




\begin{tabular}{|c|c|c|c|c|c|c|c|c|c|}
\hline 26 & $\begin{array}{l}\text { WP_0005898 } \\
25.1\end{array}$ & Periplasmic & $\begin{array}{l}\text { Outer } \\
\text { membrane }\end{array}$ & $\begin{array}{l}\text { Outer } \\
\text { membrane }\end{array}$ & No & Yes & No & No & $\begin{array}{l}\text { Membrane, } \\
1 \text { TM helix }\end{array}$ \\
\hline 27 & $\begin{array}{l}\text { WP_0050516 } \\
85.1\end{array}$ & Extracellular & $\begin{array}{l}\text { Outer } \\
\text { membrane }\end{array}$ & Extracellular & No & yes & No & $\begin{array}{l}1 \mathrm{TM} \\
\text { Helices }\end{array}$ & Soluble \\
\hline 28 & $\begin{array}{l}\text { WP_0013872 } \\
38.1\end{array}$ & Cytoplasmic & Cytoplasmic & Cytoplasmic & No & No & No & No & Soluble \\
\hline 29 & $\begin{array}{l}\text { WP_0002480 } \\
97.1\end{array}$ & Cytoplasmic & Unknown & Cytoplasmic & No & No & No & No & Soluble \\
\hline 30 & $\begin{array}{l}\text { WP_0008485 } \\
28.1\end{array}$ & Periplasmic & $\begin{array}{l}\text { Outer } \\
\text { membrane }\end{array}$ & Cytoplasmic & No & No & $\begin{array}{l}1 \mathrm{TM} \\
\text { Helices }\end{array}$ & No & $\begin{array}{l}\text { Membrane, } \\
1 \text { TM helix }\end{array}$ \\
\hline 31 & $\begin{array}{l}\text { WP_0001893 } \\
14.1\end{array}$ & $\begin{array}{l}\text { Cytoplasmic/Peripl } \\
\text { asmic }\end{array}$ & Unknown & $\begin{array}{l}\text { Outer } \\
\text { membrane }\end{array}$ & No & No & No & No & Soluble \\
\hline 32 & $\begin{array}{l}\text { WP_0012973 } \\
75.1\end{array}$ & Cytoplasmic & Cytoplasmic & Cytoplasmic & No & No & No & No & Soluble \\
\hline 33 & $\begin{array}{l}\text { WP_0008581 } \\
93.1\end{array}$ & Inner membrane & $\begin{array}{l}\text { Cytoplasmic } \\
\text { membrane }\end{array}$ & $\begin{array}{l}\text { Inner } \\
\text { membrane }\end{array}$ & No & No & $\begin{array}{l}4 \mathrm{TM} \\
\text { Helices }\end{array}$ & $\begin{array}{l}4 \mathrm{TM} \\
\text { Helices }\end{array}$ & $\begin{array}{l}\text { Membrane, } \\
3 \text { TM helix }\end{array}$ \\
\hline 34 & $\begin{array}{l}\text { WP_0012967 } \\
91.1\end{array}$ & Extracellular & Extracellular & Extracellular & No & Yes & $\begin{array}{l}1 \mathrm{TM} \\
\text { Helices }\end{array}$ & $\begin{array}{l}1 \mathrm{TM} \\
\text { Helices }\end{array}$ & Soluble \\
\hline 35 & $\begin{array}{l}\text { WP_0007787 } \\
95.1\end{array}$ & Cytoplasmic & Unknown & Cytoplasmic & No & No & No & No & Soluble \\
\hline 36 & $\begin{array}{l}\text { WP_0012052 } \\
43.1\end{array}$ & Cytoplasmic & Extracellular & Cytoplasmic & No & No & No & $\begin{array}{l}1 \mathrm{TM} \\
\text { Helices }\end{array}$ & Soluble \\
\hline 37 & $\begin{array}{l}\text { WP_0012383 } \\
62.1\end{array}$ & Periplasmic & $\begin{array}{l}\text { Outer } \\
\text { membrane }\end{array}$ & Cytoplasmic & Yes & Yes & No & $\begin{array}{l}\mathrm{TM} \\
\text { Helices }\end{array}$ & $\begin{array}{l}\text { Membrane, } \\
1 \text { TM helix }\end{array}$ \\
\hline 38 & $\begin{array}{l}\text { WP_0009439 } \\
80.1\end{array}$ & Cytoplasmic & Cytoplasmic & Cytoplasmic & No & No & No & No & Soluble \\
\hline 39 & $\begin{array}{l}\text { WP_0001326 } \\
40.1\end{array}$ & Cytoplasmic & Unknown & $\begin{array}{l}\text { Cytoplasmi } \\
\text { c }\end{array}$ & No & yes & No & No & Soluble \\
\hline
\end{tabular}


Supplementary Table 4. List of annotated functions of 39 hypothetical proteins from Shigella flexneri using CDD-BLAST, Pfam, HmmScan, SMART, Scanprosite, PS2-v2, and STRING

\begin{tabular}{|c|c|c|c|c|c|}
\hline $\begin{array}{l}\text { Sl. } \\
\text { No }\end{array}$ & Acc ID & $\begin{array}{l}\text { Functional domain } \\
\text { (BLAST,Pfam, HmmScan, } \\
\text { SMART,Scanprosite) }\end{array}$ & $\begin{array}{l}\text { Template } \\
\text { s }\end{array}$ & Domain in (PS)2-v2 & $\begin{array}{l}\text { Predicted functional partner } \\
\text { (STRING) }\end{array}$ \\
\hline 1 & $\begin{array}{l}\text { WP_005053355. } \\
1\end{array}$ & Peptidase, C92 family & $\begin{array}{l}\text { No } \\
\text { template }\end{array}$ & Error & $\begin{array}{l}\text { Minor fimbrial subunit, D- } \\
\text { mannose specific adhesin }\end{array}$ \\
\hline 2 & $\begin{array}{l}\text { WP_000092054. } \\
1\end{array}$ & DUF1615/Lipoprotein & $1 \mathrm{~m} 9 \mathrm{iA}$ & Same & Microcin B17 transporter \\
\hline 3 & $\begin{array}{l}\text { WP_001382892. } \\
1\end{array}$ & $\begin{array}{l}\text { DUF3251/lipoprotein } \\
\text { YajI/immunoglobulin like domain }\end{array}$ & 2jwyA & Same & $\begin{array}{l}\text { Hypothetical protein } \\
\text { SF0234/ATP synthase }\end{array}$ \\
\hline 4 & $\begin{array}{l}\text { WP_005053036. } \\
1\end{array}$ & $\begin{array}{l}\text { Lipoprotein_16/Uncharacterized } \\
\text { lipoprotein }\end{array}$ & 2iqiF & Same & Regulatory protein AmpE \\
\hline 5 & $\begin{array}{l}\text { WP_000779831. } \\
1\end{array}$ & Lipoprotein chaperone (YscW) & $\begin{array}{l}\text { No } \\
\text { template }\end{array}$ & Error & Universal stress protein UspB \\
\hline 6 & $\begin{array}{l}\text { WP_011110552. } \\
1\end{array}$ & YbfN-like lipoprotein & $\begin{array}{l}\text { No } \\
\text { template }\end{array}$ & Error & Hypothetical protein ybfM \\
\hline 7 & $\begin{array}{l}\text { WP_001269672. } \\
1\end{array}$ & $\begin{array}{l}\text { LPS-assembly lipoprotein RlpB } \\
\text { (LptE) }\end{array}$ & $2 \mathrm{r} 76 \mathrm{~A}$ & Same & $\begin{array}{l}\text { LPS assembly outer membrane } \\
\text { complex protein LptD }\end{array}$ \\
\hline 8 & $\begin{array}{l}\text { WP_001247854. } \\
1\end{array}$ & $\begin{array}{l}\text { Topoisomerases, DnaG-type } \\
\text { primases, Hedgehog/Intein domain }\end{array}$ & $\begin{array}{l}\text { No } \\
\text { template }\end{array}$ & Error & $\begin{array}{l}\text { DNA-directed RNA polymerase } \\
\text { subunit beta }\end{array}$ \\
\hline 9 & $\begin{array}{l}\text { WP_000070107. } \\
1\end{array}$ & ATP-binding cassette transporter & 2 dyrA & $\begin{array}{l}\text { OXIDOREDUCTAS } \\
\text { E }\end{array}$ & ATP-binding protein ybhF_2 \\
\hline 10 & $\begin{array}{l}\text { WP_000224274. } \\
1\end{array}$ & $\begin{array}{l}\text { MOSC beta barrel domain } / 2 \mathrm{Fe}-2 \mathrm{~S} \\
\text { iron-sulfur cluster binding domain }\end{array}$ & $2 \mathrm{piaA}$ & Same & $\mathrm{Fe} / \mathrm{S}$ biogenesis protein NfuA \\
\hline 11 & $\begin{array}{l}\text { WP_000749269. } \\
1\end{array}$ & YceI-like domain & $1 \mathrm{y} 0 \mathrm{gA}$ & Same & yceJ Cytochrome \\
\hline 12 & $\begin{array}{l}\text { WP_001125713. } \\
1\end{array}$ & YcgL domain & $2 \mathrm{~h} 7 \mathrm{aA}$ & Same & Hypothetical protein ycgN \\
\hline
\end{tabular}




\begin{tabular}{|c|c|c|c|c|c|}
\hline 13 & $\begin{array}{l}\text { WP_001043881. } \\
1\end{array}$ & GAF domain & $1 \mathrm{vhmB}$ & Same & $\begin{array}{l}\text { Hypothetical protein; RNA } \\
\text { chaperone proQ }\end{array}$ \\
\hline 14 & $\begin{array}{l}\text { WP_001295493. } \\
1\end{array}$ & $\begin{array}{l}\text { Endoribonuclease L- } \\
\text { PSP/YjgFfamily }\end{array}$ & 1qd9A & Same & $\begin{array}{l}\text { D-amino acid dehydrogenase } \\
\text { small subunit }\end{array}$ \\
\hline 15 & $\begin{array}{l}\text { WP_000691930. } \\
1\end{array}$ & $\begin{array}{l}\begin{array}{l}\text { Domain of unknown function } \\
\text { (DUF333) }\end{array} \\
\end{array}$ & $2 \mathrm{pqcA}$ & TRANSFERASE & Hypothetical protein yeaP \\
\hline 16 & $\begin{array}{l}\text { WP_000597196. } \\
1\end{array}$ & Glycine zipper 2TM domain & $\begin{array}{l}\text { No } \\
\text { template }\end{array}$ & Error & Flagellar fliJ protein \\
\hline 17 & $\begin{array}{l}\text { WP_000248636. } \\
1\end{array}$ & AI-2E family transporter/permease & $2 \mathrm{j} \ln \mathrm{A}$ & Same & $\begin{array}{l}\text { Glutamine } \\
\text { amidotransferase/anthranilate } \\
\text { phosphoribosyltransferase }\end{array}$ \\
\hline 18 & $\begin{array}{l}\text { WP_000755956. } \\
1\end{array}$ & SPFH domain / Band 7 family & $3 \mathrm{bk} 6 \mathrm{~A}$ & Same & Integrase \\
\hline 19 & $\begin{array}{l}\text { WP_001237866. } \\
1\end{array}$ & YecR-like lipoprotein & $\begin{array}{l}\text { No } \\
\text { template }\end{array}$ & Error & Glycosyl transferase \\
\hline 20 & $\begin{array}{l}\text { WP_000454701. } \\
1\end{array}$ & $\begin{array}{l}\text { TerC family/Transporter } \\
\text { associated domain/CBS domain }\end{array}$ & 2yvyA & Same & Glutamate synthase \\
\hline 21 & $\begin{array}{l}\text { WP_000003197. } \\
1\end{array}$ & $\begin{array}{l}\text { von Willebrand factor type A } \\
\text { domain }\end{array}$ & 1atzB & Same & Chaperonin \\
\hline 22 & $\begin{array}{l}\text { WP_005049020. } \\
1\end{array}$ & Uncharacterized lipoprotein YehR & 2joeA & Same & Transporter \\
\hline 23 & $\begin{array}{l}\text { WP_048814497. } \\
1\end{array}$ & $\begin{array}{l}\text { Leucine rich repeat protein/NEL } \\
\text { or novel E3 ligase domain }\end{array}$ & $3 \mathrm{cvrA}$ & Same & $\begin{array}{l}\text { Aerobic respiration control } \\
\text { sensor protein ArcB }\end{array}$ \\
\hline 24 & $\begin{array}{l}\text { WP_000301054. } \\
1\end{array}$ & $\begin{array}{l}\text { Lipopolysaccharide kinase } \\
\text { (Kdo/WaaP) }\end{array}$ & $1 \mathrm{blxA}$ & Same & $\begin{array}{l}\text { Lipopolysaccharide core } \\
\text { heptose(I) kinase RfaP }\end{array}$ \\
\hline 25 & $\begin{array}{l}\text { WP_000266171. } \\
1\end{array}$ & Tetratricopeptide repeat (TPR) & $\begin{array}{l}\text { No } \\
\text { template }\end{array}$ & Error & $\begin{array}{l}\text { NAGC-like transcriptional } \\
\text { regulator }\end{array}$ \\
\hline 26 & $\begin{array}{l}\text { WP_000589825. } \\
1\end{array}$ & $\begin{array}{l}\text { Outer membrane protein (ompA) } \\
\text { like domain/membrane lipoprotein }\end{array}$ & $2 \mathrm{k} 1 \mathrm{sA}$ & Same & Hypothetical protein SF2663 \\
\hline
\end{tabular}




\begin{tabular}{|c|c|c|c|c|c|}
\hline 27 & $\begin{array}{l}\text { WP_005051685. } \\
1\end{array}$ & $\begin{array}{l}\text { LysM (lysin-like motif)/ Peptidase } \\
\text { family M23 }\end{array}$ & 2gulA & Same & Beta-hexosaminidase \\
\hline 28 & $\begin{array}{l}\text { WP_001387238. } \\
1\end{array}$ & $\begin{array}{l}\text { DNA repair protein } \mathrm{RadC} \text {-like } \\
\text { JAB domain }\end{array}$ & 2qlcA & Same & Hypothetical protein SF2995 \\
\hline 29 & $\begin{array}{l}\text { WP_000248097. } \\
1\end{array}$ & $\begin{array}{l}\text { Carrier protein }(\mathrm{CP}) \text { domain and } \\
\text { phosphopantetheine attachment } \\
\text { site }\end{array}$ & $1 \times 30 A$ & Same & Class II aminotransferase \\
\hline 30 & $\begin{array}{l}\text { WP_000848528. } \\
1\end{array}$ & Lipoprotein leucine-zipper & $1 \mathrm{jcdB}$ & Same & Porin \\
\hline 31 & $\begin{array}{l}\text { WP_000189314. } \\
1\end{array}$ & GIY-YIG nuclease domain & $1 \mathrm{zg} 2 \mathrm{~A}$ & Same & Hypothetical protein yhbP \\
\hline 32 & $\begin{array}{l}\text { WP_001297375. } \\
1\end{array}$ & $\begin{array}{l}\text { DNA repair protein RadC-like } \\
\text { JAB domain }\end{array}$ & $\begin{array}{l}\text { No } \\
\text { template }\end{array}$ & Error & $\begin{array}{l}\text { DNA mismatch repair protein } \\
\text { MutS; }\end{array}$ \\
\hline 33 & $\begin{array}{l}\text { WP_000858193. } \\
1\end{array}$ & yiaA/B two helix domain & 1oedA & Same & Hypothetical protein yiaA \\
\hline 34 & $\begin{array}{l}\text { WP_001296791. } \\
1\end{array}$ & Autotransporter beta-domain & $\begin{array}{l}\text { No } \\
\text { template }\end{array}$ & Error & $\begin{array}{l}\text { Biofilm formation regulatory } \\
\text { protein BssR }\end{array}$ \\
\hline 35 & $\begin{array}{l}\text { WP_000778795. } \\
1\end{array}$ & Acetyltransferase (GNAT) domain & $2 \mathrm{k} 5 \mathrm{tA}$ & Same & Aspartate alpha-decarboxylase \\
\hline 36 & $\begin{array}{l}\text { WP_001205243. } \\
1\end{array}$ & $\begin{array}{l}\text { Xylose isomerase-like TIM barrel } \\
\text { (AP_endonuc_2) }\end{array}$ & $1 \mathrm{k} 77 \mathrm{~A}$ & Same & 3-ketoacyl-ACP reductase \\
\hline 37 & $\begin{array}{l}\text { WP_001238362. } \\
1\end{array}$ & Lipocalin-like domain & 1qwdA & Same & Sugar nucleotide epimerase \\
\hline 38 & $\begin{array}{l}\text { WP_000943980. } \\
1\end{array}$ & Glutathionylspermidine synthase & $\begin{array}{l}\text { No } \\
\text { template }\end{array}$ & Error & $\begin{array}{l}\text { Nicotinate } \\
\text { phosphoribosyltransferase }\end{array}$ \\
\hline 39 & $\begin{array}{l}\text { WP_000132640. } \\
1\end{array}$ & Toxin SymE/SpoVT-AbrB domain & $1 \mathrm{ve} 0 \mathrm{~A}$ & Same & Hypothetical protein SF1670 \\
\hline
\end{tabular}

Note: Proteins with discrepant results are shown in bold. 
Supplementary Table 5. List of annotated functions of 39 hypothetical proteins from Shigella flexneri using MOTIF, Interproscan, CATH, SUPERFAMILY, and ProtoNet

\begin{tabular}{|c|c|c|c|c|c|c|}
\hline $\begin{array}{l}\text { Sl } \\
\text { No } \\
\end{array}$ & Acc ID & MOTIF & INTERPROSCAN & CATH & $\begin{array}{l}\text { SUPERFAMIL } \\
\text { Y }\end{array}$ & ProtoNet \\
\hline 1 & $\begin{array}{l}\text { WP_00505335 } \\
5.1\end{array}$ & $\begin{array}{l}\text { Papain-like } \\
\text { amidase enzyme, } \\
\text { YaeF/YiiX, C92 } \\
\text { family }\end{array}$ & $\begin{array}{l}\text { Papain-like } \\
\text { amidase enzyme, } \\
\text { YaeF/YiiX, C92 } \\
\text { family }\end{array}$ & $\begin{array}{l}\text { Lipoprotein/Uncharacte } \\
\text { rized protein }\end{array}$ & $\begin{array}{l}\text { Cysteine } \\
\text { proteinases } \\
\text { YiiX-like }\end{array}$ & $\begin{array}{l}\text { Cluster } 3674930 \\
\text { Proteobacteria }\end{array}$ \\
\hline 2 & $\begin{array}{l}\text { WP_00009205 } \\
4.1\end{array}$ & $\begin{array}{l}\text { Protein of unknown } \\
\text { function } \\
\text { (DUF1615) }\end{array}$ & $\begin{array}{l}\text { Protein of unknown } \\
\text { function DUF1615 }\end{array}$ & No hit & GFP-like & $\begin{array}{l}\text { Cluster } 4109548 \\
\text { Protein of unknown } \\
\text { function DUF1615 }\end{array}$ \\
\hline 3 & $\begin{array}{l}\text { WP_00138289 } \\
2.1\end{array}$ & $\begin{array}{l}\text { Protein of unknown } \\
\text { function } \\
\text { (DUF3251) }\end{array}$ & $\begin{array}{l}\text { Domain of } \\
\text { unknown function } \\
\text { DUF3251 }\end{array}$ & $\begin{array}{l}\text { Hypothetical lipoprotein } \\
\text { yajI }\end{array}$ & Phase 1 flagellin & $\begin{array}{l}\text { Cluster } 3711586 \\
\text { 2JWY }\end{array}$ \\
\hline 4 & $\begin{array}{l}\text { WP_00505303 } \\
6.1\end{array}$ & $\begin{array}{l}\text { Uncharacterized } \\
\text { lipoprotein }\end{array}$ & $\begin{array}{l}\text { Uncharacterised } \\
\text { protein family, } \\
\text { YajG }\end{array}$ & No hit & Phase 1 flagellin & $\begin{array}{l}\text { Cluster } 4028813 \\
\text { Uncharacterized } \\
\text { lipoprotein }\end{array}$ \\
\hline 5 & $\begin{array}{l}\text { WP_00077983 } \\
1.1\end{array}$ & $\begin{array}{l}\text { lipoprotein } \\
\text { chaperone }(Y s c W)\end{array}$ & No result & No hit & No result & $\begin{array}{l}\text { Cluster } 4131069 \\
\text { Proteobacteria }\end{array}$ \\
\hline 6 & $\begin{array}{l}\text { WP_01111055 } \\
2.1\end{array}$ & $\begin{array}{l}\text { YbfN-like } \\
\text { lipoprotein }\end{array}$ & $\begin{array}{l}\text { YbfN-like } \\
\text { lipoprotein }\end{array}$ & No hit & No result & $\begin{array}{l}\text { Cluster } 4085534 \\
\text { Lipoprotein }\end{array}$ \\
\hline 7 & $\begin{array}{l}\text { WP_00126967 } \\
2.1\end{array}$ & $\begin{array}{l}\text { Lipopolysaccharide } \\
\text {-assembly LptE }\end{array}$ & $\begin{array}{l}\text { LPS-assembly } \\
\text { lipoprotein LptE }\end{array}$ & $\begin{array}{l}\text { LPS-assembly } \\
\text { lipoprotein LptE }\end{array}$ & No result & $\begin{array}{l}\text { Cluster } 3965977 \\
\text { Rare lipoprotein B }\end{array}$ \\
\hline 8 & $\begin{array}{l}\text { WP_00124785 } \\
4.1\end{array}$ & Toprim-like & $\begin{array}{l}\text { DNA } \\
\text { primase/Toprim } \\
\text { domain }\end{array}$ & DNA primase/helicase & $\begin{array}{l}\text { DNA } \\
\text { primase/helicasec } \\
\text { ore }\end{array}$ & $\begin{array}{l}\text { Cluster } 3410389 \\
\text { DNA helicase, } \\
\text { DnaB-like }\end{array}$ \\
\hline 9 & WP_00007010 & ABC-2 family & ABC-2 transporter & membrane transport & MFS general & Cluster 4114591 \\
\hline
\end{tabular}




\begin{tabular}{|c|c|c|c|c|c|c|}
\hline & 7.1 & transporter protein & & $\begin{array}{l}\text { permease } \mathrm{YbhS} / \mathrm{ATP}- \\
\text { binding protein }\end{array}$ & $\begin{array}{l}\text { substrate } \\
\text { transporter }\end{array}$ & $\mathrm{ABC}-2$ \\
\hline 10 & $\begin{array}{l}\text { WP_00022427 } \\
4.1\end{array}$ & $\begin{array}{l}\text { MOSC domain/ } \\
\text { 2Fe-2S iron-sulfur } \\
\text { cluster }\end{array}$ & $\begin{array}{l}\text { MOSC, } \mathrm{N} \text {-terminal } \\
\text { beta barrel }\end{array}$ & $\begin{array}{l}\text { MOSC domain/ } 2 \mathrm{Fe}-2 \mathrm{~S} \\
\text { iron-sulfur cluster }\end{array}$ & $\begin{array}{l}\text { MOSC N- } \\
\text { terminal domain- } \\
\text { like }\end{array}$ & $\begin{array}{l}\text { Cluster } 4155424 \\
\text { MOSC, N-terminal } \\
\text { beta barrel }\end{array}$ \\
\hline 11 & $\begin{array}{l}\text { WP_00074926 } \\
9.1\end{array}$ & YceI-like domain & YceI-like domain & YceI-like domain & YceI-like domain & $\begin{array}{l}\text { Cluster } 4314345 \\
\text { YceI-like }\end{array}$ \\
\hline 12 & $\begin{array}{l}\text { WP_00112571 } \\
3.1\end{array}$ & YcgL domain & YcgL domain & No hit & YcgL-like & $\begin{array}{l}\text { Cluster } 4083593 \\
\text { YcgL domain }\end{array}$ \\
\hline 13 & $\begin{array}{l}\text { WP_00104388 } \\
1.1\end{array}$ & GAF domain & GAF domain & GAF domain & GAF domain & $\begin{array}{l}\text { Cluster } 4085038 \\
\text { GAF }\end{array}$ \\
\hline 14 & $\begin{array}{l}\text { WP_00129549 } \\
3.1\end{array}$ & $\begin{array}{l}\text { Endoribonuclease } \\
\text { L-PSP }\end{array}$ & YjgF/L-PSP & $\begin{array}{l}\text { Endoribonuclease L- } \\
\text { PSP family }\end{array}$ & YjgF/L-PSP & $\begin{array}{l}\text { Cluster } 4054994 \\
\text { YjgF/L-PSP }\end{array}$ \\
\hline 15 & $\begin{array}{l}\text { WP_00069193 } \\
0.1\end{array}$ & $\begin{array}{l}\text { Domain of } \\
\text { unknown function } \\
\text { (DUF333) }\end{array}$ & $\begin{array}{l}\text { Domain of } \\
\text { unknown function } \\
\text { (DUF333) }\end{array}$ & No hit & No result & $\begin{array}{l}\text { Cluster } 4079210 \\
\text { Protein of unknown } \\
\text { function DUF333 }\end{array}$ \\
\hline 16 & $\begin{array}{l}\text { WP_00059719 } \\
6.1\end{array}$ & $\begin{array}{l}\text { Glycine zipper } \\
\text { 2TM domain }\end{array}$ & $\begin{array}{l}\text { Glycine zipper } \\
\text { 2TM domain }\end{array}$ & No hit & No result & $\begin{array}{l}\text { Cluster } 4073223 \\
\text { Glycine zipper } \\
\text { 2TM domain }\end{array}$ \\
\hline 17 & $\begin{array}{l}\text { WP_00024863 } \\
6.1\end{array}$ & $\begin{array}{l}\text { AI-2E family } \\
\text { transporter }\end{array}$ & $\begin{array}{l}\text { AI-2E family } \\
\text { transporter }\end{array}$ & No hit & No result & $\begin{array}{l}\text { Cluster } 4074174 \\
\text { AI-2E family } \\
\text { transporter }\end{array}$ \\
\hline 18 & $\begin{array}{l}\text { WP_00075595 } \\
6.1\end{array}$ & $\begin{array}{l}\text { SPFH domain / } \\
\text { Band } 7 \text { family }\end{array}$ & $\begin{array}{l}\text { SPFH domain / } \\
\text { Band } 7 \text { family }\end{array}$ & No hit & $\begin{array}{l}\text { Band 7/SPFH } \\
\text { domain }\end{array}$ & $\begin{array}{l}\text { Cluster } 3793474 \\
\text { Band 7/SPFH } \\
\text { domain }\end{array}$ \\
\hline 19 & $\begin{array}{l}\text { WP_00123786 } \\
6.1\end{array}$ & $\begin{array}{l}\text { YecR-like } \\
\text { lipoprotein }\end{array}$ & $\begin{array}{l}\text { YecR-like } \\
\text { lipoprotein }\end{array}$ & No hit & SRCR-like & $\begin{array}{l}\text { Cluster } 3743846 \\
\text { Enterobacteriales }\end{array}$ \\
\hline 20 & $\begin{array}{l}\text { WP_00045470 } \\
1.1\end{array}$ & $\begin{array}{l}\text { TerC } \\
\text { family/Transporter }\end{array}$ & $\begin{array}{l}\text { TerC } \\
\text { family/Transporter }\end{array}$ & $\begin{array}{l}\text { TerC } \\
\text { family/Transporter }\end{array}$ & $\begin{array}{l}\text { CBS-domain } \\
\text { pair/transporter- }\end{array}$ & $\begin{array}{l}\text { Cluster } 4019065 \\
\text { membrane protein }\end{array}$ \\
\hline
\end{tabular}




\begin{tabular}{|c|c|c|c|c|c|c|}
\hline & & $\begin{array}{l}\text { associated } \\
\text { domain/CBS } \\
\text { domain }\end{array}$ & $\begin{array}{l}\text { associated } \\
\text { domain/CBS } \\
\text { domain }\end{array}$ & $\begin{array}{l}\text { associated domain/CBS } \\
\text { domain }\end{array}$ & $\begin{array}{l}\text { associated } \\
\text { domain }\end{array}$ & TerC \\
\hline 21 & $\begin{array}{l}\text { WP_00000319 } \\
7.1\end{array}$ & $\begin{array}{l}\text { von Willebrand } \\
\text { factor type A } \\
\text { domain }\end{array}$ & TerY/vWA-like & $\begin{array}{l}\text { von Willebrand factor } \\
\text { type A domain }\end{array}$ & vWA-like & $\begin{array}{l}\text { Cluster } 4002958 \\
\text { TerY/vWA-like }\end{array}$ \\
\hline 22 & $\begin{array}{l}\text { WP_00504902 } \\
0.1\end{array}$ & $\begin{array}{l}\text { Protein of } \\
\text { unknown function } \\
\text { (DUF1307)/YehR- } \\
\text { like }\end{array}$ & $\begin{array}{l}\text { Protein of } \\
\text { unknown function } \\
\text { (DUF1307)/YehR- } \\
\text { like }\end{array}$ & $\begin{array}{l}\text { Putative lipoprotein } \\
\text { YehR }\end{array}$ & YehR-like & $\begin{array}{l}\text { Cluster } \\
4046970 \text { Protein of } \\
\text { unknown function } \\
\text { (DUF1307)/YehR- } \\
\text { like }\end{array}$ \\
\hline 23 & $\begin{array}{l}\text { WP_04881449 } \\
7.1\end{array}$ & $\begin{array}{l}\text { Leucine Rich } \\
\text { repeats }\end{array}$ & $\begin{array}{l}\text { LRR-containing } \\
\text { bacterial E3 ligase }\end{array}$ & $\begin{array}{l}\text { leucine rich repeat } \\
\text { protein/E3 ligase } \\
\text { domain }\end{array}$ & $\begin{array}{l}\text { Leucine Rich } \\
\text { repeats }\end{array}$ & $\begin{array}{l}\text { Cluster } 4154032 \\
\text { Protein binding }\end{array}$ \\
\hline 24 & $\begin{array}{l}\text { WP_00030105 } \\
4.1\end{array}$ & $\begin{array}{l}\text { Lipopolysaccharide } \\
\text { kinase (Kdo/WaaP) }\end{array}$ & $\begin{array}{l}\text { Lipopolysaccharide } \\
\text { kinase }\end{array}$ & $\begin{array}{l}\text { Lipopolysaccharide } \\
\text { kinase (Kdo/WaaP) }\end{array}$ & $\begin{array}{l}\text { Lipopolysacchari } \\
\text { de kinase } \\
(\mathrm{Kdo} / \mathrm{WaaP})\end{array}$ & $\begin{array}{l}\text { Cluster } 3990101 \\
\text { Lipopolysaccharide } \\
\text { kinase }\end{array}$ \\
\hline 25 & $\begin{array}{l}\text { WP_00026617 } \\
1.1\end{array}$ & $\begin{array}{l}\text { Tetratricopeptide } \\
\text { repeat }\end{array}$ & $\begin{array}{l}\text { Tetratricopeptide- } \\
\text { like domain }\end{array}$ & $\begin{array}{l}\text { TPR repeat-containing } \\
\text { protein }\end{array}$ & TPR-like & $\begin{array}{l}\text { Cluster } 4040666 \\
\text { Tetratricopeptide } \\
\text { region }\end{array}$ \\
\hline 26 & $\begin{array}{l}\text { WP_00058982 } \\
5.1\end{array}$ & OmpA family & OmpA-like domain & $\begin{array}{l}\text { outer membrane } \\
\text { lipoprotein }\end{array}$ & OmpA-like & $\begin{array}{l}\text { Cluster } 4198784 \\
\text { Outer membrane } \\
\text { protein }\end{array}$ \\
\hline 27 & $\begin{array}{l}\text { WP_00505168 } \\
5.1\end{array}$ & $\begin{array}{l}\text { Peptidase family } \\
\text { M23/LysM domain }\end{array}$ & $\begin{array}{l}\text { Peptidase } \\
\text { M23/LysM domain }\end{array}$ & Peptidase M23 & $\begin{array}{l}\text { Peptidoglycan } \\
\text { hydrolase LytM }\end{array}$ & $\begin{array}{l}\text { Cluster } 4141397 \\
\text { Peptidase M23B }\end{array}$ \\
\hline 28 & $\begin{array}{l}\text { WP_00138723 } \\
8.1\end{array}$ & $\begin{array}{l}\text { RadC-like JAB } \\
\text { domain }\end{array}$ & RadC protein & $\begin{array}{l}\text { DNA repair protein } \\
\text { RadC }\end{array}$ & $\begin{array}{l}\text { JAB1/MPN } \\
\text { domain }\end{array}$ & $\begin{array}{l}\text { Cluster } 4114260 \\
\text { RadC protein }\end{array}$ \\
\hline 29 & $\begin{array}{l}\text { WP_00024809 } \\
7.1\end{array}$ & $\begin{array}{l}\text { Phosphopantetheine } \\
\text { attachment site }\end{array}$ & $\begin{array}{l}\text { Phosphopantetheine } \\
\text { binding ACP }\end{array}$ & Acyl carrier protein & $\begin{array}{l}\text { Acyl-carrier } \\
\text { protein }(\mathrm{ACP})\end{array}$ & $\begin{array}{l}\text { Cluster } 4146821 \\
\text { Phosphopantetheine }\end{array}$ \\
\hline
\end{tabular}




\begin{tabular}{|c|c|c|c|c|c|c|}
\hline & & & & & & -binding \\
\hline 30 & $\begin{array}{l}\text { WP_00084852 } \\
8.1\end{array}$ & $\begin{array}{l}\text { Lipoprotein } \\
\text { leucine-zipper }\end{array}$ & Murein-lipoprotein & $\begin{array}{l}\text { Major outer membrane } \\
\text { lipoprotein }\end{array}$ & $\begin{array}{l}\text { Outer membrane } \\
\text { lipoprotein }\end{array}$ & $\begin{array}{l}\text { Cluster } 4066376 \\
\text { Murein-lipoprotein }\end{array}$ \\
\hline 31 & $\begin{array}{l}\text { WP_00018931 } \\
4.1\end{array}$ & $\begin{array}{l}\text { GIY-YIG catalytic } \\
\text { domain }\end{array}$ & $\begin{array}{l}\text { GIY-YIG } \\
\text { endonuclease }\end{array}$ & No hit & $\begin{array}{l}\text { GIY-YIG } \\
\text { endonuclease }\end{array}$ & $\begin{array}{l}\text { Cluster } 4157077 \\
\text { GIY-YIG } \\
\text { endonuclease }\end{array}$ \\
\hline 32 & $\begin{array}{l}\text { WP_00129737 } \\
5.1\end{array}$ & $\begin{array}{l}\text { RadC-like JAB } \\
\text { domain }\end{array}$ & $\begin{array}{l}\text { RadC-like JAB } \\
\text { domain }\end{array}$ & $\begin{array}{l}\text { DNA repair protein } \\
\text { RadC }\end{array}$ & $\begin{array}{l}\text { RuvA domain 2- } \\
\text { like/JAB1/MPN } \\
\text { domain }\end{array}$ & $\begin{array}{l}\text { Cluster } 4403730 \\
\text { RadC-like JAB } \\
\text { domain }\end{array}$ \\
\hline 33 & $\begin{array}{l}\text { WP_00085819 } \\
3.1\end{array}$ & $\begin{array}{l}\text { yiaA/B two helix } \\
\text { domain }\end{array}$ & YiaAB two helix & No hit & No result & $\begin{array}{l}\text { Cluster } 4440457 \\
\text { YiaAB two helix }\end{array}$ \\
\hline 34 & $\begin{array}{l}\text { WP_00129679 } \\
1.1\end{array}$ & $\begin{array}{l}\text { Autotransporter } \\
\text { beta-domain }\end{array}$ & $\begin{array}{l}\text { Autotransporter, } \\
\text { YhjY }\end{array}$ & No hit & Autotransporter & $\begin{array}{l}\text { Cluster } 3853611 \\
\text { Autotransporter, } \\
\text { YhjY }\end{array}$ \\
\hline 35 & $\begin{array}{l}\text { WP_00077879 } \\
5.1\end{array}$ & $\begin{array}{l}\text { Acetyltransferase } \\
\text { (GNAT) domain }\end{array}$ & $\begin{array}{l}\text { Acyl-CoA N- } \\
\text { acyltransferase }\end{array}$ & $\begin{array}{l}\text { Putative } \mathrm{N}- \\
\text { acetyltransferase }\end{array}$ & $\begin{array}{l}\text { Acyl-CoA N- } \\
\text { acyltransferases } \\
\text { (Nat) }\end{array}$ & $\begin{array}{l}\text { Cluster } 4355736 \\
\text { N-acetyltransferase } \\
\text { activity }\end{array}$ \\
\hline 36 & $\begin{array}{l}\text { WP_00120524 } \\
3.1\end{array}$ & $\begin{array}{l}\text { Xylose isomerase- } \\
\text { like TIM barrel }\end{array}$ & $\begin{array}{l}\text { Xylose isomerase- } \\
\text { like TIM barrel }\end{array}$ & $\begin{array}{l}\text { Putative } \\
\text { hydroxypyruvate } \\
\text { isomerase }\end{array}$ & $\begin{array}{l}\text { Xylose } \\
\text { isomerase-like }\end{array}$ & $\begin{array}{l}\text { Cluster } 4100779 \\
\text { Xylose isomerase- } \\
\text { type TIM barrel }\end{array}$ \\
\hline 37 & $\begin{array}{l}\text { WP_00123836 } \\
2.1\end{array}$ & $\begin{array}{l}\text { Lipocalin-like } \\
\text { domain }\end{array}$ & $\begin{array}{l}\text { Lipocalin, ApoD } \\
\text { type }\end{array}$ & $\begin{array}{l}\text { Outer membrane } \\
\text { lipoprotein Blc }\end{array}$ & Lipocalins & $\begin{array}{l}\text { Cluster } 4145424 \\
\text { Lipocalin }\end{array}$ \\
\hline 38 & $\begin{array}{l}\text { WP_00094398 } \\
0.1\end{array}$ & $\begin{array}{l}\text { Glutathionylspermi } \\
\text { dine synthase } \\
\text { preATP-grasp }\end{array}$ & $\begin{array}{l}\text { Glutathionylspermi } \\
\text { dine synthase, pre- } \\
\text { ATP-grasp }\end{array}$ & No hit & $\begin{array}{l}\text { Glutathione } \\
\text { synthetase ATP- } \\
\text { binding domain- } \\
\text { like }\end{array}$ & $\begin{array}{l}\text { Cluster } 4243753 \\
\text { Glutathionylspermi } \\
\text { dine synthase }\end{array}$ \\
\hline 39 & $\begin{array}{l}\text { WP_00013264 } \\
0.1\end{array}$ & $\begin{array}{l}\text { Toxin SymE, type I } \\
\text { toxin-antitoxin } \\
\text { system }\end{array}$ & $\begin{array}{l}\text { Type I toxin- } \\
\text { antitoxin system, } \\
\text { SymE toxin }\end{array}$ & No hit & No result & $\begin{array}{l}\text { Cluster } 4040297 \\
\text { Toxin SymE-like }\end{array}$ \\
\hline
\end{tabular}


Supplementary Table 6. List of annotated functions of 25 proteins with known function from Shigella flexneri using BLAST, Pfam, HmmScan, SMART, and Scanprosite for receiver operating characteristic analysis

\begin{tabular}{|c|c|c|c|c|c|c|c|}
\hline $\begin{array}{l}\text { SI } \\
\text { no }\end{array}$ & Acc ID protein & $\begin{array}{l}\text { Protein } \\
\text { name }\end{array}$ & BLAST & Pfam & HmmScan & SMART & Scanprosite \\
\hline 1 & $\begin{array}{l}\text { WP_000241642. } \\
1\end{array}$ & $\begin{array}{l}\text { Homoserine } \\
\text { kinase }\end{array}$ & $\begin{array}{l}\text { Homoserine } \\
\text { kinase } 1(5)\end{array}$ & $\begin{array}{l}\text { Homoserine } \\
\text { kinase } 1(5)\end{array}$ & $\begin{array}{l}\text { Homoserine } \\
\text { kinase } 1(5)\end{array}$ & $\begin{array}{l}\text { Homoserine } \\
\text { kinase } 1(5)\end{array}$ & Homoserine kinase 1 (5) \\
\hline 2 & $\begin{array}{l}\text { WP_000809168. } \\
1\end{array}$ & Protein hokC & $\begin{array}{l}\text { Protein hokC } \\
1(5)\end{array}$ & $\begin{array}{l}\text { Protein hokC } \\
1(5)\end{array}$ & $\begin{array}{l}\text { Protein hokC } \\
1(5)\end{array}$ & $\begin{array}{l}\text { Protein hokC } \\
1(5)\end{array}$ & Protein hokC 1 (5) \\
\hline 3 & $\begin{array}{l}\text { WP_001286897. } \\
1\end{array}$ & $\begin{array}{l}\text { Isoleucine-- } \\
\text { tRNA ligase }\end{array}$ & $\begin{array}{l}\text { Isoleucine-- } \\
\text { tRNA ligase } \\
1(5)\end{array}$ & $\begin{array}{l}\text { Isoleucine-- } \\
\text { tRNA ligase } \\
1(5)\end{array}$ & $\begin{array}{l}\text { Isoleucine-- } \\
\text { tRNA ligase } \\
1(5)\end{array}$ & $\begin{array}{l}\text { Isoleucine-- } \\
\text { tRNA ligase } \\
1(5)\end{array}$ & $\begin{array}{l}\text { Isoleucine--tRNA ligase } 1 \\
\text { (5) }\end{array}$ \\
\hline 4 & $\begin{array}{l}\text { WP_000124415. } \\
1\end{array}$ & $\begin{array}{l}\text { Ferrichrome } \\
\text { porin FhuA }\end{array}$ & $\begin{array}{l}\text { Ferrichrome } \\
\text { outer } \\
\text { membrane } \\
\text { transporter } 1 \\
\text { (4) }\end{array}$ & $\begin{array}{l}\text { TonB } \\
\text { dependent } \\
\text { receptor } 0(2)\end{array}$ & $\begin{array}{l}\text { TonB } \\
\text { dependent } \\
\text { receptor } 0(2)\end{array}$ & $\begin{array}{l}\text { TonB } \\
\text { dependent } \\
\text { receptor } 0(2)\end{array}$ & $\begin{array}{l}\text { TonB dependent receptor } 0 \\
\text { (2) }\end{array}$ \\
\hline 5 & $\begin{array}{l}\text { WP_001183183. } \\
1\end{array}$ & $\begin{array}{l}\text { MFS } \\
\text { transporter }\end{array}$ & $\begin{array}{l}\text { MFS } \\
\text { transporter } 1 \\
\text { (5) }\end{array}$ & $\begin{array}{l}\text { MFS } \\
\text { transporter } 1 \\
\text { (5) }\end{array}$ & $\begin{array}{l}\text { MFS } \\
\text { transporter } 1 \\
\text { (5) }\end{array}$ & $\begin{array}{l}\text { MFS } \\
\text { transporter } 1 \\
\text { (5) }\end{array}$ & MFS transporter $1(5)$ \\
\hline 6 & $\begin{array}{l}\text { WP_001230481. } \\
1\end{array}$ & $\begin{array}{l}\text { Ail/Lom } \\
\text { family protein }\end{array}$ & $\begin{array}{l}\text { OM_channels } \\
\text { super family } \\
1 \text { (3) }\end{array}$ & $\begin{array}{l}\text { Ail/Lom } \\
\text { protein } 1(5)\end{array}$ & $\begin{array}{l}\text { Ail/Lom } \\
\text { protein } 1(5)\end{array}$ & $\begin{array}{l}\text { Ail/Lom } \\
\text { protein } 1(5)\end{array}$ & $\begin{array}{l}\text { Virulence outer membrane } \\
\text { protein } 1(3)\end{array}$ \\
\hline 7 & $\begin{array}{l}\text { WP_001287126. } \\
1\end{array}$ & $\begin{array}{l}\text { Glutamine-- } \\
\text { tRNA ligase }\end{array}$ & $\begin{array}{l}\text { Glutaminyl- } \\
\text { tRNA } \\
\text { synthetase } 1 \\
\text { (5) }\end{array}$ & $\begin{array}{l}\text { tRNA } \\
\text { synthetases } 1 \\
\text { (5) }\end{array}$ & $\begin{array}{l}\text { tRNA } \\
\text { synthetases } 1 \\
\text { (5) }\end{array}$ & $\begin{array}{l}\text { tRNA } \\
\text { synthetases } 1 \\
\text { (5) }\end{array}$ & $\begin{array}{l}\text { Aminoacyl-transfer RNA } \\
\text { synthetases } 1(5)\end{array}$ \\
\hline 8 & $\begin{array}{l}\text { WP_001295442 } \\
.1\end{array}$ & $\begin{array}{l}\text { Flagellar L- } \\
\text { ring protein }\end{array}$ & $\begin{array}{l}\text { Flagellar } \\
\text { basal body L- }\end{array}$ & $\begin{array}{l}\text { Flagellar L- } \\
\text { ring protein } 1\end{array}$ & $\begin{array}{l}\text { Flagellar L- } \\
\text { ring protein } 1\end{array}$ & $\begin{array}{l}\text { Flagellar L- } \\
\text { ring protein } 1\end{array}$ & $\begin{array}{l}\text { PROKAR_LIPOPROTEI } \\
\text { N } 0 \text { (3) }\end{array}$ \\
\hline
\end{tabular}




\begin{tabular}{|c|c|c|c|c|c|c|c|}
\hline & & & $\begin{array}{l}\text { ring protein } 1 \\
\text { (4) }\end{array}$ & (5) & (5) & (5) & \\
\hline 9 & $\begin{array}{l}\text { WP_000130034. } \\
1\end{array}$ & $\begin{array}{l}\text { D-alanine--D- } \\
\text { alanine ligase }\end{array}$ & $\begin{array}{l}\text { D-alanine--D- } \\
\text { alanine ligase } \\
1(5)\end{array}$ & $\begin{array}{l}\text { D-alanine--D- } \\
\text { alanine ligase } \\
1 \text { (5) }\end{array}$ & $\begin{array}{l}\text { D-alanine--D- } \\
\text { alanine ligase } \\
1(5)\end{array}$ & $\begin{array}{l}\text { D-alanine--D- } \\
\text { alanine ligase } \\
1(5)\end{array}$ & $\begin{array}{l}\text { D-alanine--D-alanine } \\
\text { ligase } 1(5)\end{array}$ \\
\hline 10 & $\begin{array}{l}\text { WP_000197853. } \\
1\end{array}$ & $\begin{array}{l}\text { Alanine } \\
\text { racemase }\end{array}$ & $\begin{array}{l}\text { Alanine } \\
\text { racemase } 1 \\
(5)\end{array}$ & $\begin{array}{l}\text { Alanine } \\
\text { racemase } 1 \\
(5)\end{array}$ & $\begin{array}{l}\text { Alanine } \\
\text { racemase } 1 \\
(5)\end{array}$ & $\begin{array}{l}\text { Alanine } \\
\text { racemase } 1 \\
\text { (5) }\end{array}$ & Alanine racemase 1 (5) \\
\hline 11 & $\begin{array}{l}\text { WP_000569431. } \\
1\end{array}$ & $\begin{array}{l}\text { Ribonuclease } \\
\text { HII }\end{array}$ & $\begin{array}{l}\text { Ribonuclease } \\
\text { HII } 1 \text { (5) }\end{array}$ & $\begin{array}{l}\text { Ribonuclease } \\
\text { HII } 1 \text { (5) }\end{array}$ & $\begin{array}{l}\text { Ribonuclease } \\
\text { HII } 1 \text { (5) }\end{array}$ & $\begin{array}{l}\text { Ribonuclease } \\
\text { HII } 1 \text { (5) }\end{array}$ & No hit $0(5)$ \\
\hline 12 & $\begin{array}{l}\text { WP_000901098. } \\
1\end{array}$ & $\begin{array}{l}\text { VOC family } \\
\text { protein }\end{array}$ & $\begin{array}{l}\text { VOC family } \\
\text { protein } 1(5)\end{array}$ & $\begin{array}{l}\text { VOC family } \\
\text { protein } 1(5)\end{array}$ & $\begin{array}{l}\text { VOC family } \\
\text { protein } 1(5)\end{array}$ & $\begin{array}{l}\text { VOC family } \\
\text { protein } 1(5)\end{array}$ & VOC family protein 1 (5) \\
\hline 13 & $\begin{array}{l}\text { WP_001260712. } \\
1\end{array}$ & $\begin{array}{l}\text { Proline-- } \\
\text { tRNA ligase }\end{array}$ & $\begin{array}{l}\text { Proline-- } \\
\text { tRNA ligase } \\
1(5)\end{array}$ & $\begin{array}{l}\text { Proline-- } \\
\text { tRNA ligase } \\
1(5)\end{array}$ & $\begin{array}{l}\text { Proline-- } \\
\text { tRNA ligase } \\
1(5)\end{array}$ & $\begin{array}{l}\text { Proline-- } \\
\text { tRNA ligase } \\
1(5)\end{array}$ & Proline--tRNA ligase 1 (5) \\
\hline 14 & $\begin{array}{l}\text { WP_000051892. } \\
1\end{array}$ & Integrase & $\begin{array}{l}\text { Integrase } 1 \\
\text { (5) }\end{array}$ & $\begin{array}{l}\text { Integrase } 1 \\
\text { (5) }\end{array}$ & $\begin{array}{l}\text { Integrase } 1 \\
(5)\end{array}$ & $\begin{array}{l}\text { Integrase } 1 \\
\text { (5) }\end{array}$ & No hit $0(5)$ \\
\hline 15 & $\begin{array}{l}\text { WP_001120449. } \\
1\end{array}$ & $\begin{array}{l}\text { Oxidoreducta } \\
\text { se }\end{array}$ & $\begin{array}{l}\text { Oxidoreducta } \\
\text { se } 1(5)\end{array}$ & $\begin{array}{l}\text { Oxidoreducta } \\
\text { se } 1(5)\end{array}$ & $\begin{array}{l}\text { Oxidoreducta } \\
\text { se } 1(5)\end{array}$ & $\begin{array}{l}\text { Oxidoreducta } \\
\text { se } 1(5)\end{array}$ & Oxidoreductase 1 (5) \\
\hline 16 & $\begin{array}{l}\text { WP_000460136. } \\
1\end{array}$ & $\begin{array}{l}\text { LysR family } \\
\text { transcriptiona } \\
1 \text { regulator }\end{array}$ & $\begin{array}{l}\text { LysR family } \\
\text { transcriptiona } \\
1 \text { regulator } 1 \\
\text { (5) }\end{array}$ & $\begin{array}{l}\text { LysR family } \\
\text { transcriptiona } \\
1 \text { regulator } 1 \\
\text { (5) }\end{array}$ & $\begin{array}{l}\text { LysR family } \\
\text { transcriptiona } \\
1 \text { regulator } 1 \\
(5) \\
\end{array}$ & $\begin{array}{l}\text { LysR family } \\
\text { transcriptiona } \\
1 \text { regulator } 1 \\
\text { (5) }\end{array}$ & $\begin{array}{l}\text { LysR family } \\
\text { transcriptional regulator } 1 \\
\text { (5) }\end{array}$ \\
\hline 17 & $\begin{array}{l}\text { WP_001018618. } \\
1\end{array}$ & Flavodoxin-1 & $\begin{array}{l}\text { Flavodoxin-1 } \\
1(5)\end{array}$ & $\begin{array}{l}\text { Flavodoxin-1 } \\
1(5)\end{array}$ & $\begin{array}{l}\text { Flavodoxin-1 } \\
1(5)\end{array}$ & $\begin{array}{l}\text { Flavodoxin-1 } \\
1(5)\end{array}$ & Flavodoxin-1 1 (5) \\
\hline 18 & $\begin{array}{l}\text { WP_000773301. } \\
1\end{array}$ & $\begin{array}{l}\text { Acyl-CoA } \\
\text { esterase }\end{array}$ & $\begin{array}{l}\text { Acyl-CoA } \\
\text { esterase } 1(5)\end{array}$ & $\begin{array}{l}\text { Acyl-CoA } \\
\text { esterase } 1(5)\end{array}$ & $\begin{array}{l}\text { Acyl-CoA } \\
\text { esterase } 1(5)\end{array}$ & $\begin{array}{l}\text { Acyl-CoA } \\
\text { esterase } 1(5)\end{array}$ & No hit $0(5)$ \\
\hline 19 & $\begin{array}{l}\text { WP_000201488. } \\
1\end{array}$ & $\begin{array}{l}\text { DNA- } \\
\text { packaging }\end{array}$ & $\begin{array}{l}\text { DNA- } \\
\text { packaging }\end{array}$ & $\begin{array}{l}\text { DNA- } \\
\text { packaging }\end{array}$ & $\begin{array}{l}\text { DNA- } \\
\text { packaging }\end{array}$ & $\begin{array}{l}\text { DNA- } \\
\text { packaging }\end{array}$ & No hit $0(5)$ \\
\hline
\end{tabular}




\begin{tabular}{|c|c|c|c|c|c|c|c|}
\hline & & protein FI & $\begin{array}{l}\text { protein FI } 1 \\
(5)\end{array}$ & $\begin{array}{l}\text { protein FI } 1 \\
(5)\end{array}$ & $\begin{array}{l}\text { protein FI } 1 \\
(5)\end{array}$ & $\begin{array}{l}\text { protein FI } 1 \\
(5)\end{array}$ & \\
\hline 20 & $\begin{array}{l}\text { WP_005049594. } \\
1\end{array}$ & Terminase & $\begin{array}{l}\text { Terminase } 1 \\
(5)\end{array}$ & $\begin{array}{l}\text { Terminase } 1 \\
(5)\end{array}$ & $\begin{array}{l}\text { Terminase } 1 \\
(5)\end{array}$ & $\begin{array}{l}\text { Terminase } 1 \\
(5)\end{array}$ & No hit $0(5)$ \\
\hline 21 & $\begin{array}{l}\text { WP_000537402. } \\
1\end{array}$ & $\begin{array}{l}\text { Thioredoxin- } \\
\text { disulfide } \\
\text { reductase }\end{array}$ & $\begin{array}{l}\text { Thioredoxin- } \\
\text { disulfide } \\
\text { reductase } 1 \\
\text { (5) }\end{array}$ & $\begin{array}{l}\text { Thioredoxin- } \\
\text { disulfide } \\
\text { reductase } 1 \\
\text { (5) }\end{array}$ & $\begin{array}{l}\text { Thioredoxin- } \\
\text { disulfide } \\
\text { reductase } 1 \\
\text { (5) }\end{array}$ & $\begin{array}{l}\text { Thioredoxin- } \\
\text { disulfide } \\
\text { reductase } 1 \\
\text { (5) }\end{array}$ & $\begin{array}{l}\text { Thioredoxin-disulfide } \\
\text { reductase } 1(5)\end{array}$ \\
\hline 22 & $\begin{array}{l}\text { WP_000109301. } \\
1\end{array}$ & $\begin{array}{l}\text { MFS } \\
\text { transporter }\end{array}$ & $\begin{array}{l}\text { MFS } \\
\text { transporter } 1 \\
(5)\end{array}$ & $\begin{array}{l}\text { MFS } \\
\text { transporter } 1 \\
(5)\end{array}$ & $\begin{array}{l}\text { MFS } \\
\text { transporter } 1 \\
(5)\end{array}$ & $\begin{array}{l}\text { MFS } \\
\text { transporter } 1 \\
(5)\end{array}$ & MFS transporter $1(5)$ \\
\hline 23 & $\begin{array}{l}\text { WP_005047463. } \\
1\end{array}$ & Porin OmpA & $\begin{array}{l}\text { Porin OmpA } \\
1(5)\end{array}$ & $\begin{array}{l}\text { Porin OmpA } \\
1(5)\end{array}$ & $\begin{array}{l}\text { Porin OmpA } \\
1(5)\end{array}$ & $\begin{array}{l}\text { Porin OmpA } \\
1(5)\end{array}$ & Porin OmpA 1 (5) \\
\hline 24 & $\begin{array}{l}\text { WP_001247604. } \\
1\end{array}$ & $\begin{array}{l}\text { YjbF family } \\
\text { lipoprotein }\end{array}$ & $\begin{array}{l}\text { YjbF family } \\
\text { lipoprotein } 1 \\
\text { (5) }\end{array}$ & $\begin{array}{l}\text { YjbF family } \\
\text { lipoprotein } 1 \\
\text { (5) }\end{array}$ & $\begin{array}{l}\text { YjbF family } \\
\text { lipoprotein } 1 \\
\text { (5) }\end{array}$ & $\begin{array}{l}\text { YjbF family } \\
\text { lipoprotein } 1 \\
(5)\end{array}$ & $\begin{array}{l}\text { YjbF family lipoprotein } 1 \\
\text { (5) }\end{array}$ \\
\hline 25 & $\begin{array}{l}\text { WP_014532269. } \\
1\end{array}$ & $\begin{array}{l}\text { DUF333 } \\
\text { domain- } \\
\text { containing } \\
\text { protein }\end{array}$ & $\begin{array}{l}\text { Domain of } \\
\text { unknown } \\
\text { function } \\
\text { (DUF333) } 1 \\
\text { (5) }\end{array}$ & $\begin{array}{l}\text { Domain of } \\
\text { unknown } \\
\text { function } \\
\text { (DUF333) } 1 \\
\text { (5) }\end{array}$ & $\begin{array}{l}\text { Domain of } \\
\text { unknown } \\
\text { function } \\
\text { (DUF333) } 1 \\
\text { (5) }\end{array}$ & $\begin{array}{l}\text { Domain of } \\
\text { unknown } \\
\text { function } \\
\text { (DUF333) } 1 \\
\text { (5) }\end{array}$ & $\begin{array}{l}\text { PROKAR_LIPOPROTEI } \\
\text { N } 0 \text { (3) }\end{array}$ \\
\hline
\end{tabular}

True positive and true negative are denoted by " 1 " and " 0 ".

Integers in parentheses denote the confidence level. 
Supplementary Table 7. List of annotated functions of 25 proteins with known function from Shigella flexneri using MOTIF, Interproscan, CATH, SUPERFAMILY, and ProtoNet for receiver operating characteristic analysis

\begin{tabular}{|c|c|c|c|c|c|c|c|}
\hline $\begin{array}{l}\text { Sl } \\
\text { No } \\
.\end{array}$ & Acc ID protein & Protein name & MOTIF & $\begin{array}{l}\text { INTERPROSCA } \\
\mathbf{N}\end{array}$ & CATH & $\begin{array}{l}\text { SUPERFAMIL } \\
\text { Y }\end{array}$ & ProtoNet \\
\hline 1 & $\begin{array}{l}\text { WP_000241642. } \\
1\end{array}$ & $\begin{array}{l}\text { Homoserine } \\
\text { kinase }\end{array}$ & $\begin{array}{l}\text { Homoserine } \\
\text { kinase } 1(5)\end{array}$ & $\begin{array}{l}\text { Homoserine kinase } \\
1(5)\end{array}$ & $\begin{array}{l}\text { Homoserine } \\
\text { kinase } 1(5)\end{array}$ & $\begin{array}{l}\text { Homoserine } \\
\text { kinase } 1(5)\end{array}$ & $\begin{array}{l}\text { Homoserine } \\
\text { kinase } 1(5)\end{array}$ \\
\hline 2 & $\begin{array}{l}\text { WP_000809168. } \\
1\end{array}$ & Protein hokC & hok_gef 1 (3) & hok_gef $1(3)$ & $0(5)$ & hok_gef 0 (5) & hok_gef 1 (3) \\
\hline 3 & $\begin{array}{l}\text { WP_001286897. } \\
1\end{array}$ & $\begin{array}{l}\text { Isoleucine-- } \\
\text { tRNA ligase }\end{array}$ & $\begin{array}{l}\text { Isoleucine-- } \\
\text { tRNA ligase } 1 \\
(5)\end{array}$ & $\begin{array}{l}\text { Isoleucine--tRNA } \\
\text { ligase } 1(5)\end{array}$ & $\begin{array}{l}\text { Isoleucine-- } \\
\text { tRNA ligase } 1 \\
(5)\end{array}$ & $\begin{array}{l}\text { Isoleucine-- } \\
\text { tRNA ligase } 1 \\
(5)\end{array}$ & $\begin{array}{l}\text { Isoleucine-- } \\
\text { tRNA ligase } 1 \\
\text { (5) }\end{array}$ \\
\hline 4 & $\begin{array}{l}\text { WP_000124415. } \\
1\end{array}$ & $\begin{array}{l}\text { Ferrichrome } \\
\text { porin FhuA }\end{array}$ & $\begin{array}{l}\text { TonB- } \\
\text { dependent } \\
\text { Receptor } 0 \text { (2) }\end{array}$ & $\begin{array}{l}\text { TonB-dependent } \\
\text { siderophore } \\
\text { receptor } 0(2)\end{array}$ & $\begin{array}{l}\text { TonB- } \\
\text { dependent } \\
\text { siderophore } \\
\text { receptor } 0(2)\end{array}$ & $\begin{array}{l}\text { TonB-dependent } \\
\text { siderophore } \\
\text { receptor } 0(2)\end{array}$ & $\begin{array}{l}\text { TonB- } \\
\text { dependent } \\
\text { siderophore } \\
\text { receptor } 0 \text { (2) }\end{array}$ \\
\hline 5 & $\begin{array}{l}\text { WP_001183183. } \\
1\end{array}$ & $\begin{array}{l}\text { MFS } \\
\text { transporter }\end{array}$ & $\begin{array}{l}\text { MFS } \\
\text { transporter } 1 \\
(5)\end{array}$ & $\begin{array}{l}\text { MFS transporter } 1 \\
\text { (5) }\end{array}$ & $\begin{array}{l}\text { MFS } \\
\text { transporter } 1 \\
(5)\end{array}$ & $\begin{array}{l}\text { MFS transporter } \\
1(5)\end{array}$ & $\begin{array}{l}\text { MFS } \\
\text { transporter } 1 \\
\text { (5) }\end{array}$ \\
\hline 6 & $\begin{array}{l}\text { WP_001230481. } \\
1\end{array}$ & $\begin{array}{l}\text { Ail/Lom } \\
\text { family protein }\end{array}$ & $\begin{array}{l}\text { Ail/Lom family } \\
\text { protein } 1(5)\end{array}$ & $\begin{array}{l}\text { Ail/Lom family } \\
\text { protein } 1(5)\end{array}$ & $\begin{array}{l}\text { Ail/Lom } \\
\text { family protein } \\
1(5)\end{array}$ & $\begin{array}{l}\text { Ail/Lom family } \\
\text { protein } 1(5)\end{array}$ & $\begin{array}{l}\text { Ail/Lom } \\
\text { family protein } \\
1(5)\end{array}$ \\
\hline 7 & $\begin{array}{l}\text { WP_001287126. } \\
1\end{array}$ & $\begin{array}{l}\text { Glutamine-- } \\
\text { tRNA ligase }\end{array}$ & $\begin{array}{l}\text { Glutamine-- } \\
\text { tRNA ligase } 1 \\
(5)\end{array}$ & $\begin{array}{l}\text { Glutamine--tRNA } \\
\text { ligase } 1(5)\end{array}$ & $\begin{array}{l}\text { Glutamine-- } \\
\text { tRNA ligase } 1 \\
(5)\end{array}$ & $\begin{array}{l}\text { Glutamine-- } \\
\text { tRNA ligase } 1 \\
(5)\end{array}$ & $\begin{array}{l}\text { Glutamine-- } \\
\text { tRNA ligase } 1 \\
\text { (5) }\end{array}$ \\
\hline 8 & ${ }_{1}^{\text {WP_}} 001295442$. & $\begin{array}{l}\text { Flagellar L- } \\
\text { ring protein }\end{array}$ & $\begin{array}{l}\text { Flagellar L- } \\
\text { ring protein } 1 \\
\text { (5) }\end{array}$ & $\begin{array}{l}\text { Flagellar L-ring } \\
\text { protein } 1(5)\end{array}$ & $0(5)$ & $\begin{array}{l}\text { Flagellar L-ring } \\
\text { protein } 0(5)\end{array}$ & $\begin{array}{l}\text { Flagellar L- } \\
\text { ring protein } 1 \\
(5)\end{array}$ \\
\hline
\end{tabular}




\begin{tabular}{|c|c|c|c|c|c|c|c|}
\hline 9 & $\begin{array}{l}\text { WP_000130034. } \\
1\end{array}$ & $\begin{array}{l}\text { D-alanine--D- } \\
\text { alanine ligase }\end{array}$ & $\begin{array}{l}\text { D-alanine--D- } \\
\text { alanine ligase } 1 \\
\text { (5) }\end{array}$ & $\begin{array}{l}\text { D-alanine--D- } \\
\text { alanine ligase } 1 \text { (5) }\end{array}$ & $\begin{array}{l}\text { D-alanine--D- } \\
\text { alanine ligase } \\
1(5)\end{array}$ & $\begin{array}{l}\text { D-alanine--D- } \\
\text { alanine ligase } 1 \\
\text { (5) }\end{array}$ & $\begin{array}{l}\text { D-alanine--D- } \\
\text { alanine ligase } \\
1(5)\end{array}$ \\
\hline 10 & $\begin{array}{l}\text { WP_000197853. } \\
1\end{array}$ & $\begin{array}{l}\text { Alanine } \\
\text { racemase }\end{array}$ & $\begin{array}{l}\text { Alanine } \\
\text { racemase } 1(5)\end{array}$ & $\begin{array}{l}\text { Alanine } \\
\text { racemase } 1(5)\end{array}$ & $\begin{array}{l}\text { Alanine } \\
\text { racemase } 1 \\
(5)\end{array}$ & $\begin{array}{l}\text { Alanine } \\
\text { racemase } 1(5)\end{array}$ & $\begin{array}{l}\text { Alanine } \\
\text { racemase } 1 \\
(5)\end{array}$ \\
\hline 11 & $\begin{array}{l}\text { WP_000569431. } \\
1\end{array}$ & $\begin{array}{l}\text { Ribonuclease } \\
\text { HII }\end{array}$ & $\begin{array}{l}\text { Ribonuclease } \\
\text { HII } 1 \text { (5) }\end{array}$ & $\begin{array}{l}\text { Ribonuclease HII } 1 \\
\text { (5) }\end{array}$ & $\begin{array}{l}\text { Ribonuclease } \\
\text { HII } 1 \text { (5) }\end{array}$ & $\begin{array}{l}\text { Ribonuclease } \\
\text { HII } 1 \text { (5 }\end{array}$ & $\begin{array}{l}\text { Ribonuclease } \\
\text { HII } 1 \text { (5) }\end{array}$ \\
\hline 12 & $\begin{array}{l}\text { WP_000901098. } \\
1\end{array}$ & $\begin{array}{l}\text { VOC family } \\
\text { protein }\end{array}$ & $\begin{array}{l}\text { VOC family } \\
\text { protein } 1(5)\end{array}$ & $\begin{array}{l}\text { VOC family } \\
\text { protein } 1(5)\end{array}$ & $\begin{array}{l}\text { VOC family } \\
\text { protein } 1(5)\end{array}$ & $\begin{array}{l}\text { VOC family } \\
\text { protein } 1(5)\end{array}$ & $\begin{array}{l}\text { VOC family } \\
\text { protein } 1(5)\end{array}$ \\
\hline 13 & $\begin{array}{l}\text { WP_001260712. } \\
1\end{array}$ & $\begin{array}{l}\text { Proline--tRNA } \\
\text { ligase }\end{array}$ & $\begin{array}{l}\text { Proline--tRNA } \\
\text { ligase } 1(5)\end{array}$ & $\begin{array}{l}\text { Proline--tRNA } \\
\text { ligase } 1(5)\end{array}$ & $\begin{array}{l}\text { Proline--tRNA } \\
\text { ligase } 1(5)\end{array}$ & $\begin{array}{l}\text { Proline--tRNA } \\
\text { ligase } 1(5)\end{array}$ & $\begin{array}{l}\text { Proline--tRNA } \\
\text { ligase } 1(5)\end{array}$ \\
\hline 14 & $\begin{array}{l}\text { WP_000051892. } \\
1\end{array}$ & Integrase & Integrase 1 (5) & Integrase 1 (5) & Integrase $1(5)$ & Integrase $1(5)$ & Integrase $1(5)$ \\
\hline 15 & $\begin{array}{l}\text { WP_001120449. } \\
1\end{array}$ & $\begin{array}{l}\text { Oxidoreductas } \\
\text { e }\end{array}$ & $\begin{array}{l}\text { Oxidoreductase } \\
1(5)\end{array}$ & $\begin{array}{l}\text { Oxidoreductase } 1 \\
\text { (5) }\end{array}$ & $\begin{array}{l}\text { Oxidoreductas } \\
\text { e } 1(5)\end{array}$ & $\begin{array}{l}\text { Oxidoreductase } \\
1(5)\end{array}$ & $\begin{array}{l}\text { Oxidoreductas } \\
\text { e } 1(5)\end{array}$ \\
\hline 16 & $\begin{array}{l}\text { WP_000460136. } \\
1\end{array}$ & $\begin{array}{l}\text { LysR family } \\
\text { transcriptional } \\
\text { regulator }\end{array}$ & $\begin{array}{l}\text { LysR family } \\
\text { transcriptional } \\
\text { regulator } 1(5)\end{array}$ & $\begin{array}{l}\text { LysR family } \\
\text { transcriptional } \\
\text { regulator } 1(5)\end{array}$ & $\begin{array}{l}\text { LysR family } \\
\text { transcriptional } \\
\text { regulator } 1(5)\end{array}$ & $\begin{array}{l}\text { LysR family } \\
\text { transcriptional } \\
\text { regulator } 1(5)\end{array}$ & $\begin{array}{l}\text { LysR family } \\
\text { transcriptional } \\
\text { regulator } 1(5)\end{array}$ \\
\hline 17 & $\begin{array}{l}\text { WP_001018618. } \\
1\end{array}$ & Flavodoxin-1 & $\begin{array}{l}\text { Flavodoxin_1, } \\
3,4,51 \text { (3) }\end{array}$ & $\begin{array}{l}\text { Flavodoxin, long } \\
\text { chain } 1(3)\end{array}$ & $\begin{array}{l}\text { Short-chain } \\
\text { flavodoxin } \\
\text { YkuP } 1(3) \\
\end{array}$ & $\begin{array}{l}\text { Flavodoxin, long } \\
\text { chain } 1 \text { (3) }\end{array}$ & $\begin{array}{l}\text { Flavodoxin, } \\
\text { long chain } 1 \\
(3)\end{array}$ \\
\hline 18 & $\begin{array}{l}\text { WP_000773301. } \\
1\end{array}$ & $\begin{array}{l}\text { Acyl-CoA } \\
\text { esterase }\end{array}$ & $\begin{array}{l}\text { Alpha/beta } \\
\text { hydrolase fold } \\
1(3)\end{array}$ & $\begin{array}{l}\text { Alpha/beta } \\
\text { hydrolase fold, } \\
\text { alpha/beta } \\
\text { hydrolase fold, } 11 \\
\text { (3) }\end{array}$ & $\begin{array}{l}\text { Esterase YbfF } \\
1(5)\end{array}$ & $\begin{array}{l}\text { Alpha/beta } \\
\text { hydrolase fold, } \\
\text { alpha/beta } \\
\text { hydrolase fold, } 1 \\
\text { (3) }\end{array}$ & $\begin{array}{l}\text { Alpha/beta } \\
\text { hydrolase } \\
\text { fold-1 } 1 \text { (3) }\end{array}$ \\
\hline 19 & $\begin{array}{l}\text { WP_000201488. } \\
1\end{array}$ & $\begin{array}{l}\text { DNA- } \\
\text { packaging }\end{array}$ & $\begin{array}{l}\text { DNA- } \\
\text { packaging }\end{array}$ & $\begin{array}{l}\text { DNA-packaging } \\
\text { protein FI } 1(5)\end{array}$ & $0(5)$ & $\begin{array}{l}\text { DNA-packaging } \\
\text { protein FI } 0(5)\end{array}$ & $\begin{array}{l}\text { DNA- } \\
\text { packaging }\end{array}$ \\
\hline
\end{tabular}




\begin{tabular}{|c|c|c|c|c|c|c|c|}
\hline & & protein FI & protein FI 1 (5) & & & & $\begin{array}{l}\text { protein FI } 1 \\
(5)\end{array}$ \\
\hline 20 & $\begin{array}{l}\text { WP_005049594. } \\
1\end{array}$ & Terminase & $\begin{array}{l}\text { Phage } \\
\text { terminase large } \\
\text { subunit (GpA) } \\
1(3)\end{array}$ & $\begin{array}{l}\text { Bacteriophage } \\
\text { lambda, GpA } 1 \text { (3) }\end{array}$ & $0(5)$ & $\begin{array}{l}\text { Bacteriophage } \\
\text { lambda, GpA } 0 \\
(5)\end{array}$ & $\begin{array}{l}\text { Phage } \\
\text { terminase } \\
\text { GpA } 1 \text { (3) }\end{array}$ \\
\hline 21 & $\begin{array}{l}\text { WP_000537402. } \\
1\end{array}$ & $\begin{array}{l}\text { Thioredoxin- } \\
\text { disulfide } \\
\text { reductase }\end{array}$ & $\begin{array}{l}\text { Pyridine } \\
\text { nucleotide- } \\
\text { disulphide } \\
\text { oxidoreductase } \\
1(3)\end{array}$ & $\begin{array}{l}\text { Pyridine } \\
\text { nucleotide- } \\
\text { disulphide } \\
\text { oxidoreductase, } \\
\text { class-II } 1 \text { (4) }\end{array}$ & $\begin{array}{l}\text { Thioredoxin } \\
\text { reductase } 1 \text { (4) }\end{array}$ & $\begin{array}{l}\text { Pyridine } \\
\text { nucleotide- } \\
\text { disulphide } \\
\text { oxidoreductase, } \\
\text { class-II 1 (3) }\end{array}$ & $\begin{array}{l}\text { Thioredoxin- } \\
\text { disulfide } \\
\text { reductase } 1(5)\end{array}$ \\
\hline 22 & $\begin{array}{l}\text { WP_000109301. } \\
1\end{array}$ & $\begin{array}{l}\text { MFS } \\
\text { transporter }\end{array}$ & $\begin{array}{l}\text { MFS } \\
\text { transporter } 1 \\
(5)\end{array}$ & $\begin{array}{l}\text { MFS transporter } 1 \\
(5)\end{array}$ & $\begin{array}{l}\text { MFS } \\
\text { transporter } 1 \\
(5)\end{array}$ & $\begin{array}{l}\text { MFS transporter } \\
1(5)\end{array}$ & $\begin{array}{l}\text { MFS } \\
\text { transporter } 1 \\
(5)\end{array}$ \\
\hline 23 & $\begin{array}{l}\text { WP_005047463. } \\
1\end{array}$ & Porin OmpA & $\begin{array}{l}\text { Porin OmpA } 1 \\
\text { (5) }\end{array}$ & Porin OmpA 1 (5) & $\begin{array}{l}\text { Porin OmpA } 1 \\
\text { (5) }\end{array}$ & $\begin{array}{l}\text { Porin OmpA } 1 \\
\text { (5) }\end{array}$ & $\begin{array}{l}\text { Porin OmpA } 1 \\
(5)\end{array}$ \\
\hline 24 & $\begin{array}{l}\text { WP_001247604. } \\
1\end{array}$ & $\begin{array}{l}\text { YjbF family } \\
\text { lipoprotein }\end{array}$ & $\begin{array}{l}\text { YjbF family } \\
\text { lipoprotein } 1 \\
\text { (5) }\end{array}$ & $\begin{array}{l}\text { YjbF family } \\
\text { lipoprotein } 1(5)\end{array}$ & $\begin{array}{l}\text { YjbF family } \\
\text { lipoprotein } 1 \\
\text { (5) }\end{array}$ & $\begin{array}{l}\text { YjbF family } \\
\text { lipoprotein } 1 \\
\text { (5) YjbF family } \\
\text { lipoprotein } 1 \text { (5) }\end{array}$ & $\begin{array}{l}\text { YjbF family } \\
\text { lipoprotein } 1 \\
(5)\end{array}$ \\
\hline 25 & $\begin{array}{l}\text { WP_014532269. } \\
1\end{array}$ & $\begin{array}{l}\text { DUF333 } \\
\text { domain- } \\
\text { containing } \\
\text { protein }\end{array}$ & $\begin{array}{l}\text { DUF333 } \\
\text { domain- } \\
\text { containing } \\
\text { protein } 1 \text { (5) }\end{array}$ & $\begin{array}{l}\text { DUF333 domain- } \\
\text { containing protein } \\
1(5)\end{array}$ & $0(5)$ & $\begin{array}{l}\text { DUF333 } \\
\text { domain- } \\
\text { containing } \\
\text { protein } 1(5)\end{array}$ & $\begin{array}{l}\text { DUF333 } \\
\text { domain- } \\
\text { containing } \\
\text { protein } 1 \text { (5) }\end{array}$ \\
\hline
\end{tabular}

True positive and true negative are denoted by " 1 " and " 0 ."

Integers in parentheses denote the confidence level. 
Supplementary Table 8. List of predicted virulence factors of 39 hypothetical proteins by using VICMPred and Virulentpred

\begin{tabular}{|c|c|c|c|}
\hline Sl. No. & Acc ID_Protein & VICMpred & Virulentpred \\
\hline 1 & WP_005053355.1 & Cellular process & Virulent \\
\hline 2 & WP_000092054.1 & Cellular process & Virulent \\
\hline 3 & WP_001382892.1 & Information and storage & Virulent \\
\hline 4 & WP_005053036.1 & Cellular process & Virulent \\
\hline 5 & WP_000779831.1 & Cellular process & Virulent \\
\hline 6 & WP_011110552.1 & Information and storage & Virulent \\
\hline 7 & WP 001269672.1 & Metabolism Molecule & Virulent \\
\hline 8 & WP_001247854.1 & Virulence factors & Non-Virulent \\
\hline 9 & WP_000070107.1 & Metabolism Molecule & Non-Virulent \\
\hline 10 & WP_000224274.1 & Cellular process & Non-Virulent \\
\hline 11 & WP_000749269.1 & Virulence factors & Virulent \\
\hline 12 & WP 001125713.1 & Cellular process & Virulent \\
\hline 13 & WP_001043881.1 & Cellular process & Non-Virulent \\
\hline 14 & WP 001295493.1 & Metabolism Molecule & Non-Virulent \\
\hline 15 & WP_000691930.1 & Cellular process & Virulent \\
\hline 16 & WP_000597196.1 & Metabolism Molecule & Virulent \\
\hline 17 & WP_000248636.1 & Metabolism Molecule & Non-Virulent \\
\hline 18 & WP_000755956.1 & Metabolism Molecule & Non-Virulent \\
\hline 19 & WP_001237866.1 & Cellular process & Virulent \\
\hline 20 & WP_000454701.1 & Metabolism Molecule & Non-Virulent \\
\hline 21 & WP_000003197.1 & Cellular process & Virulent \\
\hline 22 & WP_005049020.1 & Cellular process & Non-Virulent \\
\hline 23 & WP_048814497.1 & Cellular process & Virulent \\
\hline 24 & WP_000301054.1 & Metabolism Molecule & Non-Virulent \\
\hline 25 & WP_000266171.1 & Metabolism Molecule & Non-Virulent \\
\hline 26 & WP_000589825.1 & Cellular process & Virulent \\
\hline 27 & WP_005051685.1 & Cellular process & Virulent \\
\hline 28 & WP_001387238.1 & Cellular process & Virulent \\
\hline 29 & WP_000248097.1 & Cellular process & Virulent \\
\hline 30 & WP_000848528.1 & Cellular process & Virulent \\
\hline 31 & WP 000189314.1 & Cellular process & Virulent \\
\hline 32 & WP_001297375.1 & Metabolism Molecule & Non-Virulent \\
\hline 33 & WP_000858193.1 & Cellular process & Non-Virulent \\
\hline 34 & WP_001296791.1 & Cellular process & Virulent \\
\hline 35 & WP_000778795.1 & Cellular process & Virulent \\
\hline
\end{tabular}




\begin{tabular}{|l|l|l|l|}
\hline 36 & WP_001205243.1 & Cellular process & Non-Virulent \\
\hline 37 & WP_001238362.1 & Cellular process & Non-Virulent \\
\hline 38 & WP_000943980.1 & Cellular process & Non-Virulent \\
\hline 39 & WP_000132640.1 & Cellular process & Non-Virulent \\
\hline
\end{tabular}

